\title{
SÍNTESIS Y POTENCIALES APLICACIONES TECNOLÓGICAS DE MATERIALES ZEOLÍTICOS OBTENIDOS A PARTIR DE CATALIZADORES FCC AGOTADOS
}

Tesis de Doctorado

\section{MAXIMILIANO RICARDO GONZALEZ}

Presentada ante la Facultad de Ingeniería de la Universidad Nacional de la Plata como requisito para la obtención del grado académico de

\section{DOCTOR EN INGENIERÍA}

Dirección de tesis: Dra. Elena I. Basaldella.

Co-Dirección : Dra. Andrea M. Pereyra.

Jurado de Tesis:

Dra. María dos Santos Afonso, Dr. Esteban F. Aglietti y Dr. Eduardo Herrero.

Fecha de la defensa oral y pública:

30 de marzo de 2015. 
Este trabajo de tesis fue llevado a cabo en el Centro de Investigación y Desarrollo en Ciencias Aplicadas "Dr. Jorge J. Ronco" bajo la dirección de la Dra. Elena I. Basaldella y la co-dirección de la Dra. Andrea M. Pereyra.

Se presenta a consideración de las autoridades de la Facultad de Ingeniería de la Universidad Nacional de La Plata para aspirar al grado académico de Doctor en Ingeniería. 


\section{AGRADECIMIENTOS}

A la Dra. Elena I. Basaldella por su gran apoyo y valiosa dirección, sin ella este trabajo no hubiera sido posible.

A la Dra. Andrea M. Pereyra por su asesoría y su constante apoyo.

A mis compañeros de trabajo más cercanos, Dra. Soledad Legnoverde, Ing. Juan Tara y Dra. Valeria Palermo por sus valiosos consejos y comprensión, recordaré siempre los buenos momentos que hemos compartido juntos; a la Lic. Ana M. Ermili por su ayuda en el desarrollo de la parte experimental de esta tesis.

Al Dr. Raúl Zerbino del LEMIT, a la Dra. Rosa Torres del CETMIC, a los Dres. Pedro Bosch y Argel Ibarra del Departamento de Cerámicos del Instituto de Investigaciones en Materiales de la Universidad Nacional Autónoma de México. Para mí trabajar con ellos ha sido una experiencia científica enriquecedora, gracias a todos.

A la Lic. Mariela Theiller, al Lic. Mario Sánchez y al Dr. Omar Novelo Peralta por los estudios de SEM-EDX, así como a la Sra. Graciela Valle por los estudios de FT-IR. También agradecer a la M. en C. Adriana Tejeda Cruz y al I.Q. Gerardo Cedillo Valverde por los estudios de DRX y NMR, respectivamente.

A todos mis compañeros del CINDECA y especialmente a su Director, Dr. Luis Gambaro por hacer posible el desarrollo de este trabajo. 
Al Consejo Nacional de Investigaciones Científicas y Técnicas, a la Universidad Tecnológica Nacional y a la Facultad Regional La Plata por el apoyo financiero.

A mis padres, María y Aníbal, a mi hermana Karina, a Laura y a mi familia toda, gracias por su apoyo constante e incondicional.

A mis amigos, que han sido importantes para mí durante todo este tiempo. 


\section{RESUMEN}

En el presente trabajo de tesis se estudió la posibilidad de reutilizar catalizadores agotados provenientes de reactores de craqueo de petróleo en lecho fluido (catalizadores FCC). Como propuesta innovadora, estos catalizadores se emplearon como materia prima para la síntesis de zeolitas. Se profundizó así en el conocimiento de los métodos de síntesis de materiales zeolíticos tradicionales a partir de productos de desecho proveniente de la industria. Adicionalmente, se investigó la factibilidad de que los productos obtenidos sean de utilidad para el desarrollo de nuevas tecnologías que contribuyan a la remediación, conservación y protección del ambiente.

En primer lugar, se sintetizaron materiales zeolíticos a partir de un catalizador FCC agotado, siendo la activación por fusión alcalina con $\mathrm{Na}_{2} \mathrm{CO}_{3}$ el método empleado como pretratamiento del catalizador para favorecer la síntesis. Luego, se llevó a cabo la síntesis hidrotérmica para la obtención del material zeolítico, utilizando opcionalmente $\mathrm{NaAlO}_{2}$ en un medio acuoso alcalino de $\mathrm{NaOH}$; se estudiaron como variables las condiciones de ensayo tales como composición química de la mezcla inicial y tiempo de reacción. Los materiales obtenidos como producto de la síntesis, presentaron un alto contenido de zeolita $\mathrm{NaA}$. La fusión con $\mathrm{Na}_{2} \mathrm{CO}_{3}$ permitió lograr un producto rico en zeolitas a tiempos cortos de síntesis, comparables a los obtenidos en las síntesis tradicionales.

Posteriormente, los materiales zeolíticos sintetizados se probaron como captores de cromo a través del método de intercambio catiónico. Como resultado de las experiencias realizadas se puede afirmar que el material zeolitizado obtenido a partir del catalizador FCC agotado puede ser utilizado como retenedor de cationes $\mathrm{Cr}(\mathrm{III})$, siendo entonces de gran 
utilidad para la eliminación de metales pesados de efluentes acuosos. Adicionalmente, se determinaron las curvas cinéticas para las reacciones de intercambio de cromo empleando los productos sintetizados, obteniéndose resultados similares a los registrados para una zeolita $\mathrm{NaA}$ pura, sintetizada a partir de sales solubles. El análisis de los datos cinéticos indicó con buena aproximación que, en las condiciones experimentales utilizadas, la reacción de intercambio catiónico se produce a través de un mecanismo de pseudo segundo orden.

Las materias primas usadas así como los materiales zeolíticos obtenidos antes y después del intercambio con $\mathrm{Cr}$ (III), fueron caracterizados por difracción de rayos $X(X R D)$, microscopía electrónica de barrido (SEM), energía de dispersión de rayos $X$ (EDX), resonancia magnética nuclear (NMR), espectroscopía infrarroja con transformada de Fourier (FT-IR), punto de cero carga (PZC) y adsorción de agua.

Por último, se elaboraron morteros de cemento portland conteniendo como aditivo distintos porcentajes del material zeolítico intercambiado con cromo. Estos morteros fueron diseñados usando una relación en peso de agua/cemento constante. Se evaluaron los efectos de estas adiciones en las propiedades tecnológicas de los morteros conjuntamente con la capacidad de inmovilización de los contaminantes en las correspondientes matrices cementíceas. Se observó que los morteros conteniendo no más de $5 \%$ de material zeolítico presentan propiedades mecánicas similares a los morteros libres de este agregado y que los ensayos de lixiviación de los mismos en medio acuoso a diversas concentraciones del catión inmovilizado son inferiores a los límites permitidos por la legislación vigente. Como resultado se obtuvo que la incorporación de material zeolítico intercambiado con cromo en morteros cementíceos puede ser considerado como una opción válida para la inmovilización de este catión. Esta metodología sería potencialmente útil 
para la retención efectiva de éste y otros metales contaminantes presentes en efluentes acuosos. 


\section{OBJETIVOS}

\section{OBJETIVOS GENERALES}

Como objetivo general se planteó sintetizar un material microporoso, a partir de una fuente no convencional de sílice y alúmina, con el fin de investigar la factibilidad de que los productos obtenidos sean de utilidad para el desarrollo de nuevas tecnologías y que además contribuyan a la remediación, conservación y protección del ambiente.

\section{OBJETIVOS ESPECÍFICOS}

Utilizar una materia prima de costo negativo, como es el catalizador agotado proveniente de la unidad de craqueo catalítico de la planta de YPF de Ensenada, para sintetizar un producto con alto contenido de zeolita NaA.

Abordar la síntesis de estos soportes con el fin de controlar sus propiedades texturales y morfológicas, lo cual permitirá la obtención de sólidos con tamaño de poro y área superficial estandarizada.

Emplear los sólidos obtenidos en procesos de retención de metales, particularmente para la eliminación de $\mathrm{Cr}$ (III) presente en aguas, ya que este metal pesado resulta controversial para el medio ambiente y para la salud. 
Inmovilizar el sólido microporoso que contiene el $\operatorname{Cr}($ III) en formulaciones de morteros de cemento portland, estudiando los porcentajes de producto a incorporar que no afecten las propiedades tecnológicas de las matrices cementíceas.

Realizar ensayos de lixiviación sobre los morteros diseñados con el fin de comprobar la inmovilización del metal pesado.

Por todo lo expuesto se obtendrá a partir de un residuo como es el catalizador FCC agotado, un material con alto contenido de zeolita $\mathrm{NaA}$ el cual será empleado en la remoción de $\mathrm{Cr}$ (III). Posteriormente a la captura de cromo, este material será inmovilizado en morteros cementíceos. 
ÍNDICE 
Capítulo I. Introducción

1.1. Aspectos generales de los sólidos porosos 2

1.2. Materiales zeolíticos 4

1.2.1. Definiciones químicas y estructurales 4

1.2.2. Síntesis de zeolitas 5

1.2.3. Descripción de la zeolita $\mathrm{NaA} \quad 6$

1.2.4. Descripción de la zeolitas $X$ e $Y \quad 7$

1.2.5. Aplicaciones tecnológicas 9

1.3. Catalizador de FCC 12

1.3.1. Componentes y características principales $\quad 12$

1.3.2 Problemática del catalizador como residuo $\quad 14$

1.4. Fuentes naturales y artificiales de cromo 15

1.4.1. Contaminación causada por efluentes líquidos industriales que contienen $\mathrm{Cr}(\mathrm{VI}) \quad 15$

1.5. Estado del arte de la investigación 17

1.5.1. Resultados preliminares $\quad 17$

1.6. Referencias 19

Capítulo II. Marco teórico 21

2.1. Síntesis hidrotérmica de zeolitas 22

2.1.1. Factores que influencian la reacción de cristalización de zeolitas 23

2.1.2. Mecanismos propuestos para la cristalización 24

2.1.3. Nucleación $\quad 27$

2.1.4. Crecimiento 27

2.1.5. Influencia de la alcalinidad 29

2.1.6. Temperatura de reacción 33

2.1.7. Influencia de los cationes $\quad 35$

2.2. Técnicas de caracterización de materiales 36

2.2.1. Difracción de rayos $X(D R X) \quad 39$

2.2.2. Microscopía electrónica de barrido (SEM) 40 
2.2.3. Energía de dispersión de rayos X (EDX) 41

2.2.4. Resonancia Magnética Nuclear (RMN) 42

2.2.5. Espectroscopía infrarroja con transformada de

Fourier. (FT-IR) 43

2.2.6. Determinación del punto de cero carga por medición del potencial zeta (PZC) 46

2.2.7. Espectroscopía de absorción atómica (AA) 46

2.3. Cinética de sorción 47

2.3.1. Cinética de primer y segundo orden $\quad 47$

2.3.2. Coeficiente de difusión 50

2.4. Morteros $\quad 50$

2.4.1. Mortero endurecido 51

2.4.1.1. Ensayos de flexión y compresión 51

2.4.1.2. Contracción por secado 51

2.5. Referencias 52

Capítulo III. Metodología experimental 54

3.1. Pretratamiento del catalizador FCC Agotado

3.2. Síntesis del material

3.2.1. Síntesis hidrotérmica del material zeolítico 55

3.3. Ensayos de intercambio iónico 62

3.4. Técnicas de caracterización. Caracterización de las muestras sólidas

3.4.1. Difracción de Rayos X (XRD) 66

3.4.2. Microscopía electrónica de barrido (SEM) 68

3.4.3. Resonancia Magnética Nuclear (NMR) 70

3.4.4. Espectrometría Infrarroja por Transformada de

Fourier (FT-IR) 74

3.4.5. Determinación del punto de cero carga por medición del potencial zeta (PZC)

3.4.6. Superficie específica $\quad 75$ 
3.5. Caracterización de las muestras líquidas

3.5.1. Espectroscopía de absorción atómica (AA) 79

3.6. Inmovilización en morteros a base de cemento portland 79

3.6.1. Diseño y manufactura de los morteros $\quad 79$

3.6.2. Evaluación de las propiedades mecánicas 83

3.6.2.1. Resistencia a la Flexión 88

3.6.2.2. Resistencia a la Compresión 88

3.6.2.3. Contracción por secado 90

3.7. Ensayos de lixiviación $\quad 92$

3.8. Referencias 94

Capítulo IV. Influencia de la modificación de diferentes parámetros de síntesis sobre la evolución de la reacción de cristalización 95

4.1. Estudios de caracterización del catalizador 96

4.1.1. Análisis químico del catalizador de partida 96

4.1.2. Caracterización fisicoquímica del catalizador de partida antes y después del pretratamiento 98

4.1.2.1. Análisis de la composición cristalográfica $\quad 98$

4.1.2.2. Determinación de la morfología y tamaño de las partículas del catalizador antes y después del pretratamiento 101

4.2. Análisis de la modificación de variables de síntesis 101

4.2.1. Influencia del pretratamiento y de la composición de la mezcla inicial de reacción sobre la estructura cristalográfica del producto de síntesis

4.2.2. Morfología y tamaño de los productos de síntesis $\quad 110$

4.2.3. Optimización de la reacción 112

4.2.3.1. Análisis de la conversión en zeolita tomando como variable la cantidad de hidróxido de sodio agregada a la mezcla inicial

4.2.3.2. Análisis de la morfología y el tamaño del 
4.3. Análisis comparativo del producto obtenido y de la muestra patrón de zeolita NaA por FT-IR

4.4. Estudio de la reacción a tiempos cortos de síntesis 120

4.4.1. Caracterización de las estructuras cristalinas

4.4.1.1. Determinación de las estructuras presentes

a través del estudio de las distancias interatómicas

4.4.1.2. Determinación de las fases presentes a través del estudio de la coordinación atómica por resonancia magnética nuclear

4.4.2. Determinación de la superficie específica

4.4.3. Morfología y tamaño de los productos a cortos tiempos de síntesis

Capítulo V. Procesos de intercambio catiónico. Estudio de la cinética de sorción de $\mathrm{Cr}(\mathrm{III})$

5.1. Intercambio catiónico con $\mathrm{Cr}(\mathrm{III})$

5.1.1. Determinación de la capacidad de intercambio del catalizador zeolitizado

5.2. Influencia de la sorción de Cr(III) sobre las propiedades del catalizador zeolitizado

5.2.1. Análisis por DRX de la influencia de la reacción de intercambio sobre la estructura cristalina

5.2.2. Análisis por EDX de la distribución del $\mathrm{Cr}(\mathrm{III})$ en el sólido obtenido. Características morfológicas del producto

5.2.3. Estudios por FTIR de las muestras intercambiadas con $\mathrm{Cr}(\mathrm{III})$

5.2.4. Mecanismo de sorción del $\operatorname{Cr}(\mathrm{III})$. Determinación del punto de cero carga.

5.3. Resultados de estudios cinéticos. 
Capítulo VI. Inmovilización en morteros

6.1. Estudio preliminares de la influencia del agregado zeolítico sobre las propiedades mecánicas de los morteros cementíceos y ensayos de lixiviación.

6.1.1 Evaluación de las propiedades mecánicas

6.1.1.1 Resistencia a la flexión y a la compresión

6.1.1.2. Pruebas de lixiviación

6.2. Reducción del agregado zeolítico

6.2.1. Propiedades de los morteros frescos

6.2.2. Resistencia a la flexión y a la compresión

6.2.3. Contracción por secado

6.2.4. Pruebas de lixiviación 


\section{CAPÍTULO I}

\section{INTRODUCCIÓN}

Síntesis y potenciales aplicaciones tecnológicas de materiales zeolíticos obtenidos a partir de catalizadores FCC agotados 1 


\section{INTRODUCCIÓN}

\subsection{Aspectos generales de los sólidos porosos}

Los materiales porosos han sido ampliamente estudiados debido a su versatilidad para ser empleados en diversos procesos tecnológicos tales como separación química y catálisis heterogénea [1, 2]. Idealmente un material poroso debe tener una distribución de tamaño de poros estrecha, la cual es crítica para varias aplicaciones. Además deben mostrar una alta estabilidad química, térmica, hidrotérmica y mecánica, elevada área superficial, gran volumen de poros y deben poseer tamaño de partícula y morfología apropiadas.

De acuerdo al tamaño de poro, la IUPAC clasificó a los sólidos porosos en [3] (Fig.1.1.)

Microporosos: diámetro de poro menor a $2 \mathrm{~nm}$. Mesoporosos: diámetro de poro entre 2 y $50 \mathrm{~nm}$. Macroporosos: diámetro de poro mayor a $50 \mathrm{~nm}$.

Las zeolitas constituyen una familia singular dentro de los materiales microporosos, caracterizada por presentar estructuras aluminosilíceas cristalinas de tamaño de poro uniforme, gran área superficial y que poseen cationes intercambiables. Estos materiales se emplean en diversas aplicaciones tecnológicas tales como:

- Catálisis: La actividad catalítica intrínseca de las zeolitas se asocia a la presencia de sitios ácidos y a su selectividad de forma. Sin embargo, esta actividad también puede modificarse por 


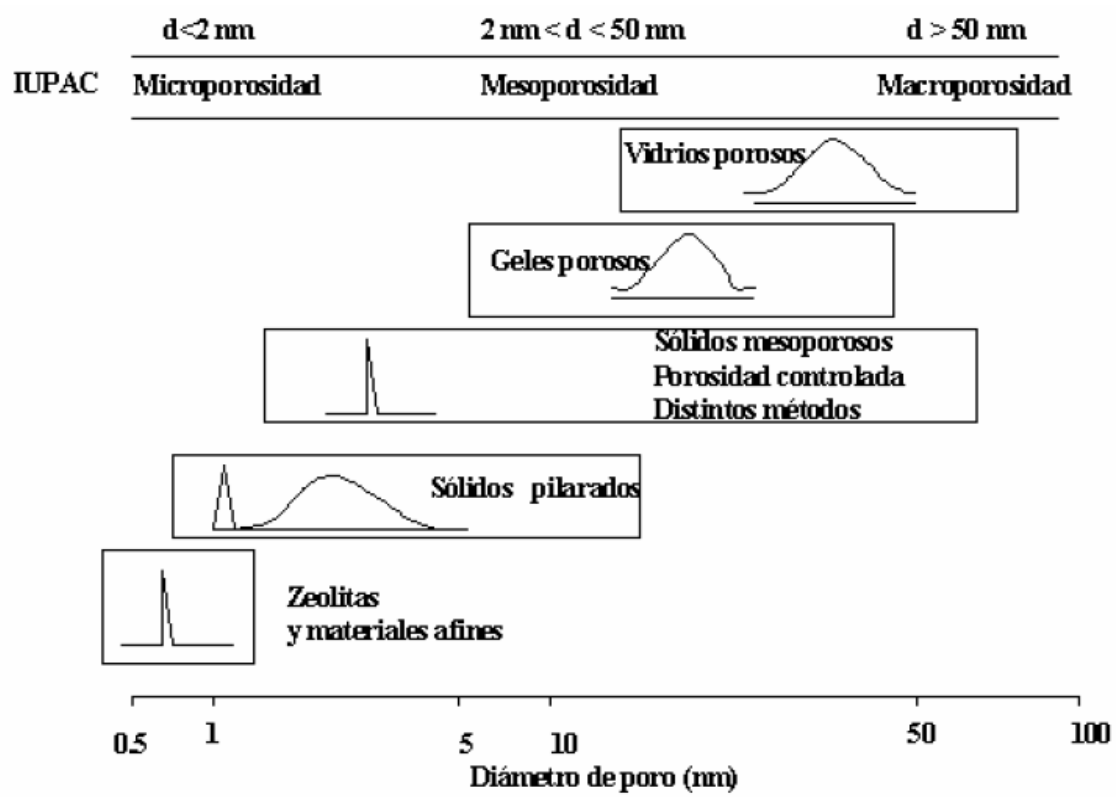

Figura 1.1. Ejemplos de materiales micro, meso y macroporosos.

Distribución de tamaño de poro típica. 
introducción de otros centros catalíticos, lo cual permite su aplicación en reacciones químicas de gran importancia como lo son el craqueo catalítico de petróleo y otras relacionadas a la industria del refino y petroquímica, así como a transformaciones denominadas de química fina.

- Adsorción: Las zeolitas se usan para la adsorción de una gran variedad de materiales. Esto incluye aplicaciones en secado, purificación y separación. Pueden extraer químicos orgánicos volátiles de las corrientes de aire, separar isómeros y mezclar gases.

- Intercambio de iones: Los cationes hidratados dentro de los poros de la zeolita están unidos débilmente y preparados para intercambiarse con otros cationes cuando se encuentran en un medio acuoso. Esta propiedad permite su aplicación como ablandadores de agua, y el uso de zeolitas en detergentes y jabones. Es incluso posible remover iones reactivos del agua contaminada.

Estos óxidos porosos sintetizados por vía hidrotermal se obtienen en forma de polvo cristalino, aunque también pueden generarse o ser moldeados en forma de membranas, monolitos o fibras. Además, pueden tener un tamaño molecular adecuado a las necesidades en servicio [4-7].

\subsection{Materiales zeolíticos}

\subsubsection{Definiciones químicas y estructurales}

De una manera amplia y tradicional, se denomina zeolitas a un grupo de aluminosilicatos cristalinos, microporosos, naturales o sintéticos, 
que poseen cationes intercambiables y que generalmente pueden adsorber y desorber especies de manera reversible. Dichos minerales fueron descubiertos por Crönsted [8], hace 258 años, quien utilizó para denominarlos la conjunción de dos palabras griegas: zein-hirviendo, lithos-piedra, o sea "piedras que hierven", con lo que se describía el desprendimiento de agua producido cuando se calentaba una zeolita natural.

En las zeolitas existe un arreglo de iones distribuidos en el espacio y unidos entre sí a través de átomos de oxígeno. El centro del tetraedro está ocupado por estos iones y de su carga depende la carga resultante

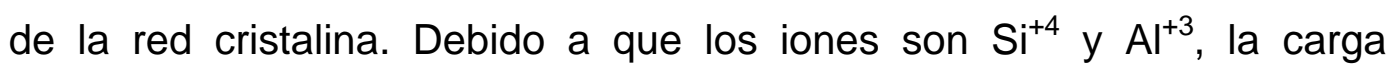
electrónica de la red será más negativa a medida que haya más $\mathrm{Al}^{+3}$ en los sitios tetraédricos.

Al existir una gran cantidad de estructuras que difieren solamente en su composición química, se asignó un código de tres letras mayúsculas que representan un conjunto de especies naturales 0 sintéticas que poseen la misma distribución espacial de los sitios tetraédricos. Puede ocurrir que posean la misma distribución tridimensional atómica pero difieran en la composición química, como en el caso de las zeolitas tipo MFI. Entre los varios tipos de zeolitas existentes en el mercado, las zeolitas $A, X$ e $Y$ son las de mayor volumen comercializado. Las zeolitas $\mathrm{X}$ e $\mathrm{Y}$ son del tipo $\mathrm{FAU}$, debido a que su estructura es similar a la faujasita natural. En cambio la zeolita $A$ es del tipo LTA.

\subsubsection{Síntesis de zeolitas}

Existen una enorme cantidad de zeolitas naturales, los cuales presentan una gran variedad de características tales como: propiedades

Síntesis y potenciales aplicaciones tecnológicas de materiales zeolíticos obtenidos a partir de catalizadores FCC agotados 5 
de intercambio catiónico y catalíticas, alto grado de hidratación, estructuras cristalinas estables, baja densidad, poros uniformes y de dimensiones moleculares específicas, entre otras.

Debido a estas propiedades y a los procesos en las cuales podrían utilizarse se encontraron métodos apropiados para reproducir en el laboratorio dichas zeolitas naturales, además se sintetizaron nuevas estructuras, lo que hizo que estos sólidos se tornaran muy importantes tanto científica como industrialmente. En los últimos años, el consumo de zeolitas ha crecido significativamente debido principalmente a la demanda de materiales económicos y ambientalmente sustentables.

La primera síntesis de zeolita con una comprobada caracterización por análisis químico, propiedades ópticas y difracción por rayos $X$ fue realizada por R.M. Barrer en la década de 1940. Este trabajo condujo a la producción de materiales sintéticos equivalentes a las especies zeolíticas naturales, pero también llevó a la obtención de nuevas fases cristalinas. En los laboratorios de la Unión Carbide, se sintetizó la zeolita tipo A, obtenida por Milton, Breck y colaboradores, siendo esta zeolita la primera estructura lograda por síntesis de laboratorio que no posee equivalente natural.

\subsubsection{Descripción de la zeolita $\mathrm{NaA}$}

Esta zeolita bajo su forma sódica puede ser representada por la fórmula [9],

$$
\mathrm{Na}_{12}\left[\left(\mathrm{AlO}_{2}\right)_{12}\left(\mathrm{SiO}_{2}\right)_{12}\right]: 27 \mathrm{H}_{2} \mathrm{O}
$$

Pertenece al sistema cúbico siendo el valor de su parámetro de celda igual a 24,60 ̊ cuando está hidratada. Su estructura cristalina 
puede describirse a través de la unión de tres poliedros diferentes:

-un cubo simple

-un cubo octaedro truncado denominado caja sodalita o caja $\beta$.

-y un poliedro de 26 caras denominado supercaja $\alpha$.

La unión de las cajas sodalita por cuatro de sus caras cuadradas con los cubos simples conduce a establecer una abertura de acceso a la supercaja constituida por 8 átomos de oxígeno y un tamaño de 4,2 Å. El arreglo tridimensional de esta zeolita se muestra en la Fig.1.2.

La estructura de la zeolita A está formada por átomos de oxígeno, silicio y aluminio. Al presentarse el aluminio en coordinación tetraédrica, aparece una carga negativa en el retículo cristalino que se compensa con los iones sodio, o sea existe un catión monovalente por cada átomo de aluminio presente en la red.

\subsubsection{Descripción de la zeolitas $X$ e $Y$}

La composición de estas zeolitas bajo la forma sódica puede ser representada por la fórmula [9],

$$
\mathrm{Na}_{2} \mathrm{O} \cdot \mathrm{Al}_{2} \mathrm{O}_{3} \cdot \mathrm{nSiO}_{2} \cdot \mathrm{xH}_{2} \mathrm{O}
$$

Donde $n$ varía entre 2 y 6 , manteniéndose una estructura cristalina del tipo de la faujasita. Cuando $n<3$, estamos en presencia de zeolita $X$, en cambio cuando $n>3$ estamos en presencia de zeolita $Y$.

El arreglo tridimensional de estas zeolitas se muestra en la Fig.1.3.

Síntesis y potenciales aplicaciones tecnológicas de materiales zeolíticos obtenidos a partir de catalizadores FCC agotados 7 
Cada vértice representa el centro de un tetraedro $\mathrm{SiO}_{4} \mathrm{O} \mathrm{AlO}_{4}$. Esta estructura puede ser representada por la unión de tres poliedros diferentes:

-prisma hexagonal,

-cubo octaedro truncado denominado caja sodalita o caja $\beta$.

-y un poliedro de 26 caras denominado supercaja $\alpha$.

El arreglo tridimensional de la zeolita está representado por la sucesión de estas supercajas ligadas las unas a las otras, generando aberturas de entrada a la supercaja cercanas a $8 \AA$. Desde el punto de vista cristalográfico, la estructura es cúbica, con un parámetro de red comprendido entre 25,02 y $24,86 \AA$, según el valor de la relación $n=$ $\mathrm{SiO}_{2} / \mathrm{Al}_{2} \mathrm{O}_{3}$.

La malla elemental comprende 8 cajas $\alpha$, siendo cada supercaja el centro de un tetraedro cuyos vértices son también supercajas.

La Fig.1.4. muestra las posiciones cristalográficas posibles para los cationes de compensación:

-sitio $S_{1}$ : centro del prisma hexagonal;

-sitio $S_{\text {l: }}$ situado dentro de la caja sodalita aproximadamente a $1 \AA$ del centro del hexágono que pertenece al prisma hexagonal;

-sitio U: centro de la caja sodalita;

-sitio $S_{\|}$: situado en la caja sodalita a aproximadamente $1 \AA$ del centro del

Síntesis y potenciales aplicaciones tecnológicas de materiales zeolíticos obtenidos a partir de catalizadores FCC agotados 8 
hexágono que permite el acceso a la supercaja;

-sitio $S_{\| l}$ : situado en la supercaja $\alpha$ a aproximadamente $1 \AA$ del centro del hexágono que separa la supercaja de la caja sodalita;

-sitio $S_{\text {III }}$ : situado en el dodecágono que separa dos cajas $\alpha$.

-sitio $\mathrm{S}_{\mathrm{IV}}$ : corresponde a los cationes cuasi libres en el centro de las supercajas $\alpha$. Estos sitios existen sólo en presencia de agua.

Las posiciones de los iones $\mathrm{Na}^{+}$dependen del estado de hidratación. Se observa que con la hidratación se produce una migración de los iones situados en los sitios I' y II' hacia los sitios I y II.

\subsubsection{Aplicaciones tecnológicas}

La zeolita NaA debido a sus propiedades físicas y químicas, es ampliamente usada como tamiz molecular, en procesos de adsorción y en separación de corrientes gaseosas. Debido a su versatilidad, ésta puede modificarse de varias formas para hacer productos innovadores para distintas aplicaciones. Entre las más importantes se encuentra la propiedad de intercambiar cationes la cual es una de las características fundamentales que hacen a su aplicación tanto como catalizadores en reacciones heterogéneas como selectivos inmovilizadores de iones en procesos de purificación.

Con respecto a esto último, hasta el presente, los procesos de intercambio de zeolitas con cationes mono y divalentes han sido estudiados ampliamente [11], no siendo así en el caso de los cationes trivalentes, difíciles de estabilizar como por ejemplo el $\mathrm{Cr}$ (III) [12], objeto de este trabajo de tesis.

Síntesis y potenciales aplicaciones tecnológicas de materiales zeolíticos obtenidos a partir de catalizadores FCC agotados 9 


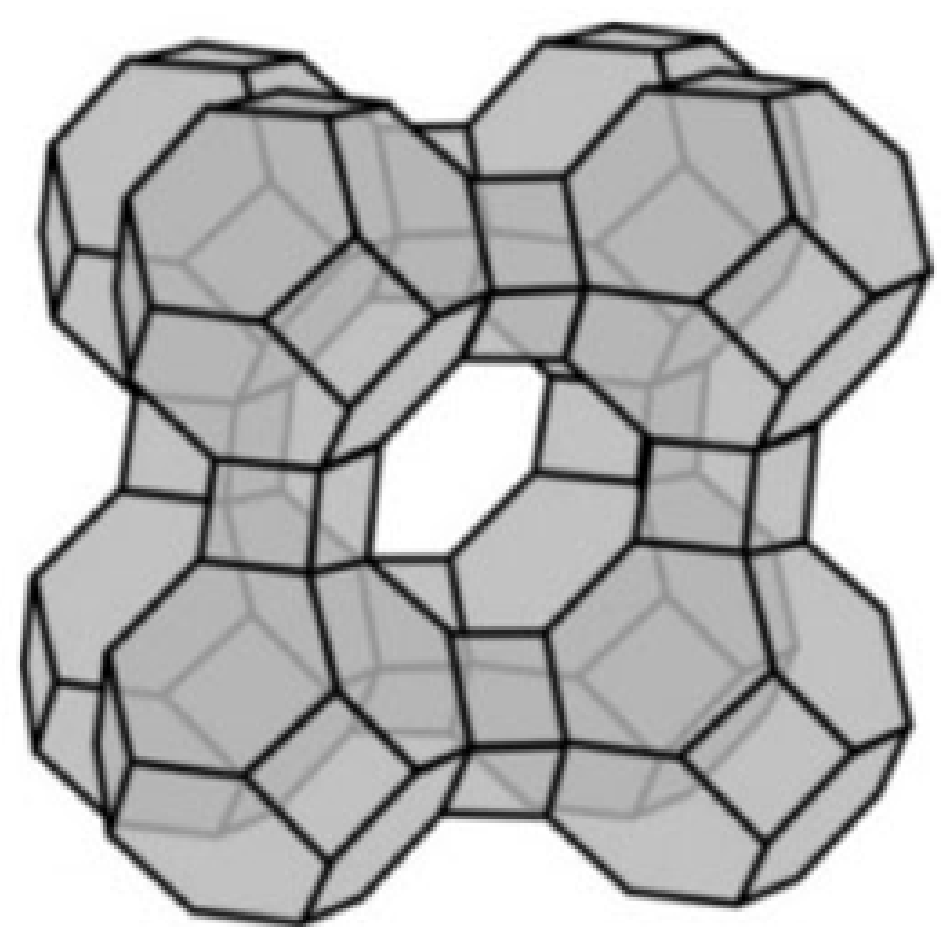

Figura 1.2. Estructura de la zeolita NaA. (Abertura octogonal) [13]. 


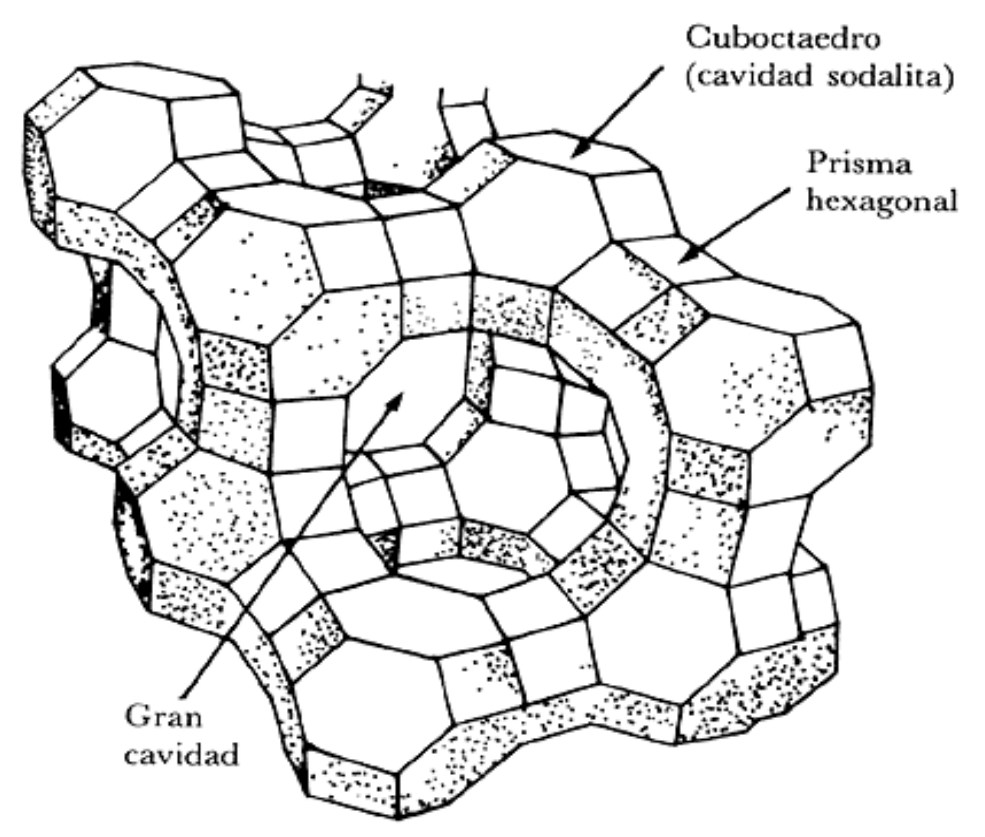

Figura 1.3. Estructura de las zeolitas X e Y. (Abertura dodecagonal) [14]. 
Por su parte, la síntesis de este material se lleva a cabo mediante una reacción de cristalización que puede nutrirse de una diversidad de materias primas, como por ejemplo aluminatos y silicatos solubles, o arcillas tratadas térmicamente [15]. Adicionalmente, durante la década pasada se publicaron algunos estudios interesantes acerca de la conversión en zeolitas de residuos aluminosilíceos provenientes de centrales térmicas (fly ashes), que han recobrado actualidad [16, 17].

Resulta de significativa importancia, desde el punto de vista del cuidado del ambiente y desde un enfoque económico, obtener productos comerciables empleando desechos provenientes de la industria, que además revisten inconvenientes en cuanto a su difícil manipulación y disposición final. Es por lo anteriormente mencionado que en este trabajo de tesis se plantea un procedimiento de síntesis innovador utilizando el catalizador FCC agotado (residuo de naturaleza aluminosilícea proveniente de la industria de refino) como una alternativa válida para la obtención de un material rico en zeolita NaA.

\subsection{Catalizador de FCC}

\subsubsection{Componentes y características principales}

Los principales componentes de los catalizadores de FCC son zeolita sintética (ca. 15 a $50 \% \mathrm{p} / \mathrm{p}$ ), una matriz aluminosilícea (ca. 5 $\% \mathrm{p} / \mathrm{p}$ ), aglutinante (ca. $20 \% \mathrm{p} / \mathrm{p}$, por lo general Ludox) y caolín (ca. 60 a $25 \% \mathrm{p} / \mathrm{p}$ ). La zeolita presente en los catalizadores de FCC corresponde al tipo $Y$ (grupo FAU), por lo general completamente intercambiada con hidrógeno (USY). La composición química del catalizador de FCC agotado utilizado resultó ser $50 \% \mathrm{p} / \mathrm{p}$ de $\mathrm{SiO}_{2}$ y $45 \% \mathrm{p} / \mathrm{p}$ de $\mathrm{Al}_{2} \mathrm{O}_{3}$; el 5 $\% p / p$ restante se distribuye entre otros componentes menores. [18]. 


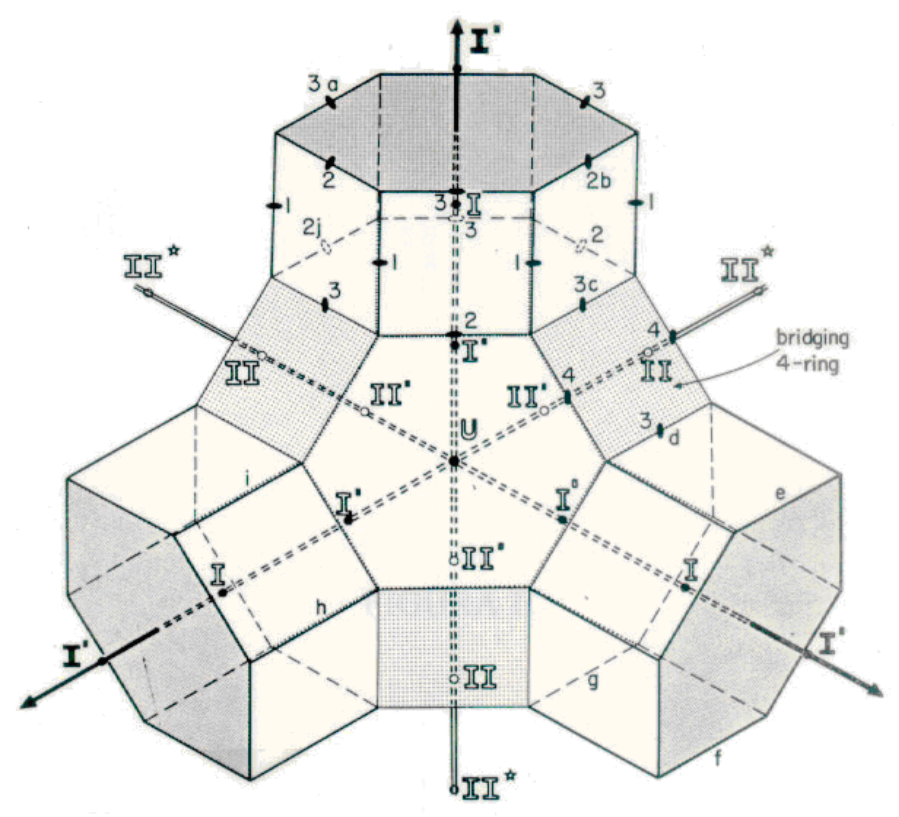

Figura 1.4. Posiciones de los cationes de compensación [10]. 
Además, el catalizador agotado también contiene cantidades muy pequeñas de metales pesados que se incorporan durante el proceso; Sin embargo, los porcentajes de sílice y alúmina son cercanos al $100 \%$, por lo tanto, este material constituye una fuente potencial para la síntesis de zeolitas aluminosilíceas.

\subsubsection{Problemática del catalizador como residuo}

La producción de gasolina en cualquier refinería se realiza tradicionalmente por craqueo catalítico en lecho fluidizado. Las modernas unidades de FCC son procesos continuos que operan las 24 horas del día durante 2 a 3 años, antes de realizar las paradas programadas para mantenimiento de rutina [19]. A nivel mundial, la producción de esta importante clase de catalizadores es de aproximadamente 300 mil toneladas/año [20], por lo cual el catalizador agotado constituye un desecho sólido de difícil manejo y comprometida disposición final.

El catalizador FCC durante el proceso de craqueo catalítico puede incorporar pequeñas cantidades de metales pesados tales como $\mathrm{As}, \mathrm{Ni}$, $\mathrm{Pb}, \mathrm{Zn}$, etc., provenientes del petróleo que se utiliza como alimentación para obtener las fracciones más ligeras. Debido a que estos metales podrían ser lixiviados al ambiente y a la gran cantidad de residuos que se genera cada año [21] el tratamiento de este residuo ha atraído la atención de investigadores comprometidos con estudios dirigidos a la conservación del ambiente, tratando de aprovecharlo en forma racional. En la actualidad, la mayor parte de estos catalizadores agotados son solidificados y enterrados, aunque algunos trabajos detallan la posibilidad de añadirlos en la formulación de materiales para la construcción [22-26]. 


\subsection{Fuentes naturales y artificiales de cromo}

El cromo se encuentra en rocas, tierra y polvo y gases volcánicos y puede producirse en diversos estados de oxidación. En los organismos vivos predominan las formas trivalentes $\mathrm{Cr}(\mathrm{III})$, mientras que el cromo hexavalente $\mathrm{Cr}(\mathrm{VI})$ y el cromo $\mathrm{Cr}(0)$ son formas producidas por procesos industriales, tales como la fabricación de productos químicos, textiles y el curtido del cuero, además de pintura para electrodeposición, la fabricación de colorantes y pigmentos. El cromo hexavalente también se puede encontrar en algunos componentes de equipos eléctricos, como piezas recubiertas de cinc, placas de circuitos y tubos de rayos catódicos.

\subsubsection{Contaminación causada por efluentes líquidos industriales que contienen $\mathrm{Cr}(\mathrm{VI})$}

La preocupación por la contaminación ambiental ha dado como resultado investigaciones intensas y el desarrollo de tecnologías sustentables, así como una normatividad cada vez más estricta. Como consecuencia, la introducción de tecnologías limpias en los procesos industriales ha logrado disminuir las descargas de sustancias contaminantes al ambiente. Sin embargo, en la mayoría de las empresas todavía se generan aguas residuales con concentraciones de sustancias contaminantes de consideración.

La contaminación del agua, aire y suelo por metales pesados es uno de los problemas ambientales más severos, además de ser muy difícil de resolver. Para el tratamiento de los efluentes líquidos que contienen metales pesados, existen diferentes métodos fisicoquímicos, siendo los de mayor auge en la actualidad los siguientes: precipitación, intercambio iónico, ósmosis inversa y adsorción. Estos, aunque efectivos presentan varias desventajas cuando son aplicados a efluentes 
industriales constituidos por soluciones metálicas diluidas. Entre las desventajas se pueden mencionar los costos importantes en términos energéticos y de consumo de productos químicos. Además, la precipitación química aunque efectiva para la eliminación de metales pesados, crea un nuevo problema ambiental: el de los lodos que después tendrán que ser almacenados. Es ampliamente conocido que estos cationes pesados se acumulan en los organismos vivos y se los considera dañinos para la salud por producir efectos citotóxicos y cancerígenos.

Entre los metales más importantes debido a los problemas medioambientales que puede ocasionar se encuentra el cromo. El cromo hexavalente se encuentra en las listas nacionales e internacionales de materiales de alta toxicidad a los que se aplican rigurosos procedimientos de control. El cromo hexavalente $\mathrm{Cr}(\mathrm{VI})$ puede convertirse a través de una reducción química en cromo trivalente, el $\mathrm{Cr}(\mathrm{III})$.

En el presente trabajo de tesis uno de los ejes que se plantea estudiar es la performance del material sintetizado rico en zeolita $\mathrm{NaA}$ como captor de cationes trivalentes, específicamente $\mathrm{Cr}(\mathrm{III})$.

Esta investigación podría aportar una metodología para el saneamiento de efluentes industriales contaminados con metales pesados, y además subsanar el problema de la disposición final, ya que se propone la inmovilización del material zeolítico que capturó el cromo en matrices cementíceas. Su desarrollo a escala industrial involucraría no sólo la purificación por retención de $\mathrm{Cr}$ (III) sino que también podría retenerse $\mathrm{Cr}(\mathrm{VI})$, previa etapa de tratamiento que comprendería la reducción a $\mathrm{Cr}(\mathrm{III})$.

Posteriormente, el material que contiene cromo acumulado en el lecho zeolítico se inmovilizaría en matrices cementíceas, incorporando en 
las mismas una cantidad de material zeolítico que no produzca el deterioro de sus propiedades mecánicas.

\subsection{Estado del arte de la investigación}

\subsubsection{Resultados preliminares}

El grupo de trabajo al cual me incorporé para la realización de mi tesis ha investigado el desarrollo de materiales porosos desde hace más de dos décadas, con resultados muy satisfactorios en zeolitas y materiales mesoporosos que se han preparado para la resolución de necesidades tecnológicas específicas. El desarrollo en particular de zeolitas y materiales relacionados en el Centro de Investigación y Desarrollo en Ciencias Aplicadas (CINDECA) ha llegado a un nivel apreciable, que se ha alcanzado gracias a los antecedentes de trabajos propios, independientes y a la participación en proyectos de colaboración con grupos iberoamericanos dentro del marco de los proyectos CYTED, tanto en años anteriores como en la actualidad. Se han logrado condiciones de síntesis que permiten controlar la composición [27, 28], el tamaño y la morfología de cristales de zeolita tipo A. En cuanto al uso específico de materiales de desecho para ser utilizados como materia prima para la producción de zeolitas y su aplicación en la retención de metales pesados, se realizaron trabajos propios y en colaboración con el grupo de los Dres. Carmine Collela y Doménico Caputo, expertos en intercambio iónico y adsorción con zeolitas naturales, de la Universidad Federico II, Nápoles, Italia, con quienes se mantuvo una estrecha y duradera colaboración a través de diferentes proyectos: Proyecto "Síntesis de zeolitas de interés tecnológico y su caracterización”. (1994-1998), Proyecto "Síntesis y caracterización de materiales zeolíticos con aplicación a la purificación de efluentes" (2004-2006), siendo las entidades financiadoras CONICET (Argentina)-CNR (Italia) [29-32]. 
Asimismo, este trabajo de tesis se desarrolló en el marco de proyectos financiados por la Universidad Tecnológica Nacional (UTN), el Consejo Nacional de Investigaciones Científicas y Técnicas y la Agencia Nacional de Promoción Científica y Tecnológica. Entre ellos pueden mencionarse "Síntesis y caracterización de adsorbentes micro y mesoporosos" (2007-2009), "Materiales micro y mesoporosos para procesos de intercambio catiónico y adsorción" (2010-2013), "Síntesis de materiales zeolíticos obtenidos a partir de catalizadores FCC agotados para aplicaciones tecnológicas amigables con el medio ambiente" (20122014) y "Aplicaciones tecnológicas de materiales zeolíticos sintetizados a partir de catalizadores FCC agotados" (2013-2016). Durante este período como becario, he publicado seis trabajos en revistas internacionales, todos ellos vinculados directa o indirectamente con este trabajo de tesis. Adicionalmente, a la fecha también soy co-autor de dos trabajos terminados en vías de publicación (uno ya enviado y otro por enviarse), seis trabajos completos publicados en actas de congresos y doce comunicaciones 0 trabajos cortos. La información relativa a esta producción se detalla en el Anexo.

La realización de la presente tesis doctoral fue llevada a cabo por medio de dos becas internas de postgrado tipo I y II del Consejo Nacional de Investigaciones Científicas y Técnica (CONICET). Adicionalmente, también fui galardonado con una beca de la Jefatura de Gabinetes de Ministros de la Nación, programa BECAR, la cual me permitió realizar un estadía en el Instituto de Investigaciones en Materiales (IIM) perteneciente a la Universidad Nacional de México. Durante los seis meses de estadía realicé estudios complementarios con equipamiento específico de los materiales diseñados en este trabajo de Tesis. 


\subsection{Referencias}

[1] Behrens, P. (1993) Adv. Mater. 5, 127.

[2] Barton, T.J., Bull, L.M., Klemperer, W.G., Loy, D.A., McEnaney, B., Misono, M., Monson, P.A., Pez, G., Scherer, G.W., Vartuli, J.C., Yaghi, M. (1999) Chem. Mater. 11, 2633.

[3] Sing, K.S.W., Devertt, D.H., Haul, R.A.W., Moscou, L., Pierrotti R.A., Rouquerol, J. (1985) Pure Appl. Chem. 57, 603.

[4] Brinker, C.J., Scherer, G.W. (1990) Sol-Gel Science, Academic Press, New York.

[5] Brinker, C.J., Scherer, G.W. (1985) J. Non. Cryst. Solids 70, 301.

[6] Hench, L.L., West, J.K. (1990) Chem.Rev. 90, 33.

[7] Mackenzie, J.D. (1982) J. Non. Cryst. Solids 1, 1.

[8] Cronsted, F. (1756) Akad Handl. Stockholm 17, 120.

[9] Robson, H., Lillerud, K.P: (2001) Verified Syntheses of zeolitic materials, Elsevier.

[10] Smith, J.V. (1971) Adv.Chem.Ser. 101, 15.

[11] Wiers, B.H., Grosse, R.J., Cilley, W.A. (1982) Environ. Sci. Technol $16,617$.

[12] Gazola, F.C., Pereira, M.R., Barros, M.A.S.D., Silva, E.A., Arroyo, P.A. (2006) Chem. Eng. J. 117, 253.

[13] Melo, C.R., Riella, H.G. (2010) Cerámica 56, 340.

[14] Bosch, P., Schifter, I. (1988) La zeolita. Una piedra que hierve, Fondo de cultura económica, México.

[15] Shi, J., Anderson, M.W. (1996) Chem. Mater. 8, 369.

[16] Cardoso, A.M., Horn, M.B., Ferret, L.S., Azevedo, C.M., Pires, M. (2015) J. Hazard. Mater. 287, 69

[17] Izidoro, J.C., Fungaro, D.A., Abbott, J.E., Wang, S. (2013) Fuel 103, 827.

[18] Basaldella, E.I., Paladino, J.C., Solari, M., Valle, G.M. (2006) Appl. Catal., B 66, 186. 
[19] Cejka, J. Corma, A., Zones S. (2010) Zeolites and catalysis, John Wiley \& Sons, Federal Republic of Germany. [20] L.R.M., Estevao, M., Le Bras, R., Delobel, R.S.V.., Nascimento (2005) Polym. Degrad. Stab. 88, 444.

[21] Pacewska, B., Wilinska, I., Kubissa, J. (1998) Thermochimica Acta. 322, 175.

[22] Su, N., Fang, H.Y., Chen, Z.H., Liu, F.S. (2000) Cem. Concr. Res. 30, 1773.

[23] Su, N., Chen, Z.H.,. Fang, H.Y. (2001) Cem. Concr. Compos. 23, 111.

[24] Antiohos, S.K., Chouliar, E. and Tsimas, S. (2006) J. Chin. Particuol. 4(2), 73.

[25] Pacewska, B., Burowska, M., Wilińska, I., Swat, M. (2002) J. Cem. Concr. Res., 32, 145.

[26] Payá, J., Monzó, J., Borrachero, M. (2001) J. Cem. Concr. Res., 31, 57.

[27] Mentasty, L., Woestyn, A., Basaldella, E.I., Kikot, A., Zgrablich, J. (1994) Adsorpt. Sci. Technol. 11, 208.

[28] Basaldella, E. I., Kikot, A., Tara, J.C. (1997) Mater. Lett. 31, 83.

[29].Basaldella, E.I., Tara, J.C. (1998) Mater. Lett 34, 119.

[30] Basaldella, E.I., Giaccio G., Zerbino R. (2002) Ciencia y Tecnología del Hormigón, N9, 30

[31] Basaldella, E.I., Vázquez, P.G., Lucolano, F., Caputo, D. (2007) J.

Colloid Interf. Sci. 313, 574.

[32] Basaldella, E.I., Torres Sanchez, R.M., Conconi, M.S. (2008) Appl.

Clay Sci. 42, 611. 


\section{CAPÍTULO II}

\section{MARCO TEÓRICO}

Síntesis y potenciales aplicaciones tecnológicas de materiales zeolíticos obtenidos a partir de catalizadores FCC agotados 21 


\section{MARCO TEÓRICO}

\subsection{Síntesis hidrotérmica de zeolitas}

Para realizar una síntesis tradicional de zeolitas, es necesario preparar un gel por el mezclado de una fuente de sílice y una de alúmina en agua, en condiciones de $\mathrm{pH}$ básico. Este gel se coloca en recipientes herméticamente cerrados durante un tiempo, a temperatura controlada, para luego obtener un producto cristalino. Además de las fuentes de sílice y alúmina, los otros componentes a introducir en el medio de reacción pueden ser cationes alcalinos o alcalino-térreos incorporados bajo la forma de óxidos, hidróxidos o sales. Estos compuestos actúan en la mencionada síntesis como fuente de $\mathrm{OH}^{-}$, como electrolitos, como contraiones de las estructuras aniónicas formadas, o como agentes directores de estructuras.

En este trabajo de tesis, la síntesis del material zeolítico se lleva a cabo utilizando como fuente alúmino-silícea el catalizador que se descarta de los reactores de lecho fluido donde se lleva a cabo el cracking de petróleo. Para la obtención de zeolitas de utilidad comercial, este tipo de catalizador actúa como única fuente de sílice e involucra una reducción en la adición del aluminato necesario para lograr una buena conversión.

Es necesario considerar que la temperatura y el tiempo de reacción, son parámetros importantes cuando se lleva a cabo la síntesis de estos productos zeolíticos. También se debe tener en cuenta la agitación de la mezcla de reacción y el orden de agregado de los reactivos, entre otros. A continuación se detallan los parámetros importantes que deben considerarse en una reacción de cristalización de zeolitas.

Síntesis y potenciales aplicaciones tecnológicas de materiales zeolíticos obtenidos a partir de catalizadores FCC agotados 22 


\subsubsection{Factores que influencian la reacción de cristalización de zeolitas}

* Composición de la mezcla inicial de reacción

a) Fuentes de $\mathrm{SiO}_{2} / \mathrm{Al}_{2} \mathrm{O}_{3}$
b) Concentración $[\mathrm{OH}]$
c) Cationes incorporados:

c.1) Inorgánicos, c.2) Orgánicos

d) Aniones diferentes a $\mathrm{OH}$ -

e) Otras especies no iónicas:

e.1) Gases disueltos, e.2) Compuestos orgánicos

f) Agua

\section{*Tiempo de reacción}

* Temperatura de reacción

a) Ambiente (25-60 $\mathrm{C})$

b) Baja (90-120 $\mathrm{C}$ )

c) Moderada (120-180 $\mathrm{C}$ )

d) Alta ( $250{ }^{\circ} \mathrm{C}$ o mayor)

\section{* Factores adicionales de importancia}

a) Envejecimiento del gel inicial

b) Agitación

c) Naturaleza de la mezcla inicial (solución, gel, sol)

d) Orden de agregado de los reactivos

En este trabajo de tesis, para la síntesis de zeolita $\mathrm{NaA}$ a partir del catalizador, se seleccionaron como parámetros la temperatura de reacción, el orden de agregado de reactivos y el envejecimiento de la mezcla preparada. Las variables de estudio involucradas son: las 
condiciones de pretratamiento, la composición de la mezcla inicial (relación sílice/alúmina, alcalinidad) y el tiempo de reacción.

La evaluación de la influencia de la aplicación de un pretratamiento (calcinación + fusión alcalina) al catalizador agotado, se realizó con el fin de determinar las condiciones que permitan obtener altos rendimientos a tiempos cortos de reacción. Se estudió la cantidad de fundente alcalino basado en $\mathrm{Na}_{2} \mathrm{CO}_{3}$, cuantificada como la relación catalizador/fundente, que permiten la activación química del catalizador favoreciendo la síntesis.

En el proceso de síntesis, con respecto a la influencia de la relación sílice/alúmina sobre el rendimiento de la reacción, los estudios se basaron en evaluar la composición de la mezcla de reacción que permita obtener un producto con mayor porcentaje de zeolita $\mathrm{A}$. Adicionalmente, al evaluar la composición, también se modificó la relación $\mathrm{Na}_{2} \mathrm{O} / \mathrm{H}_{2} \mathrm{O}$, con el fin de obtener resultados en cuanto a cómo influye la alcalinidad de la mezcla preparada sobre el producto sintetizado.

En lo referente al estudio del avance de la reacción, la extracción de muestras durante la síntesis a distintos tiempos y la evaluación a través de técnicas de caracterización tales como SEM y XRD permitieron establecer la evolución del proceso de formación de cristales zeolíticos.

\subsubsection{Mecanismos propuestos para la cristalización}

A partir de una sustancia nutriente amorfa o cristalina, en presencia de agua y de un agente mineralizante se lleva a cabo la reacción de cristalización. En general, la síntesis se lleva a cabo con la preparación de un gel obtenido por el mezclado de una fuente de sílice y una de alúmina en agua, a un pH dado y en presencia de un catión. La solución es 
colocada en un recipiente cerrado durante un tiempo determinado a una temperatura dada. El rol exacto de los tres elementos precedentes depende evidentemente de la síntesis que se considere llevar a cabo.

La hipótesis más aceptada sostenida por algunos investigadores [1-3], supone que la formación de los cristales de zeolita tiene lugar en solución. Las reacciones de condensación entre las especies presentes en la solución dan como resultado la aparición de gérmenes cristalinos y su posterior crecimiento, en donde la fase sólida hace las veces de reservorio.

En varios trabajos esta hipótesis ha sido respaldada, por ejemplo en [3], se establece una relación clara entre la velocidad de crecimiento de los cristales de faujasita y la concentración de las especies en solución. Además, la cristalización de zeolita puede realizarse a partir de soluciones claras en ausencia de gel [4]. Estos autores definieron la noción de módulo genético y ello permitió proponer una clasificación genética de las zeolitas.

Las zeolitas se forman como consecuencia de acomodar los módulos genéticos presentes en solución. Para el caso de las zeolitas tipo aluminosilicato, el complejo que orienta la disposición de los elementos genéticos es del tipo

anión aluminosilicato + catión de compensación + agua de hidratación

Los precursores aluminosilíceos complejos son necesarios para que se realice la síntesis de la zeolita. Las etapas de formación de zeolitas y la precipitación de compuestos iónicos simples son muy semejantes y consisten en la formación de pequeños agregados de precursores denominados embriones o gérmenes. Algunos embriones, al 
adquirir un tamaño crítico, pueden crecer por depósito de material para llegar a formar los cristales.

La formación de zeolitas es más lenta que la precipitación de una sal debido a que los cristales deben formarse por un mecanismo de condensación-polimerización según las tres dimensiones, con uniones Si$\mathrm{O}-\mathrm{T}(\mathrm{T}=\mathrm{Al}$ o $\mathrm{Si})$ que son parcialmente covalentes.

El análisis de la cinética global de cristalización para las zeolitas se inició con las síntesis de las zeolitas A y X, las cuales han sido estudiadas por numerosos autores, siendo los trabajos más importantes los realizados por [5-10].

Las etapas de nucleación y crecimiento cristalino constituyen el proceso de cristalización de zeolitas.

Como ya se ha mencionado, en este trabajo se aplicó al catalizador un pretratamiento preliminar a la síntesis con el fin de obtener un sólido que pueda ser empleado como precursor para la síntesis de zeolita $\mathrm{NaA}$. El método empleado para incrementar la reactividad del catalizador [11] consistió en la aplicación de un tratamiento de calcinación que produce una fusión alcalina. Se procedió a comparar los rendimientos de la reacción de síntesis con y sin aplicación del pretratamiento. Asimismo, se estudiaron las relaciones catalizador $/ \mathrm{Na}_{2} \mathrm{CO}_{3}$ que resultan adecuadas para realización de la síntesis de un producto rico en zeolita NaA. Para la metodología de síntesis, se tuvieron en cuenta los desarrollos anteriores del grupo de trabajo en este campo y los aportes de la literatura a nivel internacional [12-14].

Síntesis y potenciales aplicaciones tecnológicas de materiales zeolíticos obtenidos a partir de catalizadores FCC agotados 26 


\subsubsection{Nucleación}

La nucleación consiste en la formación de los primeros elementos del cristal de tamaño muy pequeño. En el proceso de nucleación, la sobresaturación del medio de reacción $\mathrm{S}$, tiene una gran importancia. S se define como la diferencia entre la concentración en un instante dado $\mathrm{C}$ y la concentración en el equilibrio $C_{e}$. En efecto, se demuestra que la velocidad de nucleación es prácticamente despreciable cuando $S$ es pequeña y crece de una forma extremadamente rápida luego que alcanza un valor Sm. En la Fig. 2.1. se observa la evolución de las velocidades de nucleación $V_{g}$ y crecimiento $V_{c}$ en función de la sobresaturación $S$.

\subsubsection{Crecimiento}

El crecimiento de los núcleos cristalinos es en general, función también de la sobresaturación $\mathrm{S}$, en una forma lineal o exponencial. Para valores altos de sobresaturación, la velocidad es por lo tanto menos sensible a las variaciones de sobresaturación que la velocidad de nucleación. Para valores bajos de sobresaturación, la velocidad de crecimiento, $V_{c}$, es preponderante, $y V_{g}$ lo es a sobresaturaciones altas. Por lo tanto, el tamaño de las partículas formadas va a depender de la relación de ambas velocidades $V_{g} / V_{c}$. Si $V_{c}>>V_{g}$, se formarán pocas partículas y serán de grandes dimensiones. En cambio, si $V_{g} \gg>V_{c}$, se formarán numerosas partículas y tendrán dimensiones pequeñas.

A partir de la formación de los primeros gérmenes estables, existe una competencia entre la formación de otros gérmenes y el crecimiento de los existentes. Los dos procesos consumen los precursores presentes en solución, la velocidad de nucleación pasa por un máximo y luego disminuye debido a que la sobresaturación tiende a disminuir. 


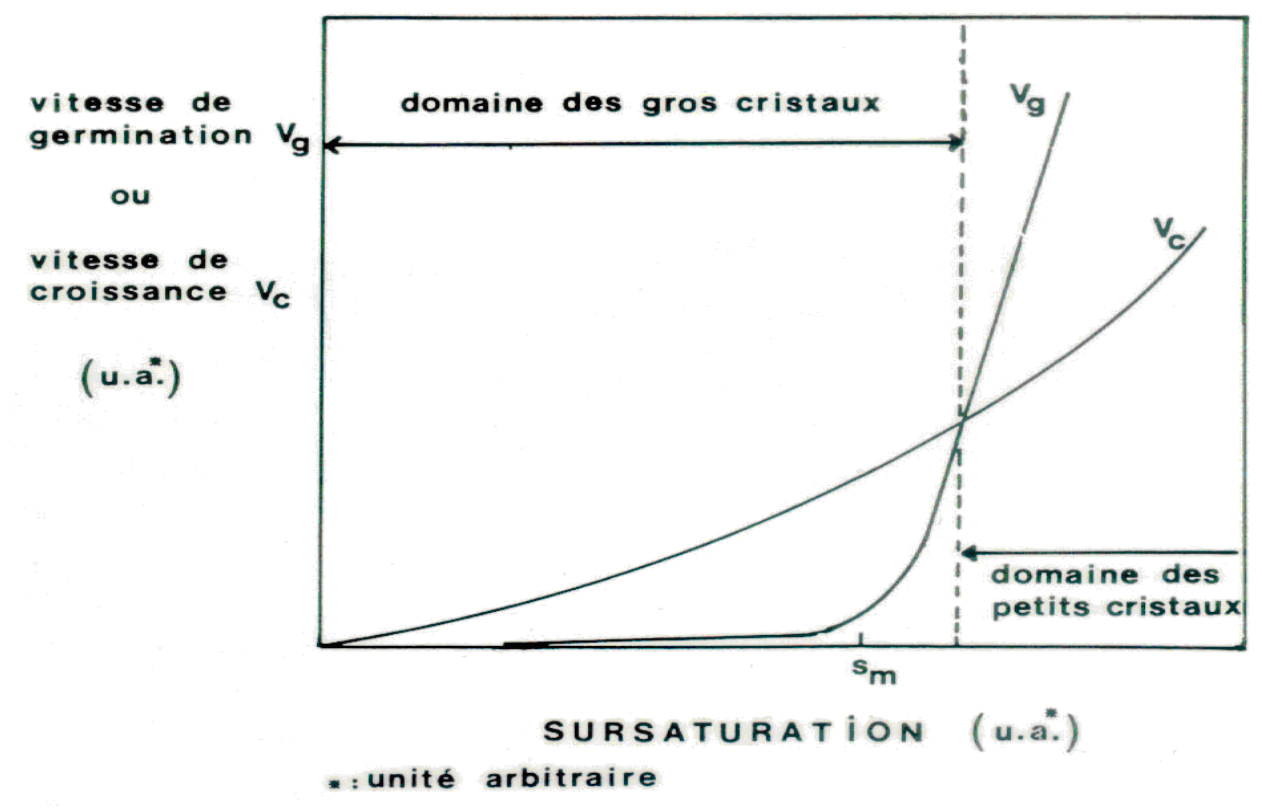

Figura 2.1. Evolución de las velocidades de nucleación $\vee_{g}$ y crecimiento $V_{c}$ en función de la sobresaturación S [15]. 
Se han sugerido expresiones de velocidad de nucleación, pero la determinación de las constantes a partir de medidas experimentales es muy dificultosa $[9,16]$. En efecto, se observa siempre una curva de conversión en forma sigmoidea con un punto de inflexión que separa la primera parte de la cristalización en la cual la nucleoformación es efectiva, de la segunda parte correspondiente solamente al crecimiento cristalino [17]. Esta evolución de la conversión ha sido observada para la zeolita $A$ [7], X e Y [3, 18-19] y es descripta por la ecuación siguiente:

$$
Z=1-\exp (-k t n)
$$

donde $Z$ es la relación entre la masa de zeolita formada al instante t respecto de la masa de zeolita obtenida al finalizar la cristalización. $k$ y $n$ son constantes. Pero esta descripción no da ninguna indicación cuantitativa sobre los principales factores responsables de la cinética de cristalización que son $V_{c}$ y $V_{g}$.

Teniendo en consideración todo lo expuesto, todas aquellas variables de síntesis que modifiquen la sobresaturación tendrán una influencia sobre la cinética del proceso de cristalización.

Hay una gran variedad de parámetros que pueden modificar la cinética de la síntesis, estos parámetros se detallaron en el punto 2.1.1. Las influencias de los principales se describirán a continuación.

\subsubsection{Influencia de la alcalinidad}

El grado de polimerización de las especies silicato presente en solución se rige por los equilibrios siguientes: 


$$
\begin{gathered}
2\left[-\mathrm{Si}^{-}+\mathrm{H}_{2} \mathrm{O} \rightarrow \mathrm{Si}-\mathrm{OH}+\mathrm{OH}^{-}\right] \\
2(-\mathrm{Si}-\mathrm{OH}) \rightarrow \text {-Si-O-Si- }+\mathrm{H}_{2} \mathrm{O} \\
2\left(-\mathrm{Si}^{-}\right)+\mathrm{H}_{2} \mathrm{O} \rightarrow-\text { Si-O-Si- }+2 \mathrm{OH}^{-}
\end{gathered}
$$

A medida que la alcalinidad disminuye, el equilibrio (1) se desplaza hacia la derecha y la concentración de las especies poliméricas que conducen a la formación de las zeolitas más ricas en sílice aumenta [20, 21]. Adicionalmente, el aumento del $\mathrm{pH}$ permite un aumento de las especies silicoalumínicas en solución y por lo tanto favorece la formación de precursores (módulos genéticos), lo cual tiende a aumentar las velocidad de nucleación. Se observa también un aumento en la velocidad de conversión en zeolita [22, 23]. A modo de ejemplo, en la Fig. 2.2. se muestra la Influencia de la alcalinidad en las velocidades de nucleación y crecimiento (arriba) y en la distribución de tamaño de los cristales obtenidos (abajo), en la síntesis de zeolita $\mathrm{NaA}$.

Además, como la solubilidad de la zeolita es más grande a mayor $\mathrm{pH}$, el rendimiento sólido es menor [20]. Como consecuencia de una variación importante de la alcalinidad, esto puede producir un cambio en la naturaleza de los módulos genéticos y conducir a la cristalización de una estructura zeolítica diferente. Por ejemplo, en el caso particular de la zeolita $\mathrm{NaY}$, se ha comprobado que la cocristalización de zeolita $\mathrm{NaP}$ puede controlarse con el agregado de $\mathrm{NaOH}$ [24]. 

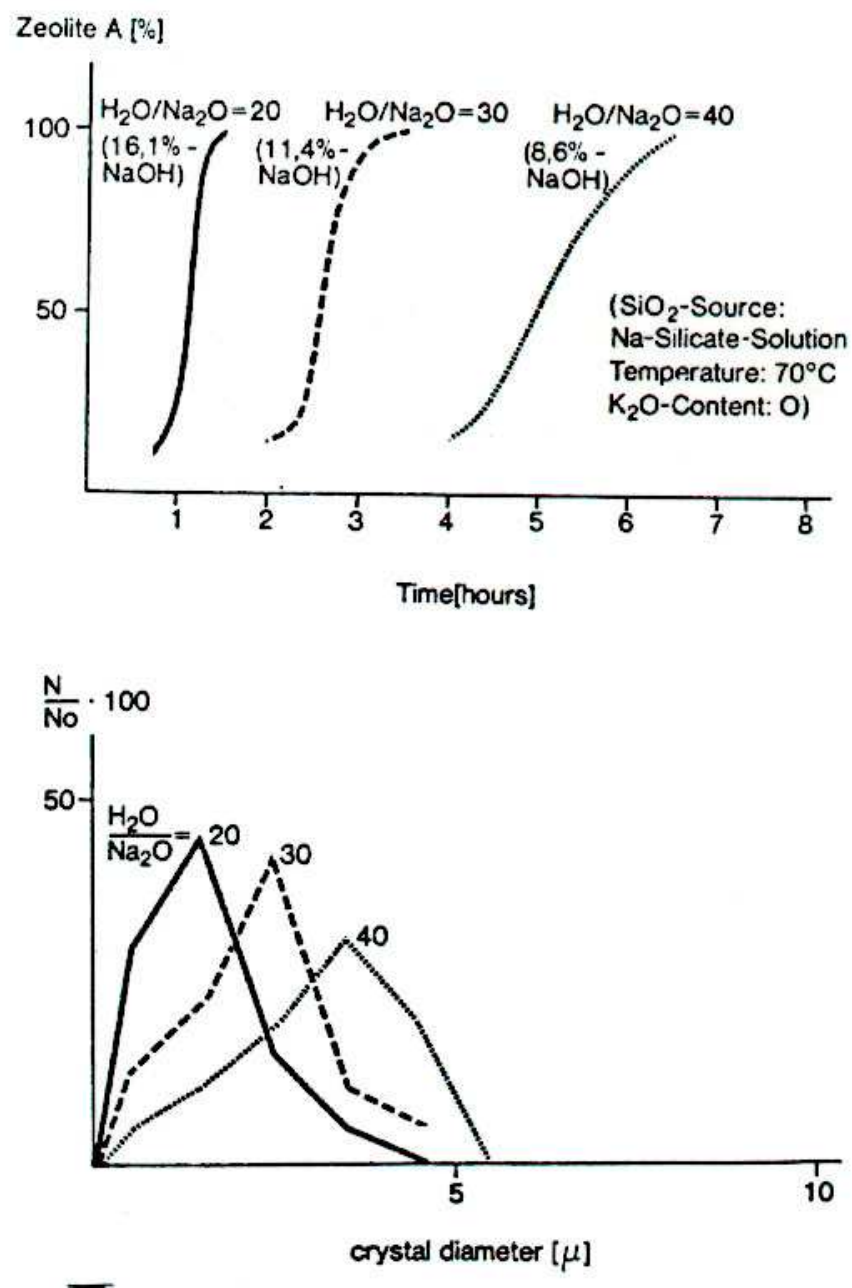

Figura 2.2. Influencia de la alcalinidad en las velocidades de nucleación y crecimiento (arriba) y sobre la distribución de tamaño de los cristales obtenidos (abajo), en la síntesis de zeolita NaA [9]. 


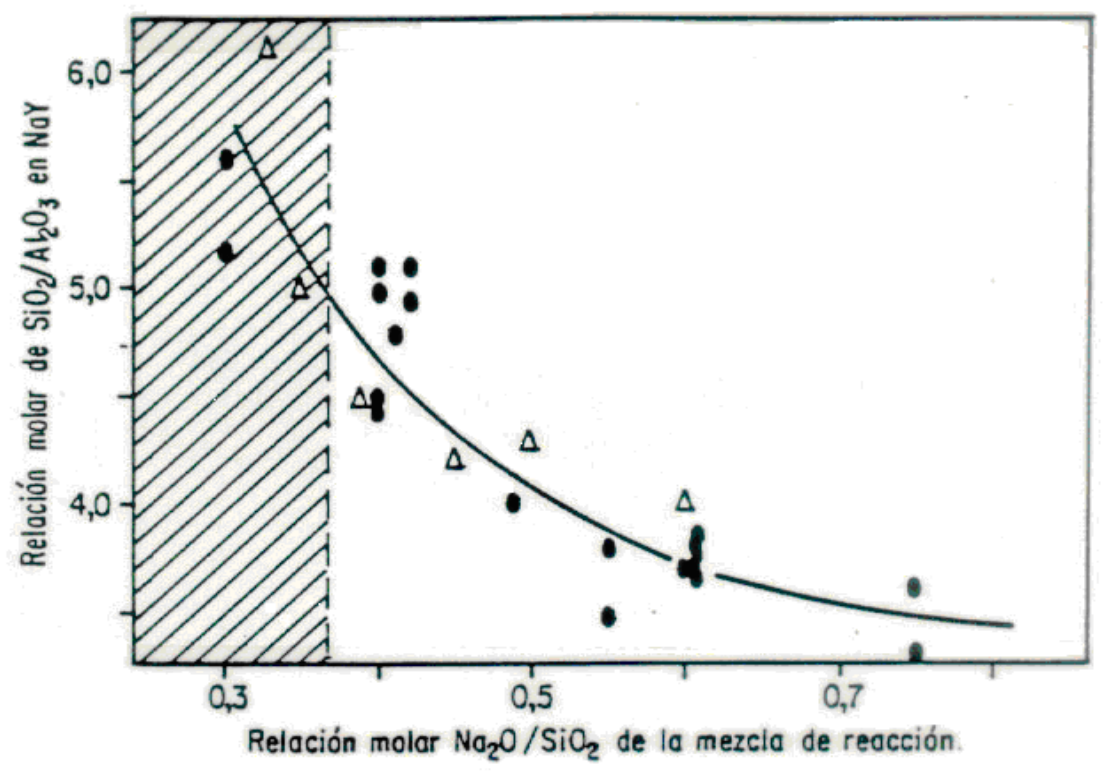

Figura 2.3. Dependencia de la relación Si/Al de la zeolita obtenida respecto de la alcalinidad de la mezcla inicial de reacción. Materia prima: caolinita [24]. 
Como resultado de un aumento de $\mathrm{pH}$ del medio de reacción, traducido en un aumento de la relación $\mathrm{Na}_{2} \mathrm{O} / \mathrm{SiO}_{2}$, el valor de la relación $\mathrm{Si} / \mathrm{Al}$ de la zeolita obtenida disminuye, ya sea utilizando metacaolinita 0 sales solubles como materias primas [24, 25]. En la Fig.2.3. se muestra este efecto cuando se realiza la síntesis de zeolita $\mathrm{NaY}$ partiendo de metacaolinita.

Además, un exceso de álcali conduce a una reducción marcada del tamaño de partícula final [24].

En los ensayos realizados para esta tesis se evaluó la influencia de la alcalinidad modificando la relación $\mathrm{Na}_{2} \mathrm{O} / \mathrm{H}_{2} \mathrm{O}$ en la composición de la mezcla de reacción.

\subsubsection{Temperatura de reacción}

El rango de temperatura para el cual es posible la cristalización depende de la zeolita a sintetizar. Las zeolitas más abiertas tales como A, $\mathrm{X}$ e $\mathrm{Y}$ se forman a baja temperatura, alrededor de $100^{\circ} \mathrm{C}$, mientras que las estructuras más cerradas lo hacen, como la analcita, a temperaturas mayores, alrededor de $200 \stackrel{\circ}{ } \mathrm{C}$. Por ejemplo, modificando algunos parámetros, en condiciones de formación de zeolita $A$, se puede sintetizar zeolita $X$ disminuyendo la temperatura de cristalización (55 ํ) [26].

Por lo tanto, la influencia de la temperatura es análoga a la de la alcalinidad. Los ensayos experimentales muestran que un aumento de temperatura a alcalinidad constante, en el rango de composiciones de una zeolita determinada, modifica la cinética global de cristalización de la misma forma que un aumento de alcalinidad a temperatura constante [17, 22, 27]. Esta dependencia se muestra en la Fig. 2.4. para el caso de la 

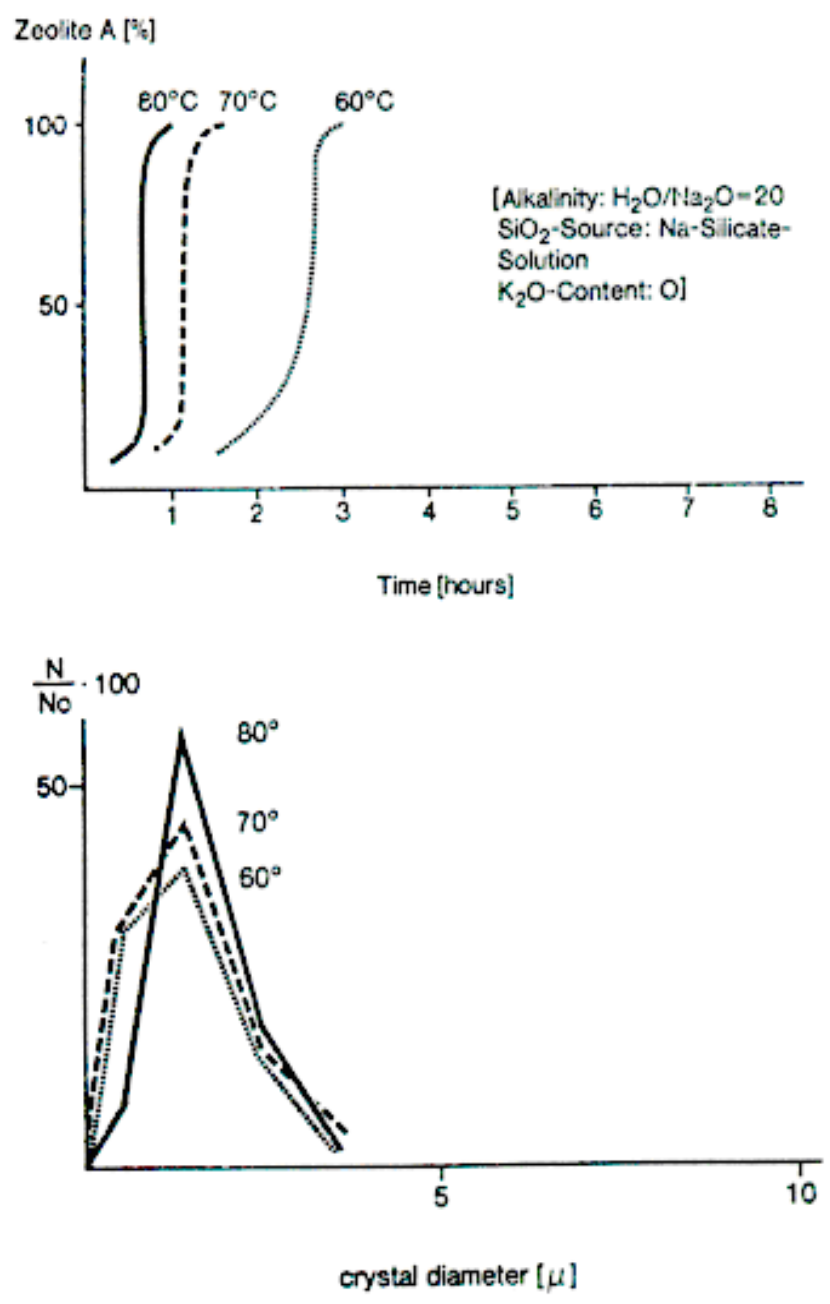

Figura 2.4. Influencia de la temperatura en la cristalización y en la distribución de tamaño de cristal en la síntesis de $\mathrm{NaA}$ [9]. 
zeolita NaA. La velocidad de calentamiento empleada para llegar a la temperatura de cristalización también es en algunos casos importante pues puede favorecer la formación de núcleos de especies indeseables.

En este trabajo de tesis, la temperatura de reacción seleccionada para todos los ensayos de síntesis fue cercana a los $90^{\circ} \mathrm{C}$, lo que permitió realizar reacciones a valores de presiones de recipiente cerrado que no requieren equipamiento especial y son por lo tanto más atractivas desde un punto de vista de aplicación tecnológica.

\subsubsection{Influencia de los cationes}

Tanto la naturaleza como la cantidad de iones presentes en la mezcla inicial de reacción son factores importantes en la síntesis de zeolitas [8, 28]. Una ligera modificación de uno de estos parámetros puede alterar la reacción de cristalización. Esto es debido al hecho de que los cationes presentes en la síntesis interaccionan con las asociaciones de moléculas de agua de manera diferente de acuerdo a su tamaño y a su carga.

Se ha estudiado, por ejemplo, la influencia de la presencia del ion potasio en la síntesis de zeolita LSX [26]. Partiendo de una composición inicial en el sistema $\mathrm{SiO}_{2}-\mathrm{Al}_{2} \mathrm{O}_{3}-\mathrm{Na}_{2} \mathrm{O}-\mathrm{H}_{2} \mathrm{O}$ y condiciones de síntesis que llevan a la cristalización de mezclas de zeolitas $A$ y $X$, se realizó un reemplazo parcial del ion $\mathrm{Na}^{+}$por el ion $\mathrm{K}^{+}$.

Puede observarse que a bajas concentraciones de $\mathrm{K}^{+}$, ocurre una co-cristalización de zeolitas A y $\mathrm{X}$, aumentando la proporción de zeolita $\mathrm{X}$ con el aumento de $\mathrm{K}^{+}$. A un nivel de 0,18 de reemplazo, se obtiene solamente $\mathrm{X}$. A niveles más altos de $\mathrm{K}^{+}$, el tiempo necesario para una determinada conversión aumenta notablemente. Para un nivel de 
reemplazo mayor a 0,5 , no se observa cristalización ni siquiera en un período de 10 días.

Las curvas de cristalización para distintas concentraciones de potasio aparecen en la Fig. 2.5. Una gradual disminución de la velocidad de cristalización puede observarse a medida que aumenta la concentración de $\mathrm{K}^{+}$. Además, la concentración de aluminio en solución aparece regulada por la cantidad de $\mathrm{K}^{+}$incorporada (Fig. 2.6.)

En los experimentos realizados se utilizó como reactivo $\mathrm{NaOH}$ y no se agregaron compuestos conteniendo cationes de diferente naturaleza porque se conoce que el ion $\mathrm{Na}^{+}$es el mejor inductor para la cristalización de zeolita tipo $\mathrm{A}$.

\subsection{Técnicas de caracterización de materiales}

Al realizar un estudio sistemático en síntesis de zeolitas, es necesario contar con la posibilidad de emplear un número importante de técnicas de caracterización que permitan identificar de manera precisa las propiedades estructurales, físicas y químicas de los materiales de partida y de las zeolitas obtenidas.

Se detallan a continuación los fundamentos para la aplicación de los métodos de caracterización empleados.

Síntesis y potenciales aplicaciones tecnológicas de materiales zeolíticos obtenidos a partir de catalizadores FCC agotados 36 


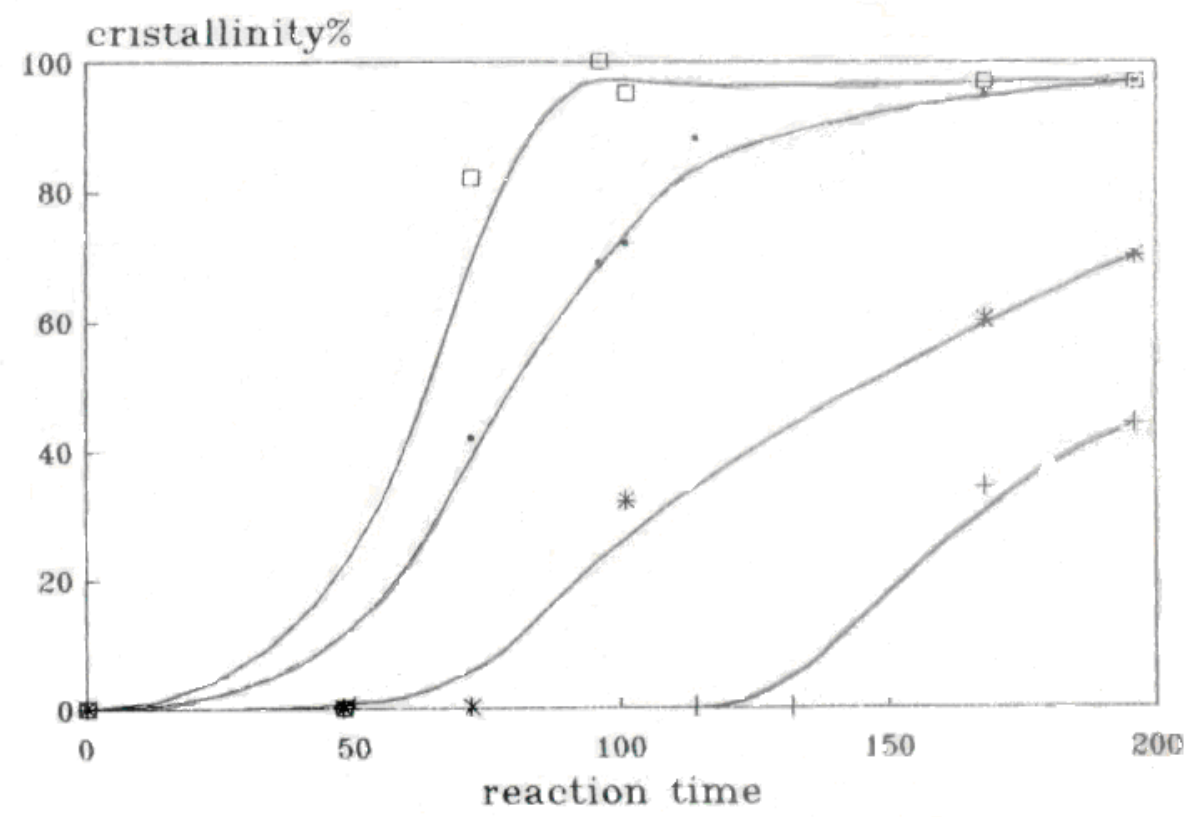

Figura 2.5. Curvas de cristalización para diferentes valores del parámetro $\mathrm{x}=\mathrm{K}_{2} \mathrm{O} / \mathrm{K}_{2} \mathrm{O}+\mathrm{Na}_{2} \mathrm{O}[26]$. 


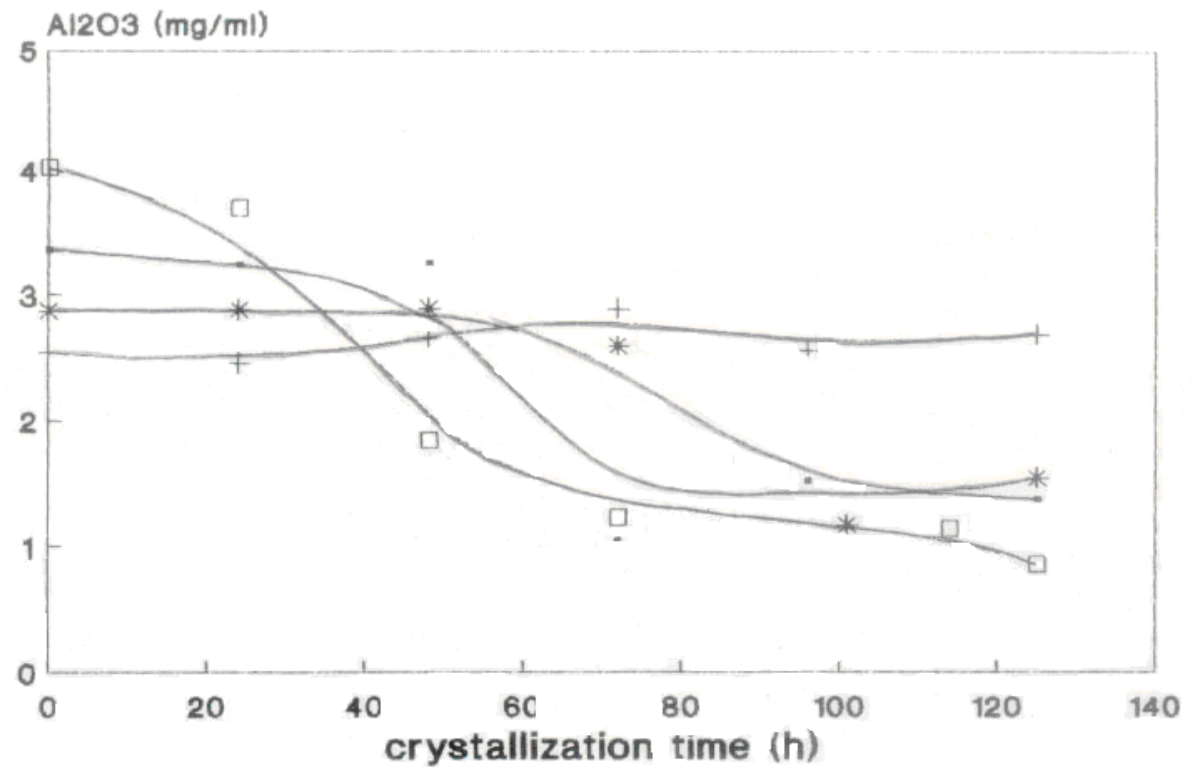

Figura 2.6. Concentración de $\mathrm{Al}$ en la fase líquida en función del tiempo de reacción para distintos valores del parámetro $\mathrm{x}=\mathrm{K}_{2} \mathrm{O} / \mathrm{K}_{2} \mathrm{O}+\mathrm{Na}_{2} \mathrm{O}$ [26]. 


\subsubsection{Difracción de rayos $X(X R D)$}

A partir del estudio por difracción de rayos $X$ se pueden caracterizar las muestras que se sintetizan, orientando sobre la eficacia y calidad de los procedimientos de síntesis. Adicionalmente puede obtenerse información acerca del tamaño de cristal y de los parámetros de red. Los rayos $X$ son radiación electromagnética de la misma naturaleza que la luz pero de longitud de onda mucho más corta. La unidad de medida en la región de los rayos $X$ es el angstrom $(\AA)$ y los rayos $X$ usados en difracción tienen longitudes de onda en el rango 0,52,5 Å mientras que la longitud de onda de la luz visible está en el orden de $6.000 \AA$. La interacción de los rayos $X$ con la materia esencialmente ocurre mediante dos procesos:

a) Algunos fotones del haz incidente son desviados sin pérdida de energía, constituyen la radiación dispersada exactamente con la misma longitud de onda que la radiación incidente (es la que origina el fenómeno de la difracción).

b) Los fotones pueden sufrir una serie de choques inelásticos al incidir sobre un blanco y su energía incrementa la temperatura de la muestra 0 da lugar al fenómeno de fluorescencia. Un rayo difractado puede definirse como un rayo compuesto de un gran número de rayos dispersados que se refuerzan mutuamente. La difracción es, por lo tanto, esencialmente un fenómeno de dispersión. Los átomos dispersan la radiación incidente en todas direcciones, y en algunas direcciones los rayos dispersados estarán completamente en fase y por tanto se refuerzan mutuamente para formar rayos difractados. 
Los rayos dispersados estarán completamente en fase si esa diferencia de fase es igual a un número entero $\mathrm{n}$ de longitudes de onda:

$$
\eta \lambda=2 d \operatorname{sen}(\theta)
$$

Esta relación se conoce como Ley de Bragg y establece la condición esencial que debe cumplirse para que ocurra la difracción; $n$ se denomina orden de difracción y debe ser un número entero consistente $\operatorname{con} \sin \theta$ menor o igual que 1 . Luego si se representa la intensidad de radiación que llega al detector, frente al ángulo $\theta$, aparecerá un pico cuando se cumpla la condición de Bragg. A dicha representación se la denomina diagrama de difracción o difractograma. Dentro de una muestra sólida, los rayos $X$ son dispersados primariamente por los electrones. Los efectos de difracción se correlacionan con la disposición de los átomos, ya que la densidad electrónica está íntimamente relacionada con las posiciones de los mismos.

\subsubsection{Microscopía electrónica de barrido (SEM)}

En un microscopio electrónico de barrido se barre mediante un rastreo programado la superficie del sólido con un haz de electrones de energía elevada y como consecuencia de ello se producen en la superficie diversos tipos de señales. Estas señales incluyen electrones retrodispersados, secundarios y Auger; fotones debido a la fluorescencia de los rayos $X$ y otros fotones de diversas energías. Todas estas señales se han utilizado en estudios de superficie, pero las más usuales son las que corresponden a: (1) electrones retrodispersados y secundarios, en los que se fundamenta el microscopio de barrido de electrones y (2) la emisión de rayos $\mathrm{X}$, que se utiliza en el análisis con microsonda de electrones [29].

Síntesis y potenciales aplicaciones tecnológicas de materiales zeolíticos obtenidos a partir de catalizadores FCC agotados $\mathbf{4 0}$ 
Los electrones secundarios de baja energía $(<50 \mathrm{eV})$ emitidos de la superficie de la muestra se pueden utilizar para dar un tipo de imagen. Para facilitar esta emisión de electrones se metaliza la muestra con una pequeña capa de un metal conductor como el Au. El haz de é se puede concentrar en una zona diminuta $(\sim 20 \AA)$ que puede barrer la superficie del espécimen al ser deflectado por bobinas adecuadas. Los electrones secundarios se detectan por encima del espécimen y la imagen muestra la intensidad de los electrones secundarios emitidos por las diferentes partes de la muestra.

El microscopio electrónico de barrido proporciona información morfológica y topográfica sobre la superficie de los sólidos que normalmente es necesaria para entender el comportamiento de las superficies. Así, un examen por microscopía de electrones es a menudo la primera etapa en el estudio de las superficies de un sólido.

\subsubsection{Energía de dispersión de rayos $X$ (EDX)}

Si el microscopio electrónico tiene acoplado un detector de energía difusa de rayos $X$ (EDX), se puede también determinar la composición química, la distribución de los elementos que componen una muestra y la relación entre ellos. La técnica descripta en [30] consiste en bombardear la muestra con un haz de electrones que al chocar con la superficie genera rayos $\mathrm{X}$. La distancia que viajan los electrones en el interior de la muestra depende del peso y del número atómico de los átomos que la componen y de la energía del haz. En general, los electrones se distribuyen en forma hemisférica en el interior del sólido. La muestra se cubre con una delgada película de Au mediante la técnica de sputtering. Esta metodología permite hacerla conductora y observable por SEM, evitando que se dañe por calentamiento o que se cargue negativamente produciendo la deflexión del haz incidente. 


\subsubsection{Resonancia Magnética Nuclear (NMR)}

La resonancia magnética nuclear es una espectroscopía de absorción cuyo fundamento es la absorción de energía (radiofrecuencias) por un núcleo magnéticamente activo, que está orientado en el seno de un campo magnético, y que por efecto de esa energía cambia su orientación. Es una herramienta analítica que proporciona una gran información estructural y estereoquímica. Para ello es necesaria la realización de diferentes tipos de experimentos de los cuales se obtiene una determinada información. La técnica no es destructiva y tiene aplicaciones en todas las áreas de la química y en algunas de la biología.

Un imán genera un campo magnético estable, dicho campo puede ser de intensidad variable, definiendo la frecuencia de resonancia de cada núcleo. Generalmente se identifica cada espectrómetro por la frecuencia de resonancia del protón, así en un imán de 7.046 Tesla, los núcleos de ${ }^{1} \mathrm{H}$ resuenan a $300 \mathrm{MHz}$, y por tanto sería un espectrómetro de $300 \mathrm{MHz}$.

Entre los núcleos más frecuentemente encontrados en los compuestos orgánicos que son magnéticamente activos podemos citar al protón $\left({ }^{1} \mathrm{H}\right)$, el carbono $\left({ }^{13} \mathrm{C}\right)$, el nitrógeno $\left({ }^{15} \mathrm{~N}\right)$ y el fósforo $\left({ }^{31} \mathrm{P}\right)$. Las muestras, generalmente, son disoluciones en disolventes que no tengan átomos de protio $\left({ }^{1} \mathrm{H}\right)$.

Frecuentemente se usan el deuterocloroformo, hexadeuterodimetilsulfóxido, óxido de deuterio, deuterobenceno, deuteropiridina y otros.

Los espectros más comunes son representaciones de la intensidad de absorción frente a la frecuencia de resonancia (generalmente a través 
del parámetro ঠ) y presentan señales cuya posición, forma y tamaño están íntimamente relacionadas con la estructura molecular.

\subsubsection{Espectroscopía infrarroja con transformada de Fourier. (FT-IR)}

La región del infrarrojo del espectro abarca la radiación con números de onda entre 12.800 y $10 \mathrm{~cm}^{-1}$, que corresponden a longitudes de onda de 0,78 a $1.000 \mu \mathrm{m}$. Tanto desde el punto de vista de las aplicaciones como de la instrumentación, es conveniente dividir el espectro infrarrojo en tres regiones denominadas infrarrojo cercano, medio y lejano; en la Tabla 2.1. y en la Tabla 2.2. se muestran los límites aproximados de cada una de ellas y las aplicaciones, respectivamente. La región más utilizada es, con mucha diferencia, la región del infrarrojo medio.

Los espectros de absorción, emisión y reflexión en el infrarrojo, de especies moleculares, se pueden explicar asumiendo que todos son el resultado de los distintos cambios energéticos producidos en las transiciones de las moléculas de unos estados de energía vibracionales a otros.

La radiación en el infrarrojo no es lo suficientemente energética para producir la clase de transiciones electrónicas que se dan cuando la radiación es ultravioleta, visible o rayos $X$. La absorción de radiación en el infrarrojo se limita así, en gran parte, a especies moleculares para las cuales existen pequeñas diferencias de energía entre los distintos estados vibracionales y rotacionales [31]. 
Tabla 2.1. Regiones del espectro infrarrojo

\begin{tabular}{|c|c|c|c|}
\hline Región & $\begin{array}{c}\text { Intervalo de } \\
\text { longitud de } \\
\text { onda }(\boldsymbol{\mu m})\end{array}$ & $\begin{array}{c}\text { Intervalo de } \\
\text { número de } \\
\text { onda }\left(\mathbf{c m}^{-1}\right)\end{array}$ & $\begin{array}{c}\text { Intervalo de } \\
\text { frecuencias } \\
\mathbf{( H z )}\end{array}$ \\
\hline Cercano & 0,78 a 2,5 & 12.800 a 4,0 & $\begin{array}{c}3,8 \times 10^{14} \text { a } 1,2 \\
\times 10^{14}\end{array}$ \\
\hline Medio & 2,5 a 50 & 4.000 a 200 & $\begin{array}{c}1,2 \times 10^{14} \mathrm{a} 6 \mathrm{x} \\
10^{12}\end{array}$ \\
\hline Lejano & $50 \mathrm{a} 1.000$ & $200 \mathrm{a} 10$ & $\begin{array}{c}6 \times 10^{12} \mathrm{a} 3 \mathrm{x} \\
10^{11}\end{array}$ \\
\hline $\begin{array}{c}\text { La más } \\
\text { utilizada }\end{array}$ & $2,5 \mathrm{a} 15$ & $4.000 \mathrm{a} 670$ & $\begin{array}{c}1,2 \times 10^{14} \mathrm{a} 2 \mathrm{x} \\
10^{13}\end{array}$ \\
\hline
\end{tabular}


Tabla 2.2. Principales aplicaciones de la espectrometría en el infrarrojo.

\begin{tabular}{|c|c|c|c|}
\hline $\begin{array}{c}\text { Regiones } \\
\text { espectrales }\end{array}$ & $\begin{array}{l}\text { Tipo de } \\
\text { medida }\end{array}$ & $\begin{array}{l}\text { Tipo de } \\
\text { análisis }\end{array}$ & Tipo de muestras \\
\hline \multirow[t]{2}{*}{$\begin{array}{l}\text { Infrarrojo } \\
\text { cercano }\end{array}$} & $\begin{array}{l}\text { Reflectancia } \\
\text { difusa }\end{array}$ & Cuantitativo & $\begin{array}{l}\text { Materiales comerciales } \\
\text { sólidos o líquidos }\end{array}$ \\
\hline & Absorción & Cuantitativo & Mezclas gaseosas \\
\hline \multirow{4}{*}{$\begin{array}{l}\text { Infrarrojo } \\
\text { medio }\end{array}$} & Absorción & Cualitativo & $\begin{array}{l}\text { Compuestos sólidos, } \\
\text { líquidos o gaseosos } \\
\text { puros }\end{array}$ \\
\hline & & Cuantitativo & $\begin{array}{l}\text { Mezclas de complejas de } \\
\text { gases, líquidos o sólidos }\end{array}$ \\
\hline & Reflectancia & Cualitativo & $\begin{array}{c}\text { Compuestos sólidos } \\
\text { puros o líquidos }\end{array}$ \\
\hline & Emisión & Cuantitativo & Muestras atmosféricas \\
\hline $\begin{array}{l}\text { Infrarrojo } \\
\text { lejano }\end{array}$ & Absorción & Cualitativo & $\begin{array}{l}\text { Especies inorgánicas } \\
\text { puras u organometálicas }\end{array}$ \\
\hline
\end{tabular}




\subsubsection{Determinación del punto de cero carga por medición del potencial de difusión (PZC)}

Al contactar un sólido genérico con una solución acuosa, de acuerdo a la teoría de formación de una doble capa eléctrica en una interfase, el valor del potencial eléctrico en la superficie alcanza un valor máximo, el cual disminuye con la distancia, aproximándose a cero fuera de la capa difusa. Si se considera una superficie cargada negativamente, el efecto sobre los iones positivos presentes en la solución hace que algunos de ellos formen una rígida capa adyacente alrededor de la superficie sólida. Esta capa de contra-iones es conocida como la capa de Stern. Otros iones positivos adicionales atraídos por la superficie, interaccionan con los formadores de la capa de Stern, produciéndose un equilibrio dinámico que resulta en la formación de una capa difusa de contra-iones. El punto donde se unen la capa difusa y la de Stern resulta de gran importancia, el potencial en dicho punto es lo que se conoce como potencial zeta. Este valor proporciona una idea de los mecanismos de dispersión electrostática, y puede ser medido de una manera muy simple, mientras que la carga de la superficie y su potencial no pueden medirse. Por ejemplo, el punto de cero carga, definido como el $\mathrm{pH}$ al cual un sólido no tiene carga superficial neta, puede ser calculado a partir de las medidas de potencial zeta. El punto de cero carga, es un valor de $\mathrm{pH}$ por debajo del cual la superficie estará cargada de forma positiva. En cambio, por encima de este valor de pH, la superficie estará cargada de forma negativa.

\subsubsection{Espectroscopía de absorción atómica (AA)}

Es una técnica para determinar la concentración de un elemento metálico determinado en una muestra. Se evalúa la concentración de un 
analito en una muestra mediante el uso de la espectrometría de absorción. Esta técnica se basa en la ley de Beer-Lambert.

$$
I_{1} / I_{0}=10^{-\alpha / c}
$$

donde:

$\mathrm{I}_{1} / \mathrm{I}_{0}=$ son las intensidades saliente y entrante respectivamente.

$A={ }^{\text {alc }}$, es la absorbancia

$\alpha=$ es el coeficiente de absorción

I = es la longitud atravesada por la luz en el medio

$\mathrm{c}=$ es la concentración del absorbente en el medio.

En el atomizador, los electrones de los átomos pueden ser promovidos a orbitales más altos por un instante mediante la absorción de una cantidad de energía. Esta cantidad de energía (o longitud de onda) se refiere específicamente a una transición de electrones en un elemento particular, generalmente, cada longitud de onda corresponde a un solo elemento. La cantidad de energía que se pone en la llama es conocida, y la cantidad restante en el otro lado (el detector) se puede medir. Por lo tanto, a partir de la ley de Beer-Lambert se puede calcular cuántas de estas transiciones tienen lugar, y así obtener una señal que es proporcional a la concentración del elemento que se mide.

\subsection{Cinética de sorción}

\subsubsection{Cinética de primer y segundo orden}

El estudio de la dinámica de sorción describe la velocidad con que el sólido elimina al catión de la solución y esta velocidad está relacionada con el tiempo de residencia en la interfase sólido-solución. La cinética de 
sorción de $\mathrm{Cr}$ (III) sobre los materiales sintetizados y sobre las zeolitas de referencia se analizaron utilizando modelos cinéticos de primer y segundo orden, de acuerdo a lo descripto en [32].

La cinética de primer orden expresado por la ecuación de Lagergren es la siguiente:

$$
d_{\mathrm{q}} / d_{t}=k_{1 a d s}\left(q_{e}-q_{t}\right)(1)
$$

donde $q_{\mathrm{e}} \mathrm{y} \mathrm{q}_{\mathrm{t}}$ son la capacidad de adsorción en el equilibrio y al tiempo $t$, respectivamente $\left(\mathrm{mg} \cdot \mathrm{g}^{-1}\right), \mathrm{k}_{1 \text { ads }}$ es la constante de velocidad de pseudoprimer orden. $\left(\min ^{-1}\right)$. Luego de integrar y aplicando las condiciones de borde.

$$
\begin{array}{ll}
\mathrm{t}=0, & \mathrm{q}_{\mathrm{t}}=0 \\
\mathrm{t}=\mathrm{t}, & \mathrm{q}_{\mathrm{t}}=\mathrm{q}_{\mathrm{t}}
\end{array}
$$

la forma integrada de la ecuación (1) nos da

$$
\log \left(q_{e}-q_{t}\right)=\log q_{e}-k_{1 \text { ads }} . t / 2,303 \text { (2) }
$$

Donde los valores de $\log \left(q_{e}-q_{t}\right)$ se encuentran linealmente correlacionados con $t$, o sea que de la pendiente de esa recta se podría determinar $k_{1 a d s} . y q_{e}$ a partir de la ordenada al origen.

Por otra parte, una cinética de adsorción de segundo orden se expresa por la ecuación (3)

$$
d_{t} / d t=k_{2 a d s}\left(q_{e}-q_{t}\right)^{2}(3)
$$


donde $\mathrm{k}_{2 \text { ads }}$ es la constante de velocidad de pseudosegundo orden (g. mg ${ }^{-1} \cdot \mathrm{min}^{-1}$ ).

Tomando como condiciones de borde

$\mathrm{t}=0 \quad \mathrm{q}_{\mathrm{t}}=0$,

$\mathrm{t}=\mathrm{t} \quad \mathrm{q}_{\mathrm{t}}=\mathrm{q}_{\mathrm{t}}$

la forma integrada de la ecuación (3) queda:

$$
1 /\left(q_{e}-q_{t}\right)=\left(1 / q_{e}\right)+k_{2} \text { ads.t }(4)
$$

O sea

$$
t / q t=1 /\left(k_{\text {zads }} q_{e}{ }^{2}\right)+t / q_{e}(5)
$$

Si la velocidad inicial de sorción es $\mathrm{h}\left(\mathrm{mg} \cdot \mathrm{g}^{-1} \mathrm{~min}^{-1}\right)$, entonces

$$
h=k_{\text {zads }} q_{e}^{2}
$$

entonces las ecuaciones (5) y (6) dan:

$$
t / q_{t}=1 / h+t / q_{e}(7)
$$

En este caso el gráfico de ( $\left.t / q_{t}\right)$ vs $t$ de la ecuación (5) debería dar una recta de la cual se podrían estimar $\mathrm{q}_{e}$ and $\mathrm{k}_{2 a d s}$ a partir de la pendiente y de la ordenada al origen. 


\subsubsection{Coeficiente de difusión}

El cálculo de los coeficientes de difusión para diferentes temperaturas y concentraciones de la solución podrían proporcionar una idea acerca de la existencia de control por difusión intraparticular, ya que un modelo basado en la ley de Fick [33] permitiría calcular los coeficientes de difusión utilizando la expresión siguiente

$$
\ln \left(1-q_{t} / q_{\infty}\right)=\ln \left(6 / \pi^{2}\right)-\left(D_{f} / r_{0}^{2}\right) \cdot \pi^{2} \cdot t
$$

Donde $q_{t} / q_{\infty}$ es la cantidad retenida en el equilibrio, $q_{t}$ la cantidad retenida a tiempo $t, r_{0}$ es el radio de los cristales y $n$ es un número entero. Por lo cual graficando In $\left(1-q_{t} / q_{\infty}\right)$ en función de $t$ podríamos estimar el coeficiente de difusión [34].

\subsection{Morteros}

Se pueden distinguir dos etapas que se diferencian por su estado físico:

*Estado fresco

*Estado endurecido

Cuando se elabora la mezcla, el mortero es plástico y manejable. La duración de esta etapa depende del tiempo de fraguado, entendiéndose por fraguado al proceso de endurecimiento donde el mortero pierde su plasticidad. Luego, el mortero se endurece hasta consolidarse. 


\subsubsection{Mortero endurecido}

\subsubsection{Ensayos de flexión y compresión}

La resistencia de un material se define como la habilidad para resistir esfuerzos sin fallar. Dicha falla se identifica, en algunos casos, con la aparición de grietas. En los morteros, la resistencia está relacionada con el esfuerzo requerido para causar fractura y es sinónimo del grado de falla en el que el esfuerzo aplicado alcanza su valor máximo.

En los ensayos de flexión, la fractura se traduce en falla, en cambio en los ensayos de compresión, la pieza ensayada se considera que ha fallado cuando, no habiendo señales de fractura externa visibles, el agrietamiento interno es tan avanzado que el mortero es incapaz de soportar una carga mayor sin fracturarse.

\subsubsection{Contracción por secado}

Se refiere a la disminución de la longitud del mortero, la cual es causada por la evaporación del agua, bajo condiciones indicadas de humedad relativa, temperatura y tasa de evaporación en el ambiente. El mortero no permanecerá dimensionalmente estable cuando se expone a humedad ambiental por debajo de la saturación, principalmente porque la pérdida de agua físicamente adsorbida de la fase H-S-C, constituida por silicato de calcio hidratado, resulta en deformación por contracción. Si la contracción por secado es intensa causa un cambio volumétrico capaz de crear tensiones importantes en zonas impedidas de deformaciones.

La contracción aumenta con:

*La mayor relación agua/cemento

*La menor relación volumen/superficie

Síntesis y potenciales aplicaciones tecnológicas de materiales zeolíticos obtenidos a partir de catalizadores FCC agotados $\mathbf{5 1}$ 


\subsection{Referencias}

[1] Zdhanov, S.P. (1971) Molecular Sieves Zeolites I, Advances in Chemistry Series 101, American Chemical Society, Washington, DC, 20.

[2] Barrer, R.M. (1982) Hydrotermal Chemistry of Zeolites, Academic Press, London.

[3] Kacirek, H., Lechert, H. (1976) J.Phys.Chem. 80, 1291.

[4] Caullet, P.,.Guth, J.L., Hurtrez, G. Wey, R. (1981) Bull. Soc. Chim. Fr., 1, 253.

[5] Kerr, G.T., (1966) J.Phys.Chem. 70, 1047.

[6].Kerr, G.T. (1968) J.Phys.Chem. 72, 1385.

[7] Ciric, J. (1968) J. Colloid. Interf. Sc. 2, 28.

[8] Breck, D.W., Flaningen, E.M. (1968) Molecular Sieves, Society of Chemical Industry, London10.

[9] Meise, W., Schwochow, F.E., (1973) Molecular Sieves, Advances in Chemistry Series 121, American Chem. Soc., Washigton D.C. ,169.

[10] Patel, A.K., Sand, L.B. (1977) Molecular Sieves II, A.C.S. Symp.Series 40, American Chemical Society, Washington DC, 207.9 [11] Abdemeizien-Hamoudi, H., Siffert B. (1989) Appl. Clay Sci. 4, 1.

[12] Basaldella E.I., Paladino, J.C., Solari, M., Valle, G.M. (2006) Appl. Catal., B 66, 186.

[13] Basaldella, E.I., Torres Sánchez, R.M., Conconi, M.S. (2009) Appl. Clay Sci. 42, 611.

[14] Escardino, A., Barba, A., Sanchez, E., Cantavella, V. (1999) Br.

Ceram. Trans. 98, 172.

[15] Marcilly, C. (1984) Revue de l'Institut Français du Pétrole, 39.

[16] Jacobs, P.W.M., Tomkins, F.C. (1955) Chemistry of the solid state, Ed. W.E.Garner, London.

[17] Zhdanov, S.P., Samulevich, N.N. (1980) Proc. 5th Int. Conf. on Zeolites, Ed. L.V.C.Rees, Heyden, 75.

[18] Kacirek H., Lechert, H. (1975) J.Phys.Chem., 79, 1589. 
[19] Freund, E.F. (1976) .J.Cryst.Growth, 34, 11.

[20] Barrer, R.M., Mainwaring, D.E. (1972) J.Chem.Soc.Dalton, 1254.

[21] Rouet, P. (1984)Tesis Doctoral, Mulhouse, 1984.

[22] Domine D., Quobex, J. (1968) Molecular Sieves, Society of the Chemical Industry, London, 78.

[23] Hayhurst, D.T., Sand, L.B. (1977) Molecular Sieves II, Ed. Katzer, J.R., Am.Chem.Soc. Symp.Ser. 40, 219.

[24] Basaldella, E.I., Kikot, A.,Pereira, E. (1992) Desarrollo de catalizadores para el proceso de craqueo catalítico en lecho fluidizado, Ediciones Técnicas INTEVEP, 84, 101.

[25] Basaldella, E.I.,Tara J.C. (1993) Ind.Eng.Chem.Res., 32, 751.

[26] Basaldella, E.I., Tara, J.C. (1995) Zeolites 15, 243.

[27] Culfaz, A., Sand, L.B. (1973) Adv.Chem.Ser., 121, 140.

[28] Erdem, A. Sand, L.B. (1979) J.Cat., 60, 241.

[29] Skoog, Holler, Nieman. (2001) Principios de ánalisis instrumental. Quinta edición. Mc Graw and Hill Madrid-España, Cap 21.

[30] Goldstein, J., Muldoon, J. (1977) Practical scanning electron microscopy. Electron and ion probe microanalysis", Plenum Press.

[31] Skoog, Holler, Nieman. (2001) Principios de análisis instrumental.

Quinta edición. Mc Graw and Hill Madrid-España, Cap 16.

[32] Ruthven D.M. (1984) Principles of Adsorption and Adsorption Process, John Wiley. New York.

[33] Niboua D., Mekatela H., Amokranea S., Barkatb M., Trari M. (2010) J. Hazard. Mater.173, 637. 


\title{
CAPÍTULO III
}

\author{
METODOLOGÍA \\ EXPERIMENTAL
}

Síntesis y potenciales aplicaciones tecnológicas de materiales zeolíticos obtenidos a partir de catalizadores FCC agotados 54 


\section{METODOLOGÍA EXPERIMENTAL}

En este capítulo se describe la metodología empleada:

\subsection{Pretratamiento del catalizador FCC Agotado}

Se empleó el método de activación por fusión alcalina con $\mathrm{Na}_{2} \mathrm{CO}_{3}$ (Baker, grado analítico) como pretratamiento del catalizador FCC agotado con el fin de incrementar su reactividad. Se calcinó el catalizador con el fundente a $800 \stackrel{\circ}{\circ}$ en una mufla Estigia modelo D1 con programador de temperatura (Fig. 3.1.) con una velocidad de calentamiento de $5 \% / \mathrm{min}$, en condiciones estáticas, estudiando los resultados para mezclas con diferentes proporciones en peso de $\mathrm{Na}_{2} \mathrm{CO}_{3}$. Para la calcinación se prepararon mezclas utilizando $25 \%$ y $50 \%$ de $\mathrm{Na}_{2} \mathrm{CO}_{3}$.como fundente.

\subsection{Síntesis del material}

\subsubsection{Síntesis hidrotérmica del material zeolítico}

Los ensayos de síntesis hidrotérmica se realizaron a partir del catalizador FCC agotado proveniente de una unidad comercial de lecho fluidizado de cracking catalítico, que constituye la fuente principal de sílice y alúmina. Para llevar a cabo las experiencias se utilizaron como materiales adicionales $\mathrm{NaOH}$ (Carlo Erba, $98 \% \mathrm{p} / \mathrm{p}$ ), $\mathrm{NaAlO}_{2}$ comercial (36,5\%p/p $\mathrm{pl}_{2} \mathrm{O}_{3}, 29,6 \% \mathrm{p} / \mathrm{p} \mathrm{Na}{ }_{2} \mathrm{O}, 33,9 \% \mathrm{p} / \mathrm{p} \mathrm{H}_{2} \mathrm{O}$ ) y $\mathrm{H}_{2} \mathrm{O}$ destilada.

Síntesis y potenciales aplicaciones tecnológicas de materiales zeolíticos obtenidos a partir de catalizadores FCC agotados 55 


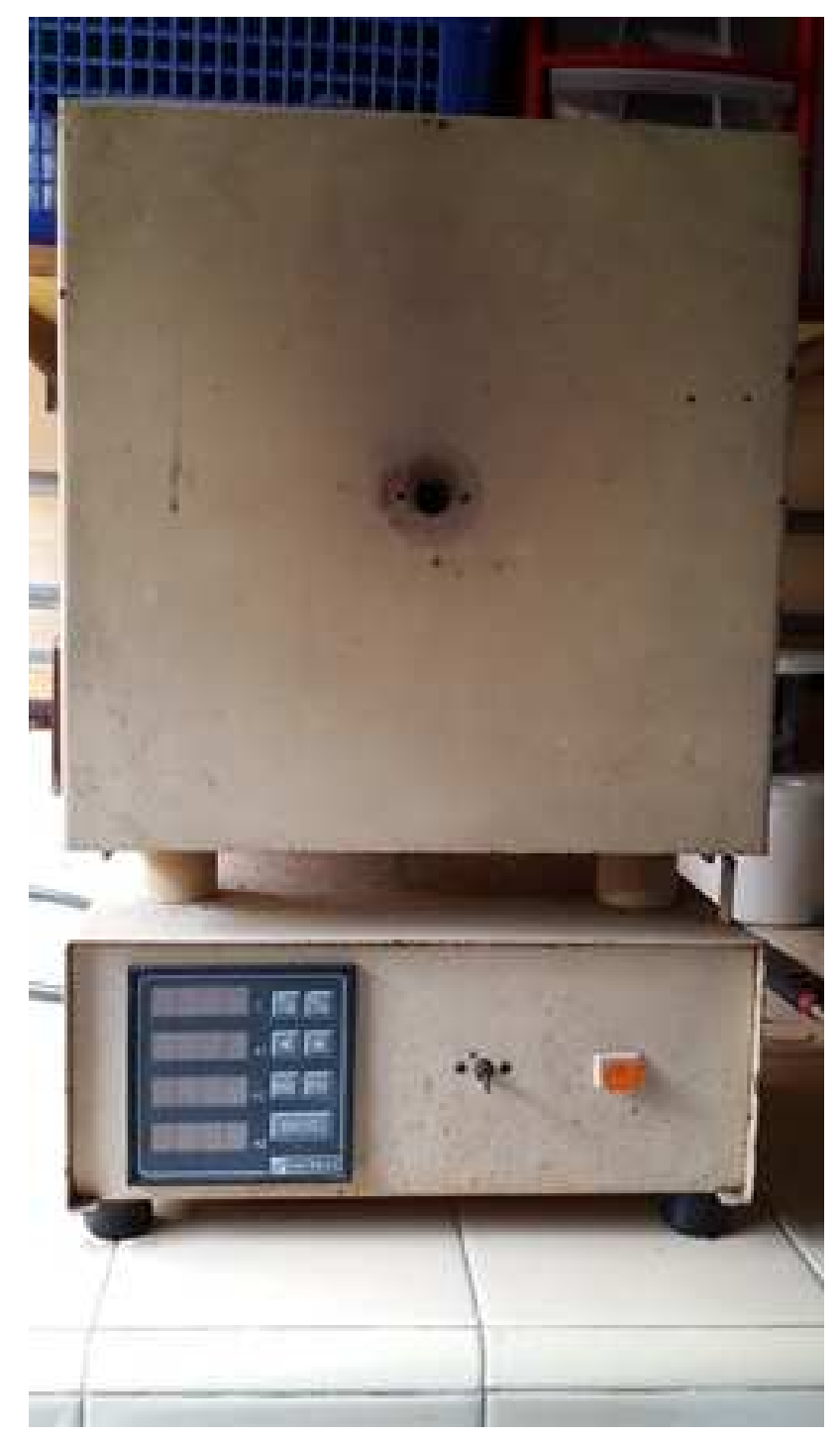

Figura 3.1. Mufla calefactora Marca Estigia, modelo D1. 
Tabla 3.1. Composiciones iniciales de los ensayos realizados.

\begin{tabular}{|c|c|c|}
\hline Ensayo & $\begin{array}{c}\mathrm{Na}_{2} \mathrm{CO}_{3} \\
(\% \mathrm{p} / \mathrm{p})\end{array}$ & $\begin{array}{c}\mathrm{NaAlO}_{2} \\
(\% \mathrm{p} / \mathrm{p})\end{array}$ \\
\hline 1272-0h & - & $2 \%$ \\
\hline $1272-2 \mathrm{~h}$ & - & $2 \%$ \\
\hline 1272-3h & - & $2 \%$ \\
\hline 1272-21h & - & $2 \%$ \\
\hline 1273-0h & $50 \%$ & $2 \%$ \\
\hline 1273-2h & $50 \%$ & $2 \%$ \\
\hline 1273-3h & $50 \%$ & $2 \%$ \\
\hline 1273-21h & $50 \%$ & $2 \%$ \\
\hline 1279-0h & - & - \\
\hline 1279-1h & - & - \\
\hline 1279-2h & - & - \\
\hline 1279-3h & - & - \\
\hline 1280-0h & $25 \%$ & - \\
\hline $1280-1 h$ & $25 \%$ & - \\
\hline $1280-2 h$ & $25 \%$ & - \\
\hline $1280-3 h$ & $25 \%$ & - \\
\hline 1281-0h & $25 \%$ & $2 \%$ \\
\hline 1281-1h & $25 \%$ & $2 \%$ \\
\hline 1281-2h & $25 \%$ & $2 \%$ \\
\hline 1281-3h & $25 \%$ & $2 \%$ \\
\hline
\end{tabular}

Síntesis y potenciales aplicaciones tecnológicas de materiales zeolíticos obtenidos a partir de catalizadores FCC agotados 57 
En una primera etapa, se realizaron una serie de síntesis con el fin de evaluar la influencia de la aplicación del pretratamiento y del agregado de $\mathrm{NaAlO}_{2}$ en los valores de conversión en zeolita $\mathrm{NaA}$. En estas reacciones se prepararon mezclas iniciales conteniendo el catalizador (se probó con y sin pretratamiento) junto con $\mathrm{NaOH}, \mathrm{NaAlO}_{2}$ (opcional) y $\mathrm{H}_{2} \mathrm{O}$, con agitación hasta homogeneidad. La cantidad de $\mathrm{NaOH}$ y agua permaneció constante para todos los ensayos. Las composiciones de cada una de las mezclas ensayadas se observan en la Tabla 3.1., donde en la segunda columna se detalla la proporción en peso de $\mathrm{Na}_{2} \mathrm{CO}_{3}$ usado en el pretratamiento de calcinación.

En una segunda etapa, se estudió la influencia de la variación de la cantidad de $\mathrm{NaOH}$ adicionado en la síntesis sobre las características del producto final. Para llevar a cabo este análisis, se tomó como referencia el ensayo 1273-3h debido a que presentó la mayor conversión en zeolita $\mathrm{NaA}$, cuantificada a través de los ensayos de XRD. Para ello, se llevaron a cabo tres ensayos. El primero se realizó en las mismas condiciones que el ensayo 1273, nombrado 4013. Luego se redujo la cantidad de $\mathrm{NaOH}$ agregado. Los restantes reactivos se mantuvieron constantes. Las composiciones de las mezclas ensayadas se observan en la Tabla 3.2. 
Tabla 3.2. Composiciones iniciales de los ensayos realizados.

\begin{tabular}{|c|c|c|c|c|}
\hline Ensayo & $\begin{array}{c}\mathrm{NaOH} \\
(\mathbf{g})\end{array}$ & $\begin{array}{c}\mathrm{NaAlO}_{2} \\
(\mathbf{g})\end{array}$ & $\begin{array}{c}\mathrm{H}_{2} \mathrm{O} \\
(\mathbf{g})\end{array}$ & $\begin{array}{c}\text { Catalizador } \\
\text { calcinado con } \\
\mathrm{Na}_{2} \mathrm{CO}_{3} \\
(\mathbf{g})\end{array}$ \\
\hline $\mathbf{4 0 1 3}$ & 35,6 & 3 & 219 & 24 \\
\hline $\mathbf{4 0 1 4}$ & 17,8 & 3 & 219 & 24 \\
\hline $\mathbf{4 0 1 5}$ & 8,2 & 3 & 219 & 24 \\
\hline
\end{tabular}


El procedimiento empleado para llevar a cabo la síntesis hidrotérmica fue común para todas las experiencias. La mezcla obtenida se dejó en reposo $48 \mathrm{~h}$ a temperatura ambiente, sin agitación. Luego la mencionada mezcla fue transferida a reactores de polipropileno de $250 \mathrm{ml}$ de capacidad. Previamente, la solución, fue pre-calentada a una temperatura cercana a la temperatura de reacción. Las síntesis fueron realizadas en una estufa termoregulable con ventilación forzada, en todas las reacciones la temperatura fue de $90 \pm 1{ }^{\circ} \mathrm{C}$. Cada mezcla de reacción fue colocada en estufa en recipientes cerrados, sin agitación. Se estimó que a los 10 minutos la mezcla se encontraba a la temperatura deseada. Se tomó como tiempo cero el tiempo de ingreso del reactor en la estufa.

Para todas las reacciones de cristalización se tomaron muestras a diferentes tiempos con el fin de observar la evolución de la cristalinidad del material sintetizado.

Los sólidos obtenidos se lavaron con el fin de eliminar las impurezas originarias de la síntesis, hasta llegar a un pH de 10, luego se secaron a $110^{\circ} \mathrm{C}$ en una estufa (Fig. 3.2.)

Todas las muestras obtenidas se caracterizaron por difracción de rayos $X(X R D)$ y microscopía electrónica de barrido (SEM).

Los ensayos de síntesis y de intercambio catiónico con sus respectivas caracterizaciones fueron llevados a cabo en el Centro de Investigación y Desarrollo en Ciencias Aplicadas (CINDECA) perteneciente a la Universidad Nacional de La Plata (UNLP). 


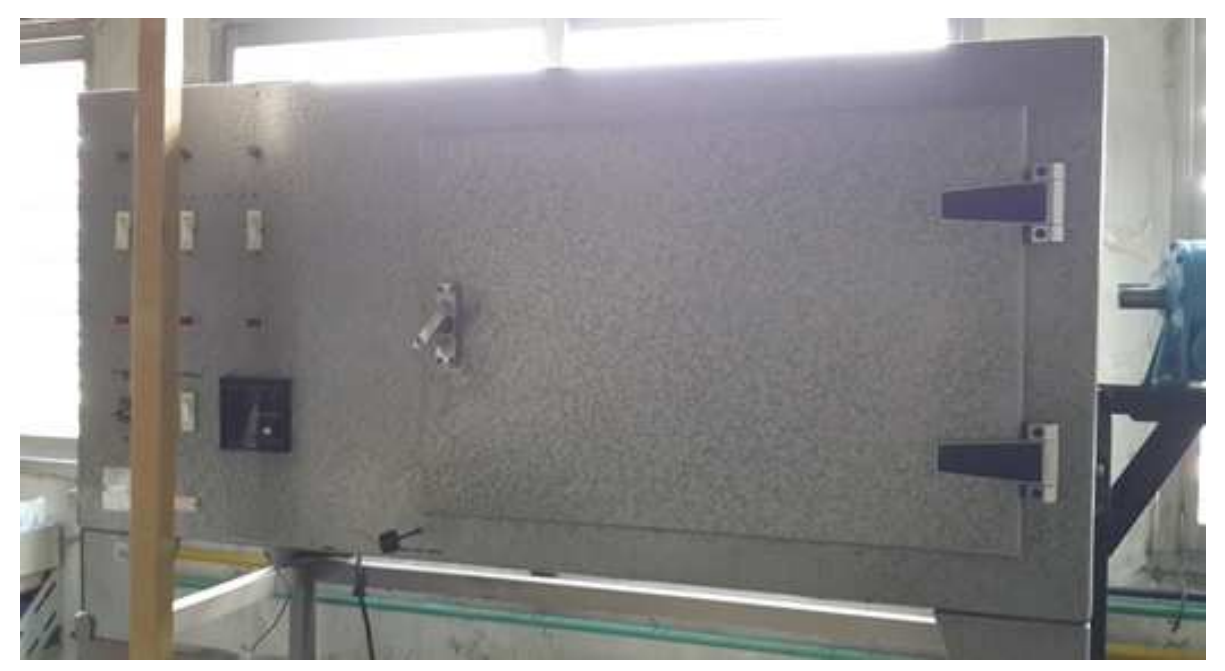

Figura 3.2. Estufa termoregulable marca Científica Central, modelo CFE. 


\subsection{Ensayos de intercambio iónico}

Para llevar a cabo los ensayos de intercambio catiónico se seleccionó la muestra que permitió obtener la más alta conversión en zeolita $\mathrm{NaA}$ empleando la menor cantidad de $\mathrm{NaOH}$ en la etapa 2, ensayo 4015.

Este material zeolítico sintetizado se probó como captor de cromo. Se prepararon soluciones conteniendo $\sim 42 \mathrm{mg} . \mathrm{L}^{-1} \mathrm{y} \sim 135 \mathrm{mg} \cdot \mathrm{L}^{-1}$ de $\mathrm{Cr}$ (III) respectivamente, las mismas se obtuvieron por disolución de $\mathrm{Cr}\left(\mathrm{NO}_{3}\right)_{3} \cdot 9 \mathrm{H}_{2} \mathrm{O}$ (Carlo Erba, p.a.) en agua desmineralizada ( $\mathrm{pH}$ entre 3,7 y 4). Estas concentraciones fueron seleccionadas por ser valores típicos presentes el menor en aguas levemente contaminadas y el mayor en soluciones de efluentes de curtiembres.

Los intercambios catiónicos con las soluciones de $\mathrm{Cr}(\mathrm{III})$, se realizaron agregando en cada experimento 1 ó $3 \mathrm{~g}$ de material zeolítico obtenido a partir del catalizador agotado muestra 4015, 1 ó $3 \mathrm{~g}$ zeolita $\mathrm{NaA}$ pura, con el fin de evaluar la incidencia de la relación sólido/líquido en la reacción de intercambio. En todos los casos para estos ensayos de intercambio catiónico, se empleó $1 \mathrm{~L}$. de solución de $\mathrm{Cr}\left(\mathrm{NO}_{3}\right)_{3} 9 \mathrm{H}_{2} \mathrm{O}$ (Anedra).

La muestra de zeolita A sódica se empleó como patrón con el objetivo de comparar la eficiencia del catalizador zeolitizado para el intercambio. Esta muestra fue sintetizada en nuestro laboratorio por el método de síntesis hidrotérmica y caracterizada por XRD y SEM. Las reacciones en batch se realizaron en un reactor de polipropileno a $90{ }^{\circ} \mathrm{C}$, sin agitación. Las materias primas utilizadas fueron $\mathrm{NaOH}$ (Carlo Erba, grado analítico), $\mathrm{NaAlO}_{2}$ comercial (36,5\% \% $/ \mathrm{p} \mathrm{Al}_{2} \mathrm{O}_{3}, 29,6 \% \mathrm{p} / \mathrm{p} \mathrm{Na} \mathrm{Na}_{2} \mathrm{O}$, 
$\left.33,9 \% \mathrm{p} / \mathrm{p} \mathrm{H}_{2} \mathrm{O}\right)$ silicato de sodio comercial $\left(9,2 \% \mathrm{p} / \mathrm{p} \mathrm{Na}_{2} \mathrm{O}, 26,8 \% \mathrm{p} / \mathrm{p}\right.$ $\mathrm{SiO}_{2}, 64 \% \% \mathrm{p} / \mathrm{p} \mathrm{H}_{2} \mathrm{O}$ ), y agua destilada.

La capacidad de intercambio iónico de la zeolita $A$ es de 7,04 $\mathrm{mEq} \cdot \mathrm{g}^{-1}$ (base deshidratada) y de $5,48 \mathrm{mEq} \cdot \mathrm{g}^{-1}$ (base hidratada).

Se tomaron muestras a diferentes tiempos. Estas muestras se filtraron, determinándose la concentración de cromo en el líquido remanente por AA. El ensayo se realiza tomando muestras hasta llegar a tiempos donde se observan valores inferiores al límite de detección por espectroscopía de absorción atómica (AA) o hasta constancia de la concentración del catión en la fase líquida.

Asimismo, se evaluó la influencia de la variación de la temperatura sobre la reacción de intercambio. Para ello, se seleccionaron dos temperaturas: $25 \stackrel{\circ}{\circ}$ y $50 \stackrel{\circ}{\circ}$, determinándose la curva cinética para cada uno de los ensayos.

Los ensayos realizados se detallan en la Tabla 3.3., muestra 4015 se refiere al material zeolítico obtenido a partir del catalizador y $\mathrm{NaA}$ es la zeolita pura de referencia.

Síntesis y potenciales aplicaciones tecnológicas de materiales zeolíticos obtenidos a partir de catalizadores FCC agotados 63 
Tabla 3.3. Resumen de ensayos realizados.

\begin{tabular}{|c|c|c|c|c|}
\hline Muestra & Material & $\begin{array}{c}\text { Cantidad } \\
\mathbf{( g )}\end{array}$ & $\begin{array}{c}\text { Temperatura } \\
(\mathbf{C})\end{array}$ & $\begin{array}{c}\text { Concentración de } \\
\text { solución } \mathbf{C r}(\mathbf{I I I}) \\
\text { (mg. }^{-1} \mathbf{)}\end{array}$ \\
\hline $\mathbf{5 0 0 0}$ & 4015 & 1 & 25 & 42 \\
\hline $\mathbf{5 0 0 1}$ & 4015 & 3 & 25 & 42 \\
\hline $\mathbf{5 0 0 2}$ & 4015 & 3 & 25 & 135 \\
\hline $\mathbf{5 0 0 3}$ & 4015 & 1 & 50 & 42 \\
\hline $\mathbf{5 0 0 4}$ & 4015 & 3 & 50 & 42 \\
\hline $\mathbf{5 0 0 5}$ & 4015 & 3 & 50 & 135 \\
\hline $\mathbf{5 0 0 6}$ & $\mathrm{NaA}$ & 1 & 25 & 42 \\
\hline $\mathbf{5 0 0 7}$ & $\mathrm{NaA}$ & 3 & 25 & 42 \\
\hline $\mathbf{5 0 0 8}$ & $\mathrm{NaA}$ & 3 & 25 & 135 \\
\hline $\mathbf{5 0 0 9}$ & $\mathrm{NaA}$ & 1 & 50 & 42 \\
\hline $\mathbf{5 0 1 0}$ & $\mathrm{NaA}$ & 3 & 50 & 42 \\
\hline $\mathbf{5 0 1 1}$ & $\mathrm{NaA}$ & 3 & 50 & 135 \\
\hline
\end{tabular}




\subsection{Técnicas de caracterización. Caracterización de las muestras sólidas}

Las muestras sólidas obtenidas durante el transcurso de las reacciones de cristalización, así como los productos obtenidos después de los intercambios catiónicos se caracterizaron por difracción de rayos $X$ (XRD), microscopía electrónica de barrido (SEM), energía de dispersión de rayos $X$ (EDX), resonancia magnética nuclear (NMR), espectroscopía infrarroja por transformada de Fourier (FT-IR), punto de cero carga (PZC) y adsorción de agua.

El equipamiento necesario para las caracterizaciones se encuentra en diferentes centros de investigación: Centro de Investigación y Desarrollo en Ciencias Aplicadas (CINDECA) perteneciente a la Universidad Nacional de La Plata (UNLP); Centro de Tecnología de Recursos Minerales y Cerámica (CETMIC) perteneciente a la Comisión de Investigaciones Científicas de la provincia de Buenos Aires (CIC); Instituto de Investigación en Materiales (IIM) perteneciente a la Universidad Nacional Autónoma de México (UNAM). 


\subsubsection{Difracción de Rayos X}

Con el fin de identificar las fases cristalinas, se obtuvieron los difractogramas de rayos $\mathrm{X}$ del catalizador antes y después del pretratamiento, así como también los espectros de los sólidos obtenidos durante la reacciones de síntesis e intercambio. Se usó un difractómetro Philips 3020. Las condiciones de trabajo fueron: 40 kV y 30 mA, radiación de $\mathrm{Cu}-\mathrm{K} \alpha$, filtro de Ni. Los difractogramas se barrieron en un rango de $2 \theta$ entre $5^{\circ}-40^{\circ}$. Todas las muestras fueron analizadas por el método para sólidos en polvo. En la Fig. 3.3. se observa el equipo utilizado para el análisis.

Para obtener información complementaria del material sintetizado, se estudiaron las funciones de distribución radial. La observación de los picos característicos permitió determinar la distancia interatómica de los elementos que constituyen el material. La función de distribución radial se obtuvo a partir de los diagramas de difracción de rayos $\mathrm{X}$ adquiridos con un difractómetro de polvo Siemens D500 PW acoplado a un tubo de ánodo de cobre. La radiación $\mathrm{Cu}-\mathrm{K} \alpha$ fue seleccionada con un monocromador de haz difractado. La radiación $\mathrm{K} \alpha$ fue seleccionada con un filtro de $\mathrm{Ni}$. Los datos de intensidad, fueron medidos con un contador de centelleo Radiale [1].

El análisis de los difractoframas de XRD realizados para obtener el grado de cristalinidad de la muestra, se realizó considerando la intensidad de los picos de difracción, lo que permitió obtener información sobre el material cristalino que se formaba en función del tiempo de reacción. Este cálculo se realizó comparando las intensidades de determinados picos característicos con las de los picos correspondientes a la muestra patrón a la cual se le asigna una cristalinidad $100 \%$. El porciento de fase cristalina se calcula de la siguiente manera: 


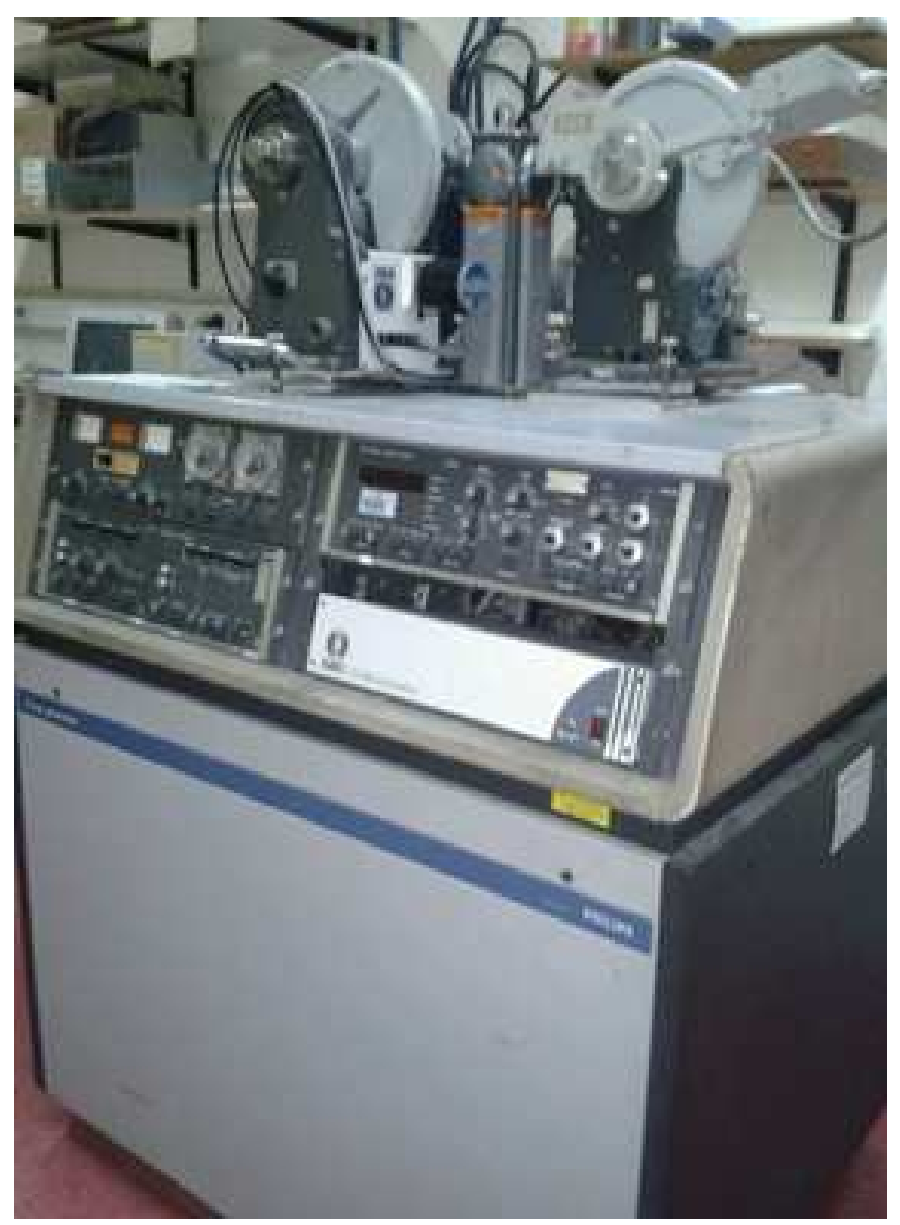

Figura 3.3. Difractómetro de Rayos X Philips 3020 .

Síntesis y potenciales aplicaciones tecnológicas de materiales zeolíticos obtenidos a partir de catalizadores FCC agotados 67 
Intensidad del pico (hkl) de la muestra

\%cristalinidad $=$

Intensidad del pico (hkl) de la muestra patrón

Además, se utilizó el método Rietveld [2] para la determinación cuantitativa de los componentes cristalinos del producto obtenido. Se utilizó el programa "FULLPROF" [3]. Los datos cristalográficos usados para cada fase fueron extraídos de la literatura [4]. Para la obtención de los difractogramas se utilizó un equipo Philips 3710. Las condiciones de trabajo fueron: $40 \mathrm{kV}$ y $30 \mathrm{~mA}$, radiación de Cu-Ko, filtro de Ni. Los difractogramas se barrieron en un rango de $2 \theta$ entre $5^{\circ}-40^{\circ}$. Todas las muestras fueron analizadas por el método para sólidos en polvo. En la Fig. 3.4. se muestra el equipo utilizado para el análisis.

\subsubsection{Microscopía electrónica de barrido (SEM)}

El tamaño de partícula y la morfología del catalizador antes y luego de la calcinación, así como los sólidos antes y después de la síntesis se observaron por microscopía electrónica de barrido (SEM), utilizando un equipo Philips 505. La preparación de las muestras, al no ser conductoras, consistió en realizar un depósito delgado de $\mathrm{Au}$ por el método de sputtering en un metalizador Balzers SCD 030. El espesor de la capa para el examen y análisis de características microestructurales de las muestras, osciló entre 150 y 200 A. En las Figs. 3.5. y 3.6. se muestran el microscopio y la metalizadora, respectivamente.

Para el análisis de la distribución de catión cromo en el material zeolítico obtenido (mapping), las micrografías SEM se obtuvieron por medio de un microscopio de 400 FEI Quanta, utilizando también muestras 


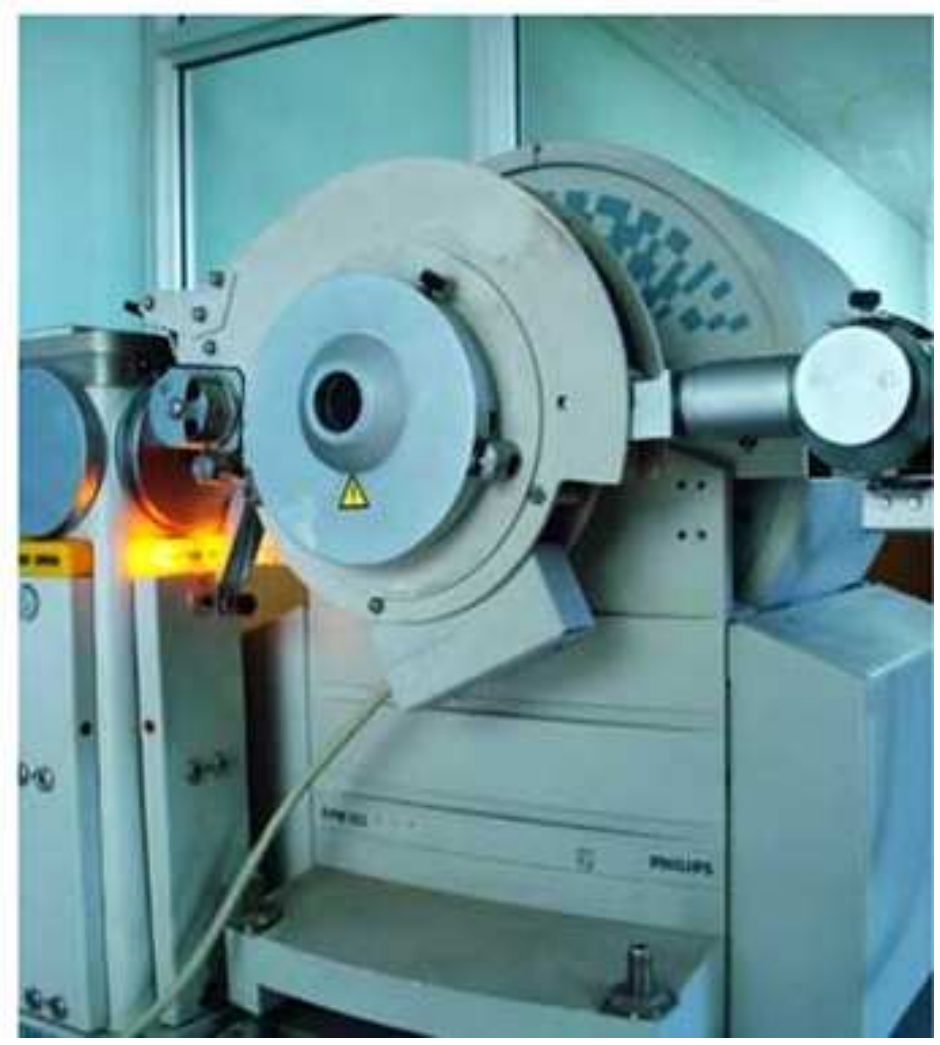

Figura 3.4. Difractómetro de Rayos X Philips 3710.

Síntesis y potenciales aplicaciones tecnológicas de materiales zeolíticos obtenidos a partir de catalizadores FCC agotados 69 
recubiertas con una fina capa de Au. La determinación de la concentración de cromo en las muestras, se realizó a través del análisis químico semicuantitativo por sonda EDX, utilizando un EDAX SDD Apollo 40, acoplado al microscopio electrónico de barrido. La muestra fue preparada sometiendo a alta presión el sólido en un portamuestra con la finalidad de formar una pastilla. Luego se procedió a pulir la superficie de la pastilla, empleando papel esmeril de 400, 280, 150 y 100 hasta poder visualizar un corte transversal de las microesferas.

Para la observación de la morfología del catalizador zeolitizado, el producto sólido fue prensado para obtener un gránulo cilíndrico. Este último fue entonces transversalmente pulido con papel de lija fino con el fin de exponer una superficie plana correspondiente a una sección transversal de las microesferas. En la Fig. 3.7. se muestra el equipo utilizado.

\subsubsection{Resonancia Magnética Nuclear (NMR)}

NMR fue la técnica seleccionada para determinar la coordinación de los átomos de aluminio y silicio en la zeolita A obtenida a partir del catalizador FCC. Dichas mediciones se realizaron en un espectrómetro Bruker Avance 400. El espectrómetro se hizo funcionar a una frecuencia de resonancia de 79,50 y $104,27 \mathrm{MHz}$ para ${ }^{29} \mathrm{Si}$ y ${ }^{27} \mathrm{Al} \mathrm{MAS}$, respectivamente. Los espectros se registraron después de una sola excitación $\pi / 2$ con tiempos de repetición de 5 ss y $7 \mu$ s para Si y Al, respectivamente. Los desplazamientos químicos se referenciaron utilizando tetrametilsilano (TMS). En la Fig. 3.8. se muestra el equipo utilizado. 


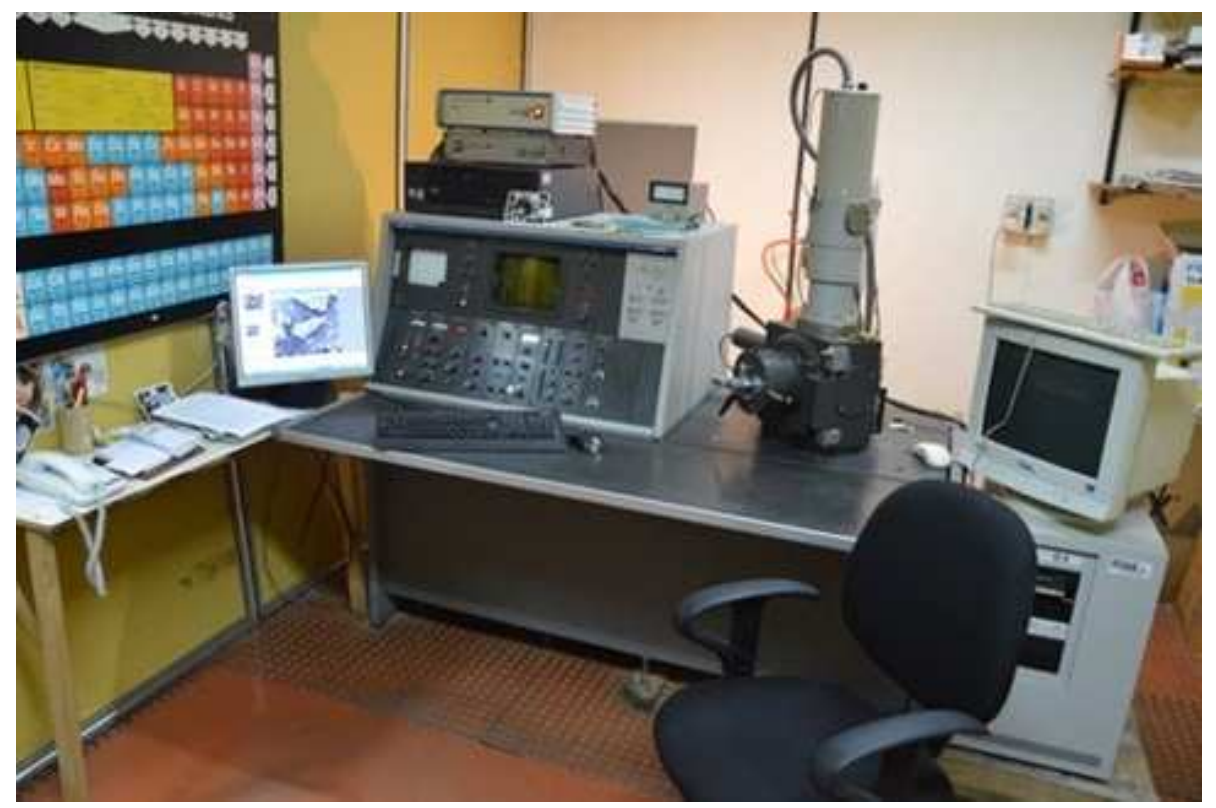

Figura 3.5. Microscopio electrónico de barrido Philips 505. 


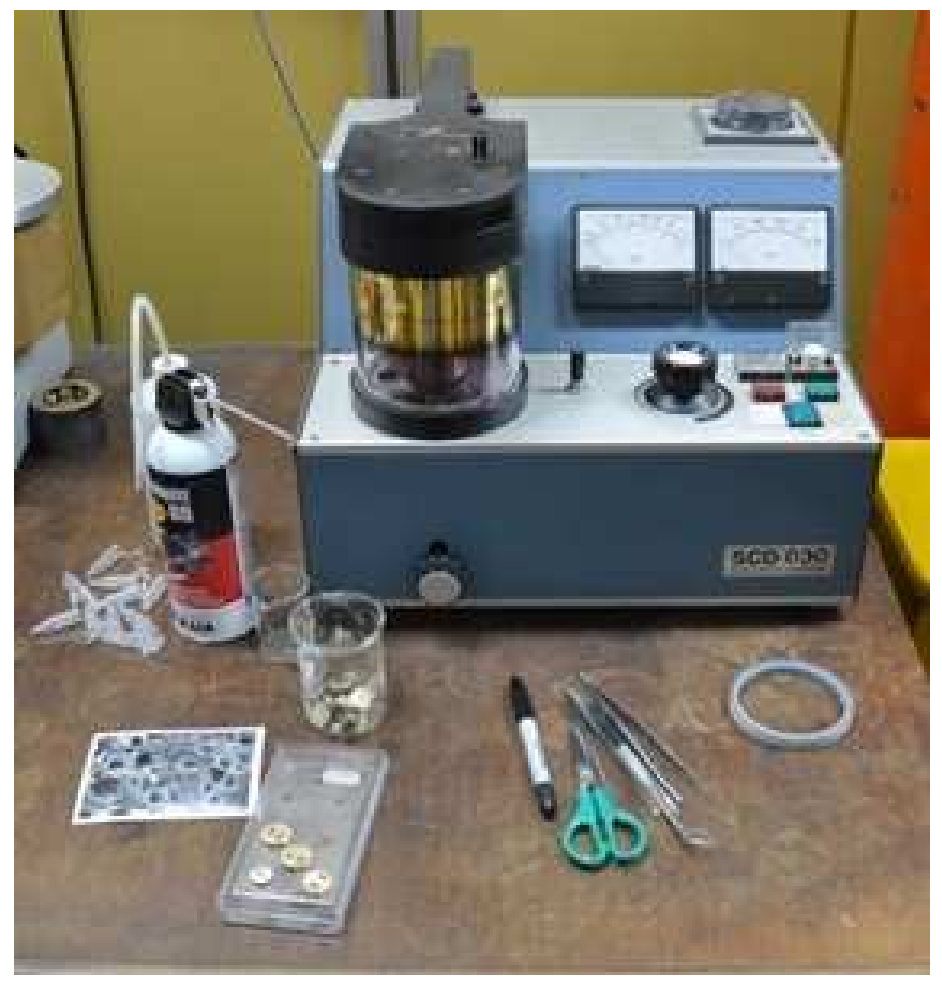

Figura 3.6. Metalizador Balzers SCD 030.

Síntesis y potenciales aplicaciones tecnológicas de materiales zeolíticos obtenidos a partir de catalizadores FCC agotados 72 


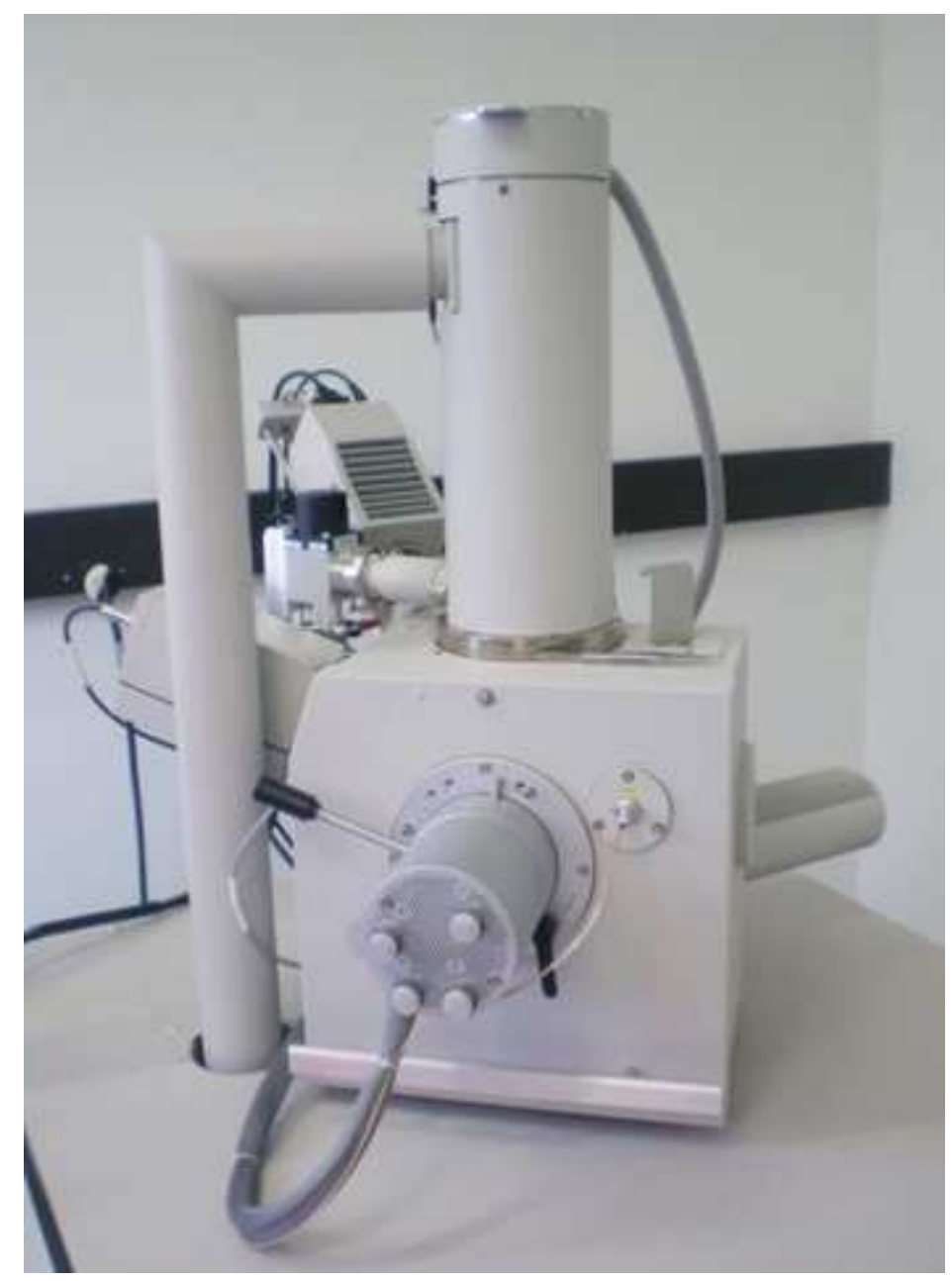

Figura 3.7. Microscopio electrónico de barrido 400 FEI Quanta. 


\subsubsection{Espectrometría Infrarroja por Transformada de Fourier (FT-IR)}

Para determinar los grupos funcionales presentes en el sólido obtenido a partir del catalizador y posteriormente realizar la comparación con una zeolita A comercial se empleó espectrometría infrarroja por transformada de Fourier. Los espectros se obtuvieron con un equipo Bruker IFS 66. Las muestras se prepararon por dilución en bromuro de potasio. La mezcla se sometió a alta presión en un portamuestra con la finalidad de formar una pastilla. Finalmente fueron secadas a $40{ }^{\circ} \mathrm{C}$. En la Fig. 3.9. se muestra el equipo utilizado.

\subsubsection{Determinación del punto de cero carga por medición del potencial zeta (PZC)}

La presencia de adsorción superficial del catión $\operatorname{Cr}(I I I)$ en la zeolita A se estimó a través del calculo del PZC, el cual se obtuvo a partir de las medidas de potencial zeta. Se prepararon mezclas compuestas por $0,04 \mathrm{~g}$ de sólido y $40 \mathrm{~mL}$ de una solución de $10^{-3} \mathrm{M}$ de $\mathrm{KCl}$ como electrolito soporte. Para cada una de las muestras, se agregó $\mathrm{HCl} \circ \mathrm{KOH}(0,1 \mathrm{M})$ con el fin de obtener muestras con distintos valores de $\mathrm{pH}$. Para la determinación de los valores de potencial zeta de dichas muestras se utilizó un equipo Brookhaven 90Plus/Bi-MAS Multi Angle Particle Sizing, operando a: $\lambda=635 \mathrm{~nm}, 15 \mathrm{mV}$, láser en estado sólido,

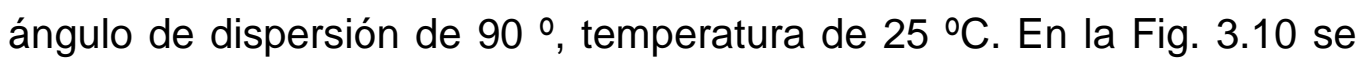
observa el equipo utilizado. Con los datos obtenidos de potencial zeta, se grafica estos valores en función del pH de equilibrio en la suspensión, obteniéndose la curva de potencial zeta $\mathrm{vs} \mathrm{pH}$. El punto de cero carga corresponde al valor de $\mathrm{pH}$ en el cual el potencial zeta es cero. 


\subsubsection{Superficie específica}

Para la determinación de la superficie específica del material se empleó la técnica de adsorción de agua. Las muestras fueron secadas a $90 \stackrel{\circ}{\circ}$ durante 3 días, luego se utilizó $\mathrm{P}_{2} \mathrm{O}_{5}$ como secador durante $24 \mathrm{~h}$. Posteriormente, se expuso la muestra a una atmósfera de humedad saturada [5]. Finalmente los sólidos fueron pesados cada 15 días hasta que se logró un peso constante.

Síntesis y potenciales aplicaciones tecnológicas de materiales zeolíticos obtenidos a partir de catalizadores FCC agotados 75 


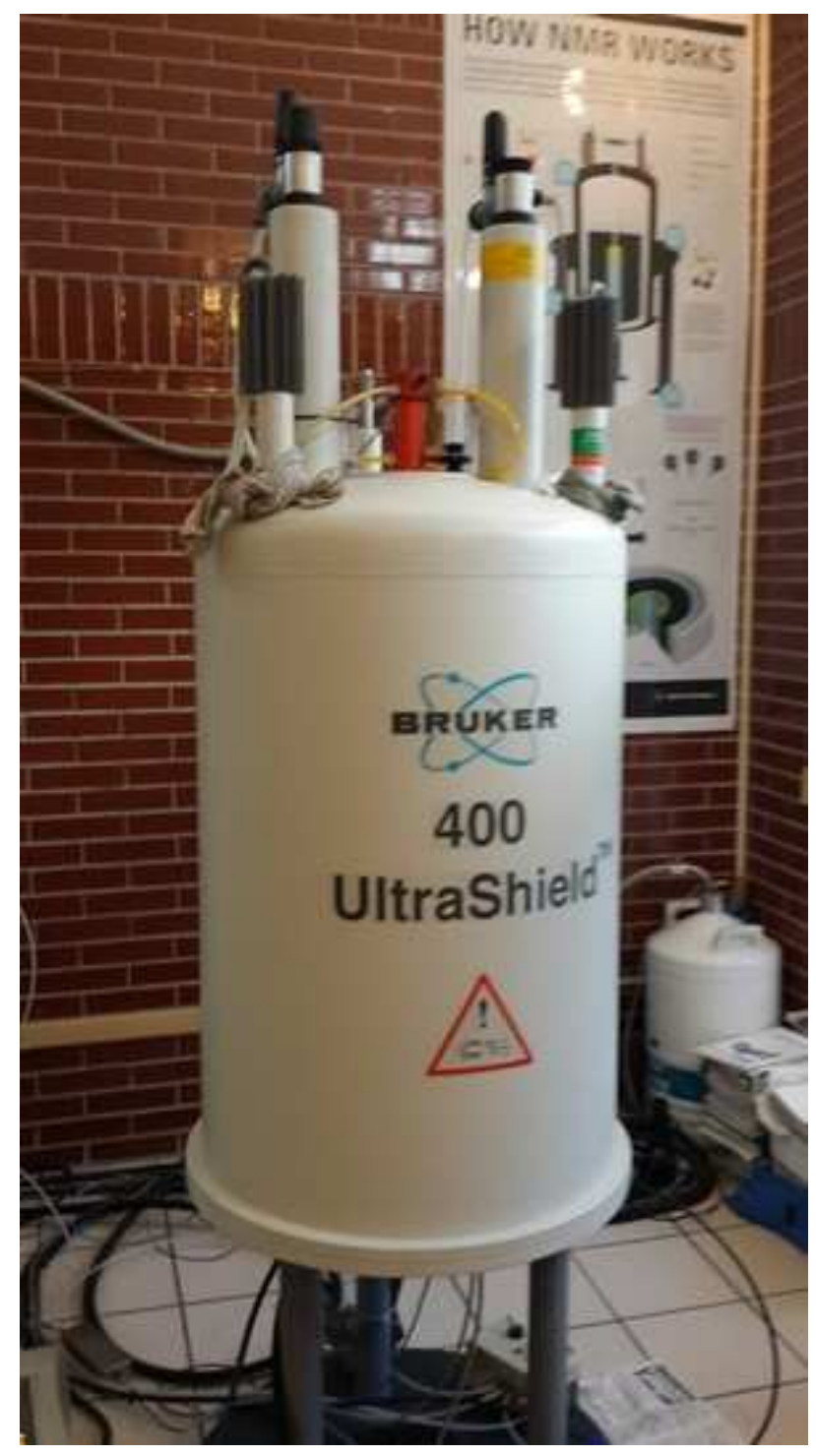

Figura 3.8. Equipo espectrómetro Bruker Avance 400. 


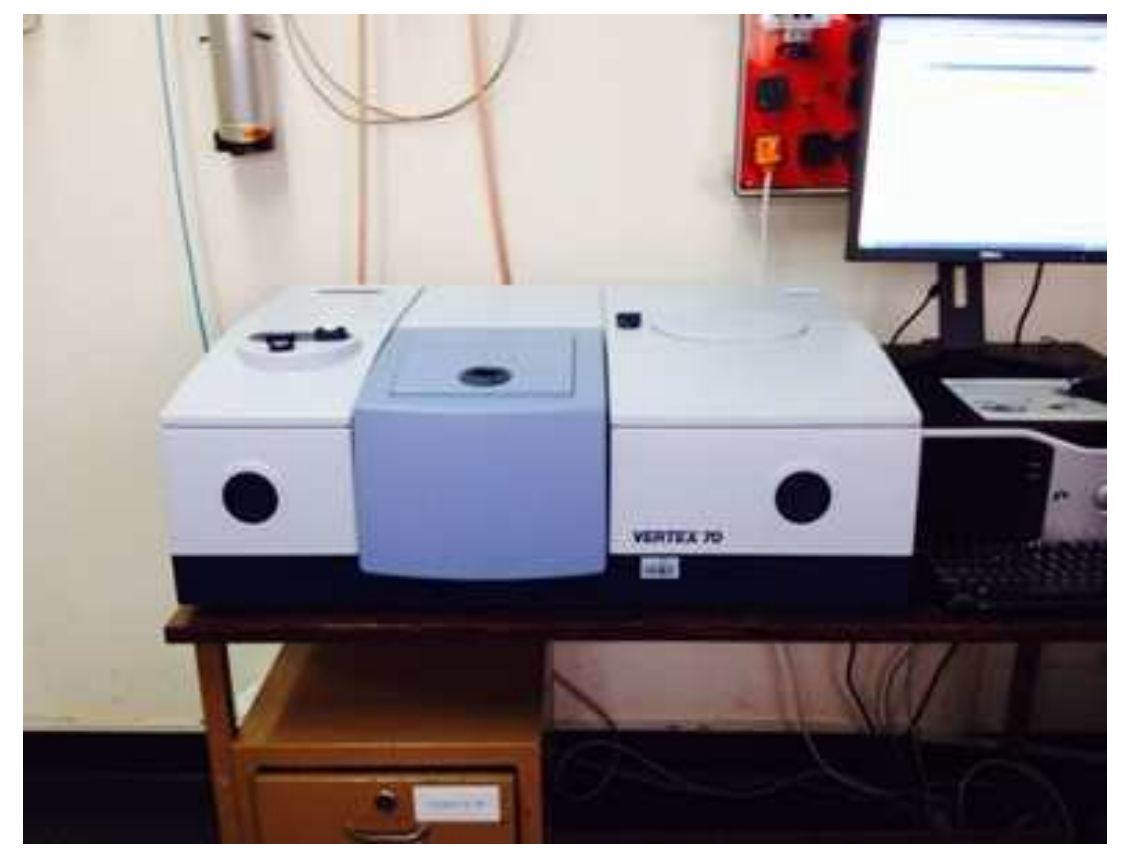

Figura 3.9. Equipo Bruker IFS 66.

Síntesis y potenciales aplicaciones tecnológicas de materiales zeolíticos obtenidos a partir de catalizadores FCC agotados 77 


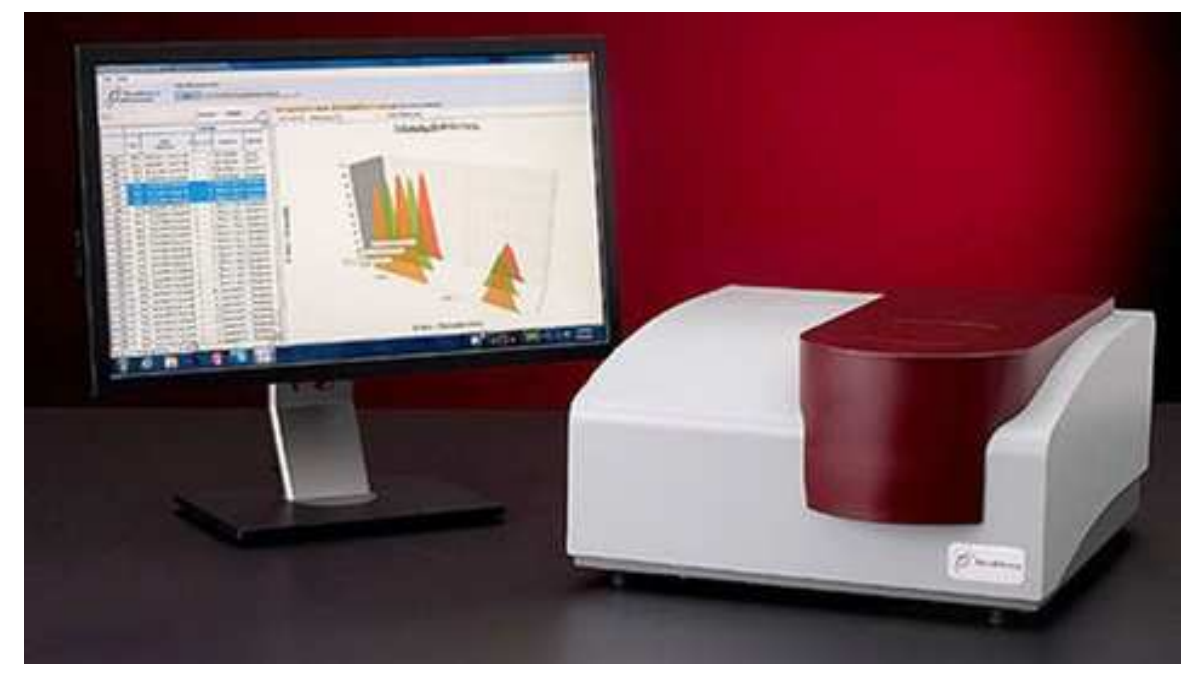

Figura 3.10. Equipo Brookhaven 90Plus/Bi-MAS Multi Angle Particle Sizing. 


\subsection{Caracterización de las muestras líquidas}

\subsubsection{Espectroscopía de absorción atómica (AA)}

Las concentraciones de $\operatorname{Cr}(\mathrm{III})$ en las soluciones líquidas remanentes del ensayo de intercambio catiónico y en los líquidos provenientes de los ensayos de lixiviación de los morteros, fueron determinadas utilizando un equipo Varian SpectrAA 240 cuya imagen se muestra en la Fig. 3.11. Los análisis se realizaron en llama óxido nitrosoacetileno a una longitud de onda de $425,4 \mathrm{~nm}$ y un slit de $0,1 \mathrm{~nm}$.

\subsection{Inmovilización en morteros a base de cemento portland}

La elaboración de los morteros como así también los ensayos realizados sobre los mismos se llevaron a cabo en el Laboratorio de Entrenamiento Multidisciplinario para la Investigación Tecnológica (LEMIT) perteneciente a la Comisión de Investigaciones Científicas (CIC) de la Provincia de Buenos Aires.

\subsubsection{Diseño y manufactura de los morteros}

El material con cromo incorporado se empleó como aditivo en la formulación de morteros en base cemento portland. Los morteros fueron preparados usando una relación agua/cemento de 0,47 , y una relación de cemento/arena 1:3 en peso.

El material rico en zeolita $\mathrm{NaA}$ obtenido a partir del catalizador FCC agotado muestra 4090 y zeolita $\mathrm{NaA}$ pura, ambos materiales intercambiados con una solución de $\sim 135 \mathrm{mg}^{-\mathrm{L}^{-1}}$ de $\operatorname{Cr}(\mathrm{III})$ fueron seleccionadas para usarse como aditivos para la elaboración de los morteros. Se reemplazó un 10\%, $20 \%$ y un $30 \%$ en peso de cemento 


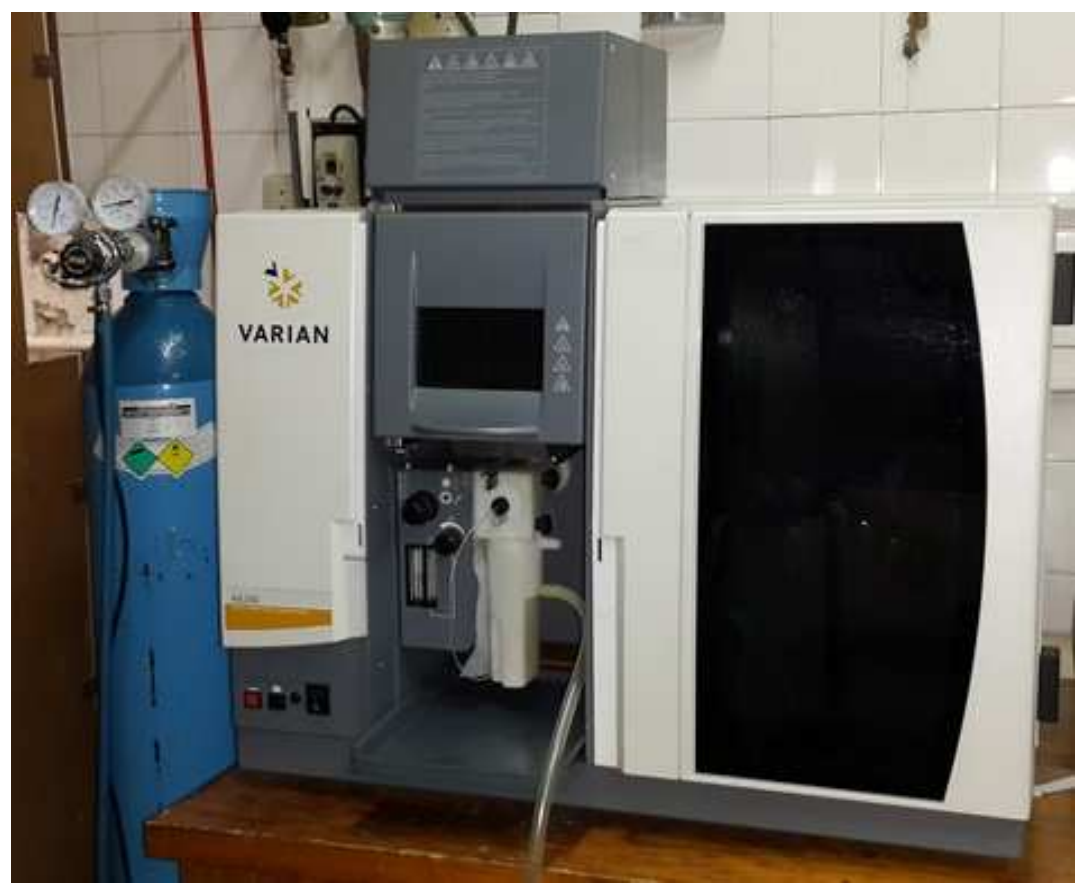

Figura 3.11. Equipo Varian SpectrAA 240.

Síntesis y potenciales aplicaciones tecnológicas de materiales zeolíticos obtenidos a partir de catalizadores FCC agotados $\mathbf{8 0}$ 
por la muestra 4090 intercambiada con $\mathrm{Cr}(\mathrm{III})$, obteniéndose los morteros denominados ZC10, ZC20 y ZC30 respectivamente.

En función de los resultados obtenidos correspondientes a los valores de resistencia mecánica se procedió a la formulación de otra serie de morteros, en este caso a la mezcla se incorporó un $5 \%$ ó un $10 \%$ en peso del aditivo en reemplazo del cemento. Asimismo, se empleó microsílice en las mismas cantidades con el fin de comparar la adición de zeolita con un agregado que mejora las propiedades del mortero. Paralelamente, se preparó un mortero de referencia sin adiciones minerales, el cual se utilizó como patrón para comparar los diferentes resultados de los ensayos.

Las mezclas se realizaron en una mezcladora marca Cosacoc No100 (Fig. 3.12).

En la tabla 3.4. se detalla la composición de todos los morteros elaborados. Cr-ZeoCat-135 corresponde al mortero conteniendo material zeolítico obtenido a partir de catalizador FCC agotado, Cr-NaA-135 corresponde a los morteros que contienen zeolita $A$, ambos intercambiados con $\mathrm{Cr}(\mathrm{III})$, y SF a los morteros que contienen microsílice agregada.

En el diseño de los morteros se contempló la fluidez de la mezcla. Para la determinación de la consistencia (fluidez) se realizaron ensayos de asentamiento empleando un cono metálico de $150 \mathrm{~mm}$ de altura (con las mismas proporciones geométricas que el cono de Abrams). El ensayo consistió en colocar el cono en una superficie lisa, con la abertura más pequeña hacia arriba, llenándolo con la mezcla en tres capas (Fig.3.13.). Cada capa se apisona 25 veces con una varilla de acero, luego se levanta 


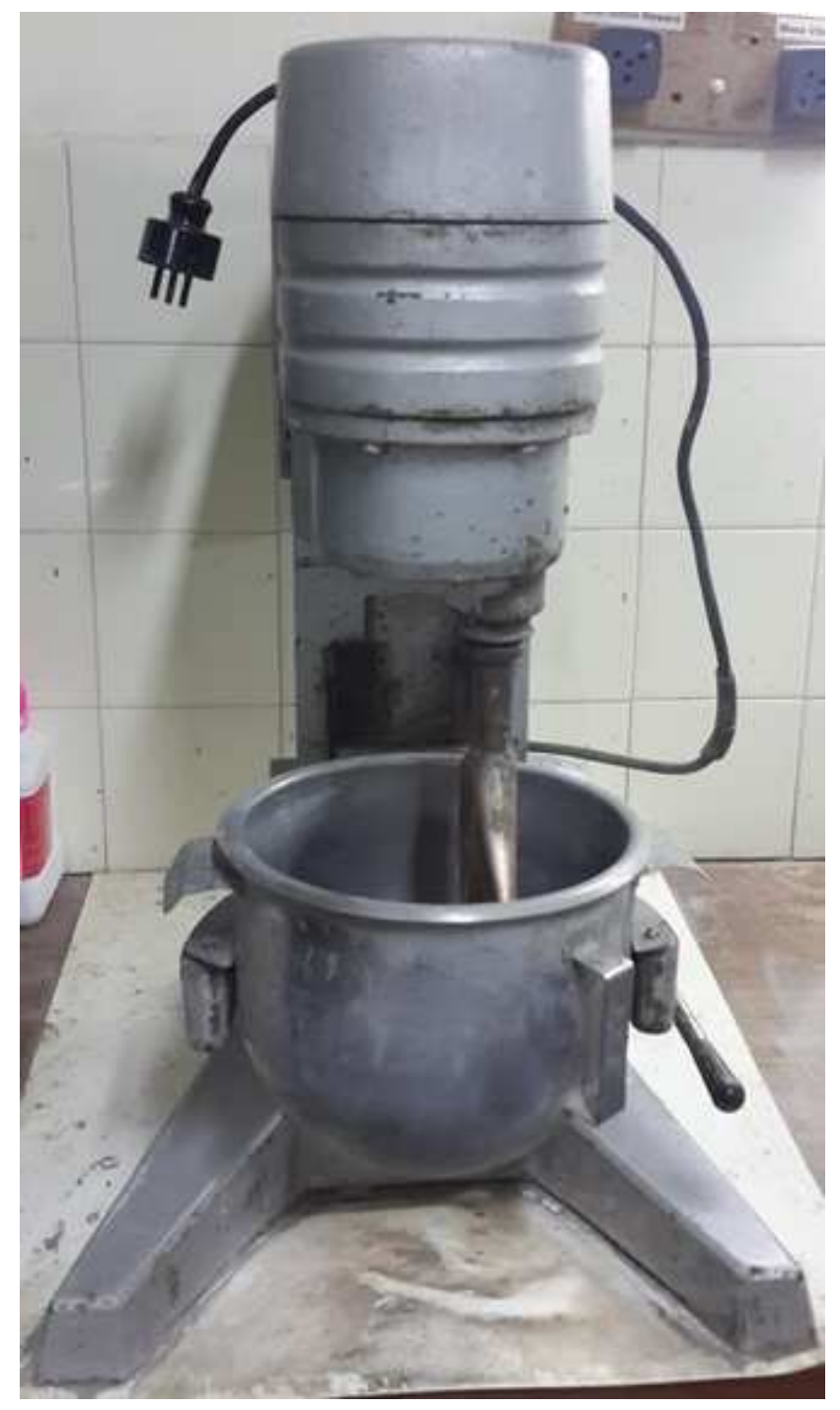

Figura 3.12. Mezcladora marca Cosacoc.

Síntesis y potenciales aplicaciones tecnológicas de materiales zeolíticos obtenidos a partir de catalizadores FCC agotados 82 
lentamente el cono. La disminución en altura de la parte superior de la mezcla se denomina asentamiento.

Posteriormente, se elaboraron dos tipos de morteros: prismas de $40 \times 40 \times 160 \mathrm{~mm}^{3}$ de tamaño para las mediciones de flexión y compresión (Fig. 3.14.), y prismas $30 \times 30 \times 220 \mathrm{~mm}^{3}$ (Fig. 3.15.) para evaluar la contracción por secado. Los moldes se untaron con aceite mineral en su interior.

Los morteros fueron compactados por vibración externa, se seleccionó el tiempo de vibración de acuerdo con el valor medido de asentamiento.

\subsubsection{Evaluación de las propiedades mecánicas}

Se evaluaron la resistencia a la flexión y a la compresión así como la contracción por secado con el fin de determinar la influencia de las adiciones sobre las propiedades mecánicas de los morteros diseñados.

Todos los experimentos se realizaron por triplicado y los resultados fueron promediados.

Las muestras fueron extraídas de los moldes después de 1 día de secado. Para los ensayos de flexión y compresión, los morteros fueron colocados en agua por 28 y 90 días para realizar el curado de las mismas a una temperatura de $20^{\circ} \mathrm{C}$. Se procuró asegurar el contacto de todas sus caras con el agua. El volumen del agua de curado fue 4/1 veces con respecto al de las probetas. Las probetas se retiraron 15 minutos antes de realizar el ensayo de flexión. 
Tabla 3.4. Resumen de morteros elaborados.

\begin{tabular}{|c|c|c|}
\hline Mortero & Material & $\begin{array}{c}\text { Cantidad reemplazada } \\
(\% \mathbf{p} / \mathbf{p})\end{array}$ \\
\hline $\mathbf{P}$ & Cemento & - \\
\hline $\mathbf{Z 5}$ & Cr-NaA-135 & 10 \\
\hline Z10 & Cr-NaA-135 & 5 \\
\hline ZC5 & Cr-ZeoCat-135 & 10 \\
\hline ZC10 & Cr-ZeoCat-135 & 20 \\
\hline ZC20 & Cr-ZeoCat-135 & 30 \\
\hline ZC30 & Cr-ZeoCat-135 & 5 \\
\hline S5 & SF & 10 \\
\hline S10 & SF & \\
\hline
\end{tabular}




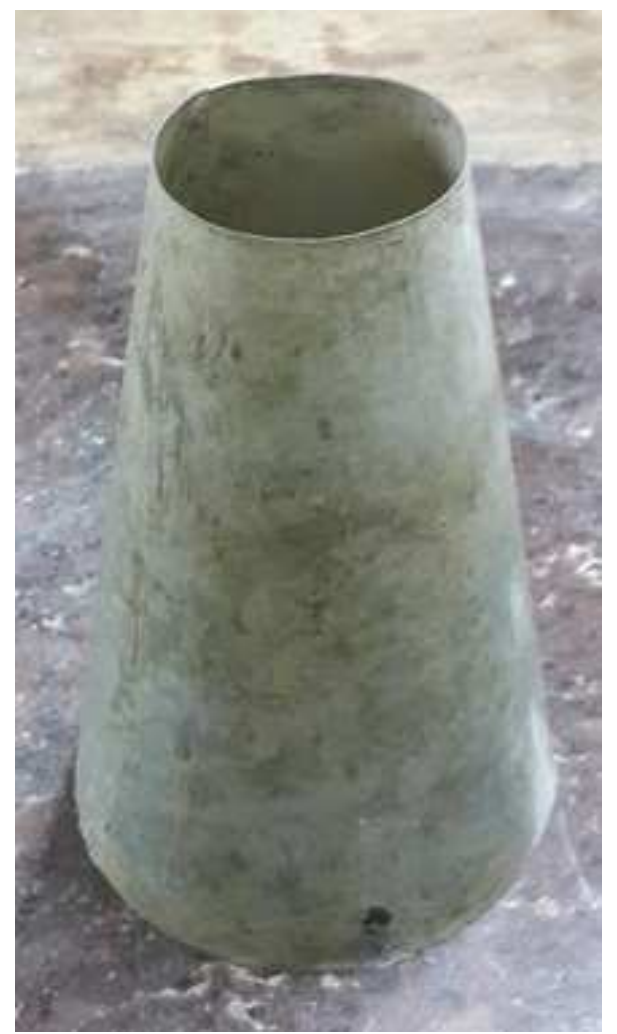

Figura 3.13. Cono metálico de $150 \mathrm{~mm}$ de altura.

Síntesis y potenciales aplicaciones tecnológicas de materiales zeolíticos obtenidos a partir de catalizadores FCC agotados 85 


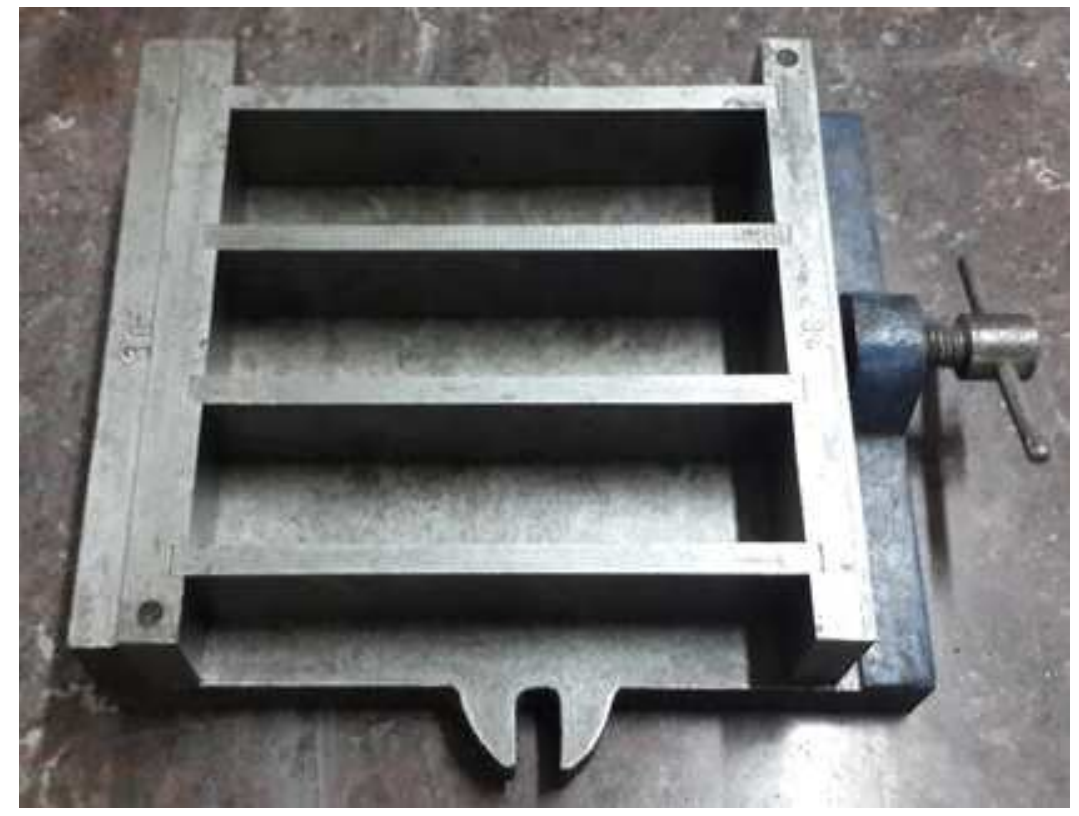

Figura 3.14. Molde para morteros de $40 \times 40 \times 160 \mathrm{~mm}^{3}$ de tamaño.

Síntesis y potenciales aplicaciones tecnológicas de materiales zeolíticos obtenidos a partir de catalizadores FCC agotados 86 


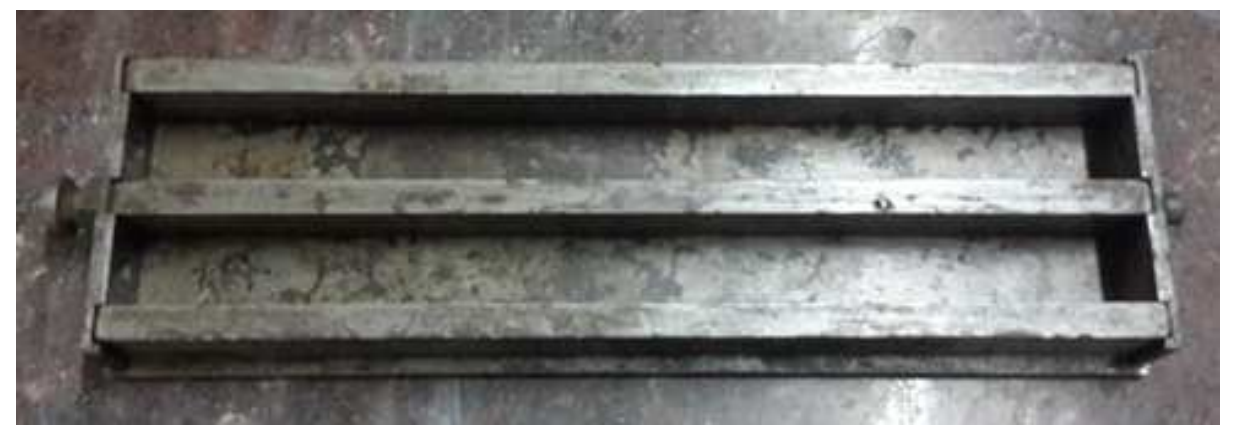

Figura 3.15. Molde para morteros de $30 \times 30 \times 220 \mathrm{~mm}^{3}$ de tamaño. 


\subsubsection{Resistencia a la Flexión}

El procedimiento se llevó a cabo según la Norma IRAM 1622. En ese marco, las probetas fueron dispuestas en el equipo marca Amsler, tipo 1033, el cual se muestra en la Fig. 3.16. y acomodadas cuidadosamente en la parte central. La carga $(P)$ se aumentó progresivamente $5 \mathrm{Kg} \cdot \mathrm{s}^{-1} \pm 1 \mathrm{Kg} \cdot \mathrm{s}^{-1}$ hasta que se produjo la rotura. Luego se determinó por lectura la carga total indicada por el equipo.

\subsubsection{Resistencia a la Compresión}

Este procedimiento también se llevó a cabo según la Norma IRAM 1622 y el equipo empleado fue el mismo en el cual se realizó el ensayo de flexión (Equipo marca Amsler, tipo 1033). Luego del ensayo de flexión se obtuvieron dos mitades del prisma, las cuales fueron utilizadas para realizar este ensayo. Las dos mitades se conservaron húmedas hasta el momento del ensayo. Se colocaron las placas de apoyo centradas en el equipo de alineación, quedando un borde de $1 \mathrm{~cm}$ libre, y la probeta en el dispositivo de ensayo a la compresión. La carga se aumentó a una velocidad que permitió un incremento de la tensión entre $10 \mathrm{Kg}_{\mathrm{cm}} \mathrm{cm}^{-2}$ a $20 \mathrm{Kg} \cdot \mathrm{cm}^{-2}$ por segundo. La duración del ensayo fue de 10 segundos para cada probeta.

Síntesis y potenciales aplicaciones tecnológicas de materiales zeolíticos obtenidos a partir de catalizadores FCC agotados $\mathbf{8 8}$ 


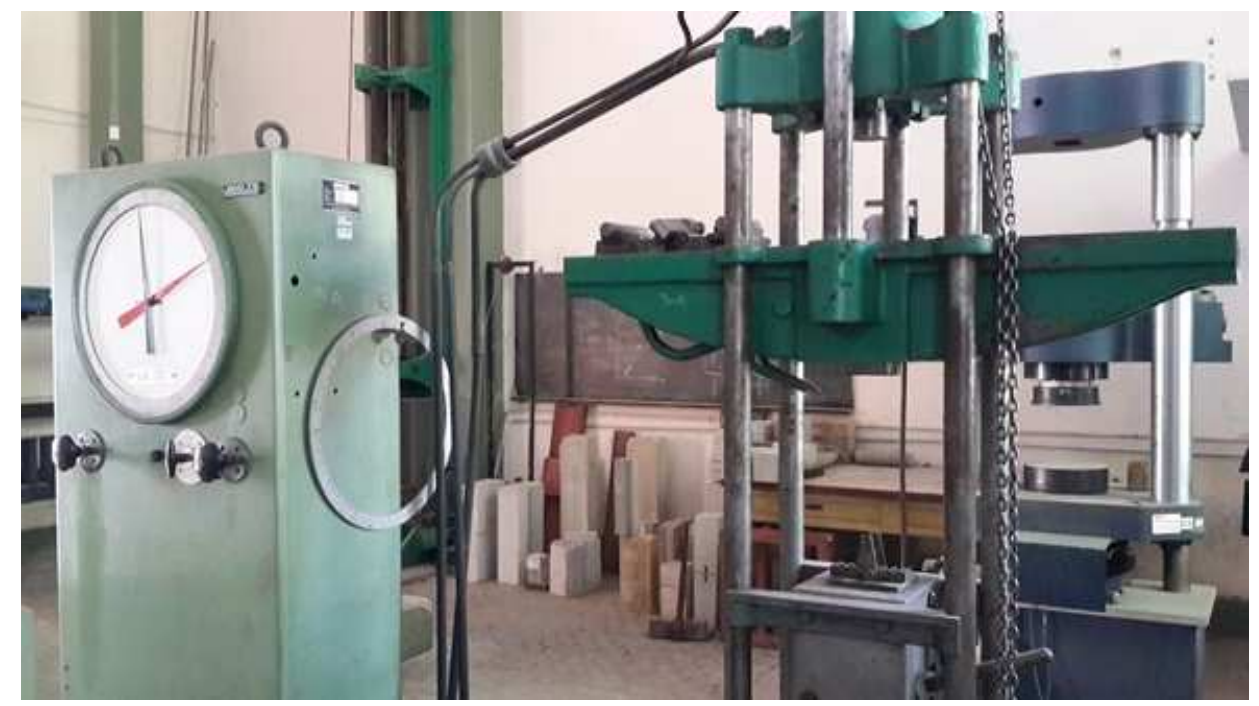

Figura 3.16. Equipo Amsler, tipo 1033. 


\subsubsection{Contracción por secado}

Para este ensayo, los morteros fueron curados en agua a $23^{\circ} \mathrm{C}$ durante 8 días y luego fueron expuestas al aire en una habitación $\left(22^{\circ} \mathrm{C}\right.$ y $55 \%$ de humedad relativa) durante seis meses. Durante ese tiempo se realizaron las mediciones de los morteros en el comparador de longitud para así determinar la variación de la longitud del mortero. Para las determinaciones de las medidas se empleó un indicador digital marca Schwyz, el cual se muestra en la Fig. 3.17.

Además, en esta etapa, se determinó la presencia de $\mathrm{Cr}$ (III) por AA en el agua de curado con el fin de evaluar la posible aparición de lixiviación de cromo durante el proceso de curado. 


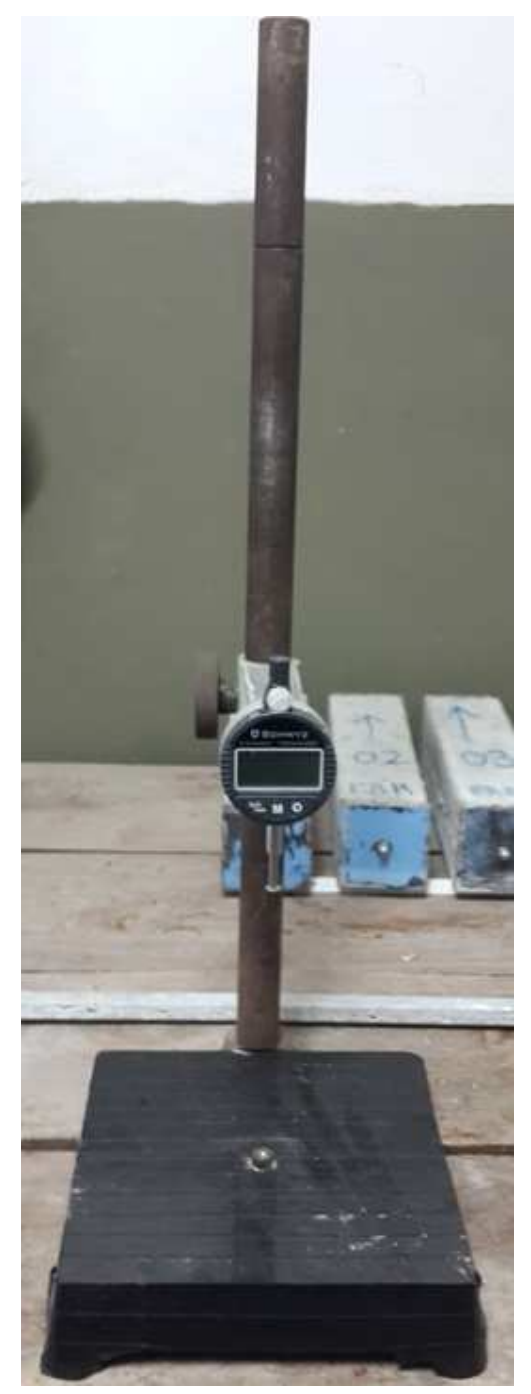

Figura 3.17. Comparador de longitud.

Síntesis y potenciales aplicaciones tecnológicas de materiales zeolíticos obtenidos a partir de catalizadores FCC agotados 91 


\subsection{Ensayos de lixiviación}

Los ensayos de lixiviación se llevaron a cabo en la Universidad Tecnológica Nacional (UTN) y el Centro de Investigación y Desarrollo en Ciencias Aplicadas (CINDECA) perteneciente a la Universidad Nacional de La Plata (UNLP).

Sobre los morteros diseñados se realizaron pruebas de lixiviación utilizando un método estándar (método 1311, USA EPA) [6]. La solución de extracción se preparó utilizando $5,7 \mathrm{~cm}^{3}$ de $\mathrm{CH}_{3} \mathrm{CH}_{2} \mathrm{OOH}$ glacial disuelto en agua destilada hasta $1 \mathrm{~L}$ de volumen. Los morteros elaborados con material zeolítico obtenido a partir del catalizador y zeolita $\mathrm{NaA}$ pura, ambos con $\mathrm{Cr}$ (III) incorporado, se molieron y la fracción $<1 \mathrm{~mm}$.

Las muestras se pusieron en contacto con el fluido de extracción y se transfirieron a un recipiente de vidrio. Posteriormente se sometieron a agitación en un agitador rotatorio a 30 rpm durante 18 h (Fig. 3.18.). El líquido obtenido luego de $18 \mathrm{~h}$, fue sometido a un ensayo por AA para la determinación del lixiviado de $\operatorname{Cr}(I I I)$. 


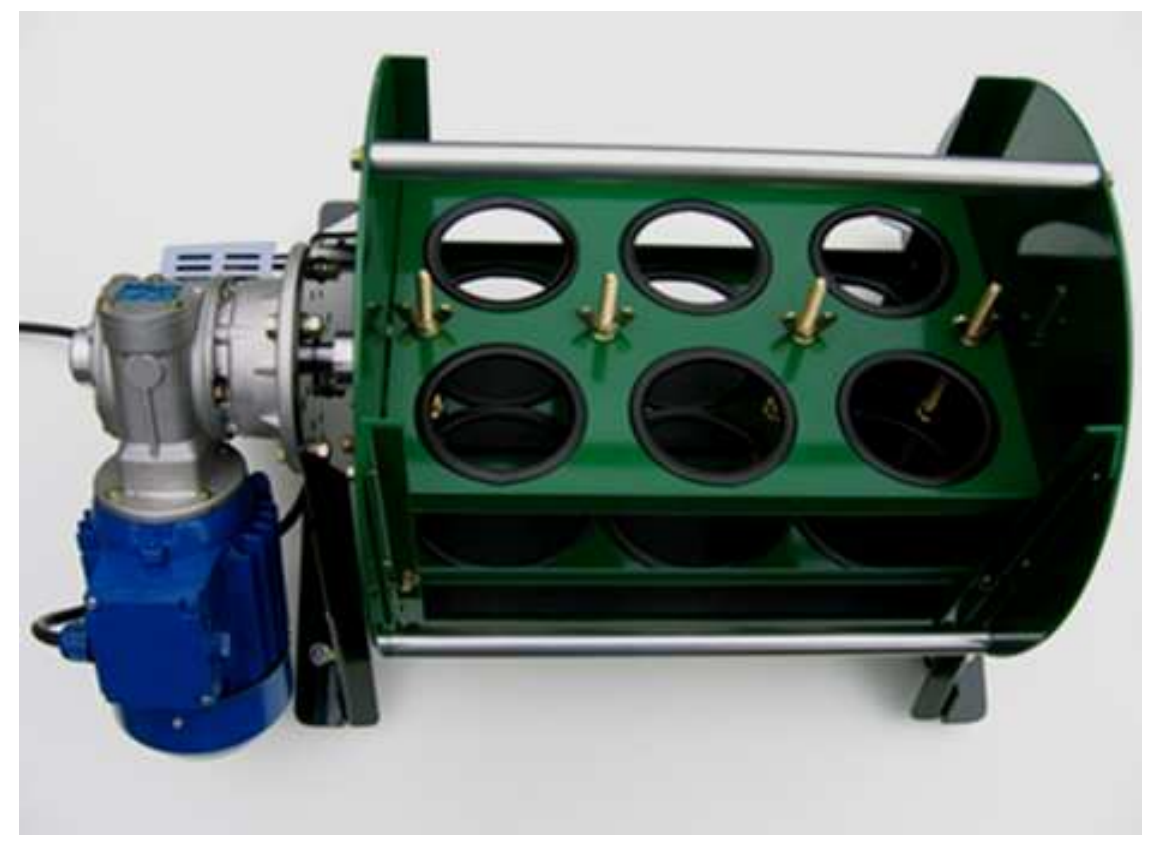

Figura 3.18. Equipo empleado para los ensayos de lixiviación. 


\subsection{Referencias}

[1] Magini M., Cabrini A. (1972). J. Appl. Crystallogr. 5, 14.

[2] Rietveld, H.M. (1969). J. Appl. Crystal 2, 65.

[3] Rodriguez-Carvajal J. (1990). Fullprof, A program for Rietveld refinement and pattern matching analysis, in: Abstracts of the Satellite Meeting on Powder Diffraction of the XV Congress of the IUCr, Toulouse, France. 127.

[4] Breck D.W. (1974). Zeolite Molecular Sieves; Wiley, New York.

[5] Torres Sanchez, R.M., Falasca, S. (1997) Bodenk 160, 223.

[6] US EPA, Method 1311. (1992) Toxicity characteristic leaching procedure, US Enviromental Protection Agency, Washington, D.C., U.S.A. 


\section{CAPÍTULO IV}

\section{INFLUENCIA DE LA MODIFICACIÓN DE DIFERENTES PARÁMETROS DE SÍNTESIS SOBRE LA EVOLUCIÓN DE LA REACCIÓN DE CRISTALIZACIÓN}




\section{INFLUENCIA DE LA MODIFICACIÓN DE DIFERENTES PARÁMETROS DE SÍNTESIS SOBRE LA EVOLUCIÓN DE LA REACCIÓN DE CRISTALIZACIÓN}

En este capítulo se presentan y discuten aspectos referidos a la optimización del proceso de obtención de la estructura zeolítica tipo A. Se aborda el estudio de la conveniencia de utilizar el pretratamiento por fusión alcalina y de determinar la cantidad de fundente necesario para modificar la reactividad del catalizador. La reactividad es cuantificada por el rendimiento de la reacción de síntesis en cuanto a la formación de zeolita del tipo A medido como porcentaje cristalino determinado por XRD. Además de este pretratamiento, se estudia la influencia de la adición de $\mathrm{NaAlO}_{2}$ a la mezcla inicial de síntesis y la variación en el agregado de $\mathrm{NaOH}$.

Adicionalmente se determinan las fases presentes en los productos de reacción para verificar la transformación del catalizador en zeolita A. Las estructuras se estudian a través de diferentes técnicas de caracterización, tales como XRD (método Rietvield y función de distribución radial, NMR y SEM). Finalmente se evalúa el área específica del producto obtenido durante el transcurso de la reacción.

\subsection{Estudios de caracterización del catalizador}

\subsubsection{Análisis químico del catalizador de partida}

Con el objetivo de determinar la composición porcentual general y las cantidades de $\mathrm{SiO}_{2}$ y de $\mathrm{Al}_{2} \mathrm{O}_{3}$ presentes en el catalizador (CAT), se realizó un análisis químico por EDX. Los resultados de este análisis se detallan en la Tabla 4.1.

Síntesis y potenciales aplicaciones tecnológicas de materiales zeolíticos obtenidos a partir de catalizadores FCC agotados 96 
Capítulo IV - Influencia de la modificación de diferentes parámetros de síntesis sobre la evolución de la reacción de cristalización

Tabla 4.1. Análisis químico del catalizador.

\begin{tabular}{|c|c|}
\hline Óxidos (\%p/p) & Catalizador \\
\hline $\mathrm{SiO}_{2}$ & 49,5 \\
\hline $\mathrm{Al}_{2} \mathrm{O}_{3}$ & 45,1 \\
\hline $\mathrm{NaO}_{2}$ & 1,4 \\
\hline $\mathrm{Fe}_{2} \mathrm{O}_{3}$ & 1,7 \\
\hline $\mathrm{TiO}_{2}$ & 1,0 \\
\hline $\mathrm{La}_{2} \mathrm{O}_{3}$ & 0,5 \\
\hline $\mathrm{P}_{2} \mathrm{O}_{5}$ & 0,5 \\
\hline $\begin{array}{l}\text { Otros óxidos } \\
\text { metálicos }\end{array}$ & 0,2 \\
\hline
\end{tabular}

Síntesis y potenciales aplicaciones tecnológicas de materiales zeolíticos obtenidos a partir de catalizadores FCC agotados 97 
Del análisis de los resultados obtenidos surge que el catalizador está compuesto en su mayoría por $\mathrm{SiO}_{2}$ y $\mathrm{Al}_{2} \mathrm{O}_{3}$, aproximadamente en un $95 \%$, por lo cual, resulta viable su empleo como fuente de $\mathrm{SiO}_{2}$ y $\mathrm{Al}_{2} \mathrm{O}_{3}$ para la síntesis de fases zeolíticas de interés tecnológico como lo es la zeolita tipo A.

\subsubsection{Caracterización fisicoquímica del catalizador de partida antes y después del pretratamiento}

\subsubsection{Análisis de la composición cristalográfica}

De acuerdo a la literatura, es ampliamente conocido que un catalizador de cracking debería estar constituido por un porcentaje de zeolita sintética del tipo $\mathrm{Y}$ (grupo FAU), diluido en una matriz amorfa mayoritariamente aluminosilícea. En el difractograma del catalizador agotado CAT se observa un pico en $2 \theta=6,19$, además de otro en $2 \theta=$ 15,61 , los cuales se identifican como picos característicos de la estructura de la zeolita tipo $\mathrm{Y}$.

La aplicación del pretratamiento al catalizador generó otro sólido con fases cristalinas diferentes, detallados en la Tabla 4.2. La activación por fusión alcalina con un $50 \% p / p$ de $\mathrm{Na}_{2} \mathrm{CO}_{3}$ a $800^{\circ} \mathrm{C}$ (CAT50) generó un sólido que contiene carbonato de sodio (natrita) y cantidades apreciables de aluminosilicatos cristalinos (en su mayoría nefelina) apreciados por la técnica de XRD, Figura 4.1. Resultados preliminares [1], confirmaron la validez de las fases cristalinas halladas en este trabajo. Asimismo, la utilización de un $25 \%$ p/p de $\mathrm{Na}_{2} \mathrm{CO}_{3}$ (CAT 25) para la calcinación otorgó resultados similares en cuanto a las fases presentes pero se diferenció en la composición porcentual de cada uno de los componentes, que se produjeron en cantidades menores. Los resultados del análisis cuantitativo se detallan en la Tabla 4.2.

Síntesis y potenciales aplicaciones tecnológicas de materiales zeolíticos obtenidos a partir de catalizadores FCC agotados 98 
Capítulo IV - Influencia de la modificación de diferentes parámetros de síntesis sobre la evolución de la reacción de cristalización

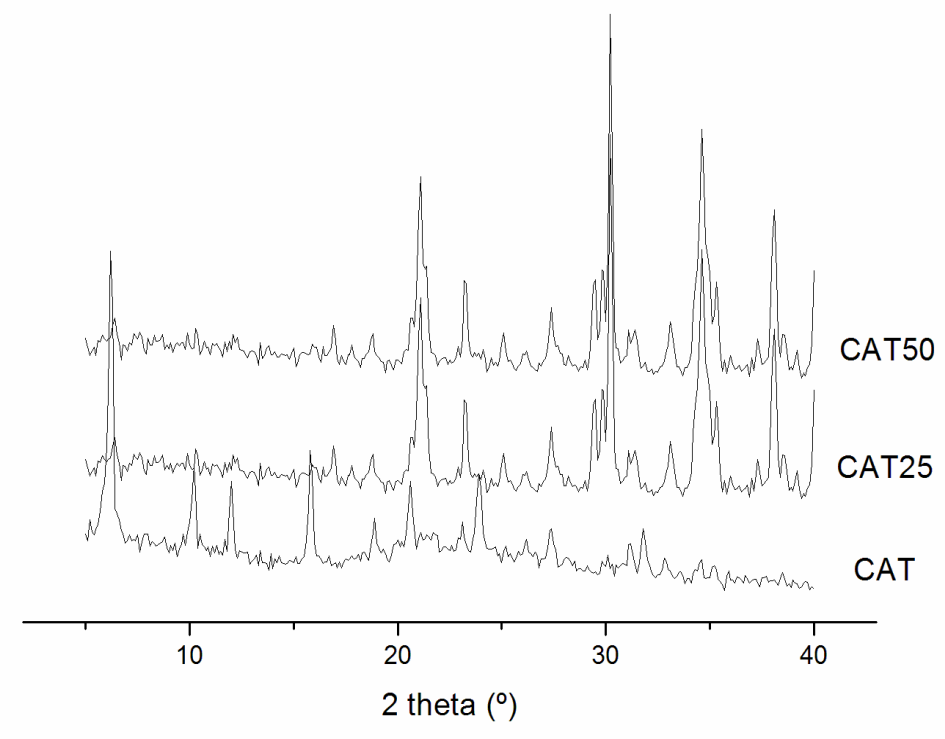

Figura 4.1. Difractogramas de rayos $X$ de las muestras CAT, CAT25 y CAT50. 
Capítulo IV - Influencia de la modificación de diferentes parámetros de síntesis sobre la evolución de la reacción de cristalización

Tabla 4.2. Análisis cuantitativo (método Rietvield) de las fases componentes.

\begin{tabular}{|c|c|c|c|c|c|c|}
\hline Muestra & $\begin{array}{c}\text { Zeolita } \\
\text { FAU } \\
(\% p / p)\end{array}$ & $\begin{array}{c}\text { Natrita } \\
(\% p / p)\end{array}$ & $\begin{array}{c}\text { Nefelina } \\
(\% p / p)\end{array}$ & $\begin{array}{c}\text { Carnagieita } \\
(\% p / p)\end{array}$ & $\begin{array}{c}\text { Mullita } \\
(\% p / p)\end{array}$ & $\begin{array}{c}\text { Anatasa } \\
(\% p / p)\end{array}$ \\
\hline CAT25 & 5 & 24 & 36 & 28 & 6 & 1 \\
\hline CAT50 & 3 & 35 & 41 & 17 & 3 & 1 \\
\hline
\end{tabular}


Capítulo IV - Influencia de la modificación de diferentes parámetros de síntesis sobre la evolución de la reacción de cristalización

\subsubsection{Determinación de la morfología y tamaño de las partículas del catalizador antes y después del pretratamiento}

La morfología y el tamaño del catalizador fueron estudiados a través de microscopía electrónica de barrido. Se observó que el catalizador de origen presenta partículas esféricas lisas del orden de los $60-100 \mu \mathrm{m}$ de diámetro, Fig. 4.2a.

Luego del pretratamiento por fusión alcalina, la morfología se mantuvo constante. No obstante, se observó una modificación superficial de las partículas posiblemente generadas por nuevos compuestos formados durante el pretratamiento con $\mathrm{Na}_{2} \mathrm{CO}_{3}$, según Tabla 4.2. Figura $4.2 \mathrm{~b}$.

\subsection{Análisis de la modificación de variables de síntesis}

Como ya se ha mencionado, en la primera etapa, se realizó una serie de experiencias de síntesis a tiempos medianamente largos con el fin de evaluar la influencia de la aplicación del pretratamiento al catalizador y del agregado de $\mathrm{NaAlO}_{2}$.

4.2.1. Influencia del pretratamiento y de la composición de la mezcla inicial de reacción sobre la estructura cristalográfica del producto de síntesis

Las Figs. 4.3. a 4.7. muestran los difractogramas correspondientes a las muestras sólidas tomadas a diferentes tiempos de reacción $(t=0 \mathrm{~h}$, $1 \mathrm{~h}, 2 \mathrm{~h}, 3 \mathrm{~h}, 21 \mathrm{~h}$ ) durante el transcurso de los experimentos de síntesis. 
Capítulo IV - Influencia de la modificación de diferentes parámetros de síntesis sobre la evolución de la reacción de cristalización

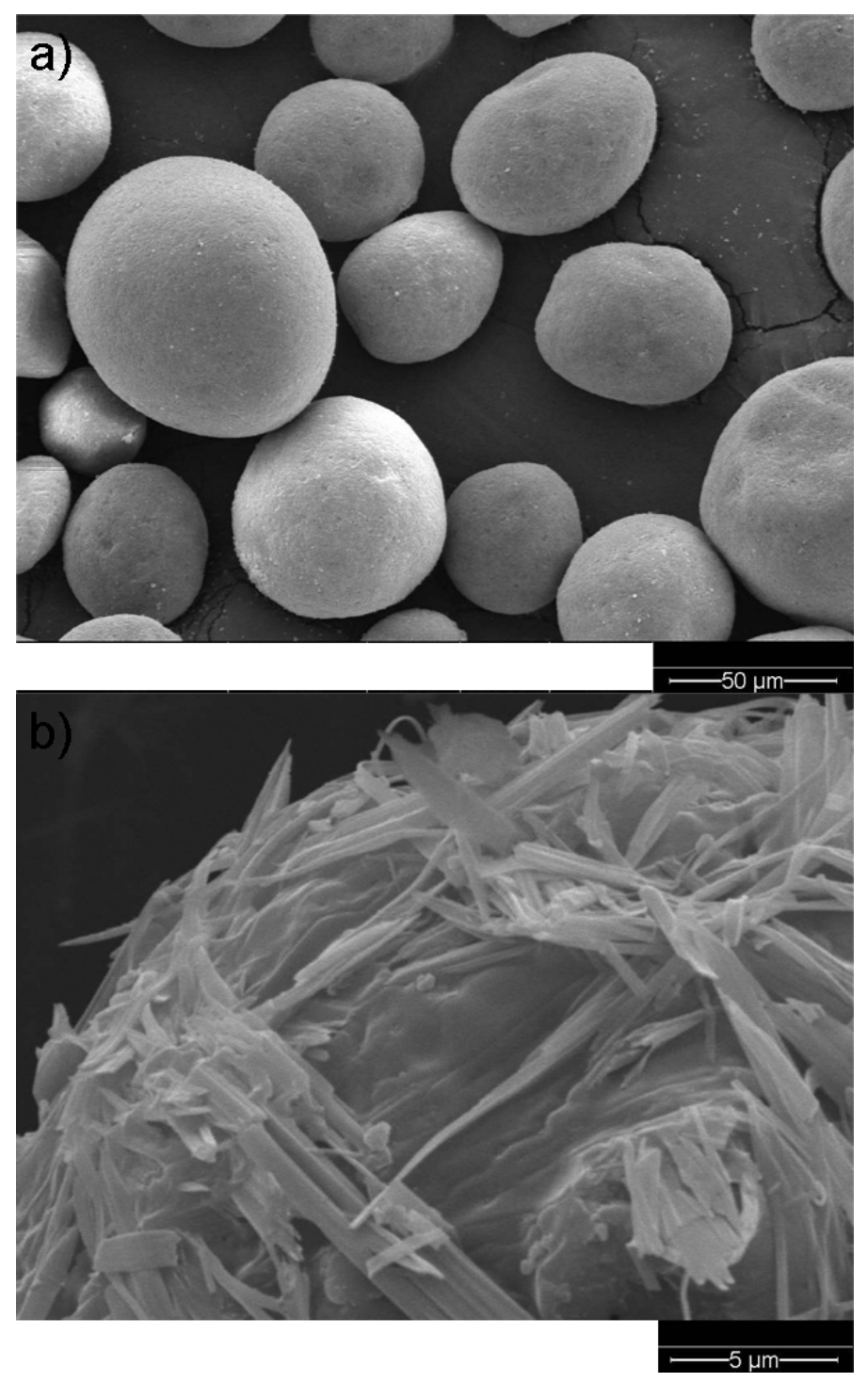

Figura 4.2. Micrografías SEM del catalizador sin y con pretratamiento. a) muestra CAT, magnificación X500, b) muestra CAT50, magnificación X5000.

Síntesis y potenciales aplicaciones tecnológicas de materiales zeolíticos obtenidos a partir de catalizadores FCC agotados 102 
El análisis de las figuras mencionadas permitió concluir que todas las muestras tienen fondos elevados en la zona $20-25^{\circ} 2(\theta)$, típicas de los vidrios de sílice. Los porcentajes de conversión de las muestras se estimaron en base a la intensidad de los picos de difracción. La intensidad de los picos característicos (zeolita $\mathrm{A}, \mathrm{X}$ y $\mathrm{HS}$ ) es confrontada con la de los picos correspondientes de una muestra patrón de la misma estructura a la cual se le asigna una cristalinidad $100 \%$.

De los resultados obtenidos surge que la conversión en fases zeolíticas es apreciable, y en muchos casos los productos de reacción presentan altos porcentajes de zeolitas tipo A (LTA) y X (FAU), Tabla 4.3. También en algunas muestras se observaron trazas de natrita, nefelina, carnagieita, mullita y anatasa.

Comparando los resultados obtenidos con y sin fusión alcalina previa, (Figs. 4.4., 4.6., 4.7. y Figs. 4.3. y 4.5., respectivamente) se concluyó que la aplicación del pretratamiento acelera apreciablemente la transformación. Asimismo, se puede apreciar que la cristalización de la zeolita $A$ se ve favorecida cuando se usan los mayores porcentajes de $\mathrm{Na}_{2} \mathrm{CO}_{3}$ para la fusión y paralelamente se agrega la fuente de $\mathrm{NaAlO}_{2}$ adicional (Fig. 4.4. y Tabla 4.3., muestra 1273-3h). Cabe señalar que para los ensayos 1272 y 1273 el tiempo de reacción máximo correspondió a 21 h. En el primer caso (sin pretratamiento), debido a la baja reactividad de la mezcla, a partir de las $21 \mathrm{~h}$ de reacción se observó una conversión apreciable de material zeolítico del tipo X. Para el segundo caso, al cual se le aplicó fusión alcalina, se observó que para extensos tiempos de reacción las fases zeolíticas tipo LTA se transformaron en hidroxisodalita. Además se observó que el ensayo realizado sin fusión ni fuente de aluminio extra agregada (muestra 1279) presentó una conversión muy baja.

Síntesis y potenciales aplicaciones tecnológicas de materiales zeolíticos obtenidos a partir de catalizadores FCC agotados 103 
Capítulo IV - Influencia de la modificación de diferentes parámetros de síntesis sobre la evolución de la reacción de cristalización

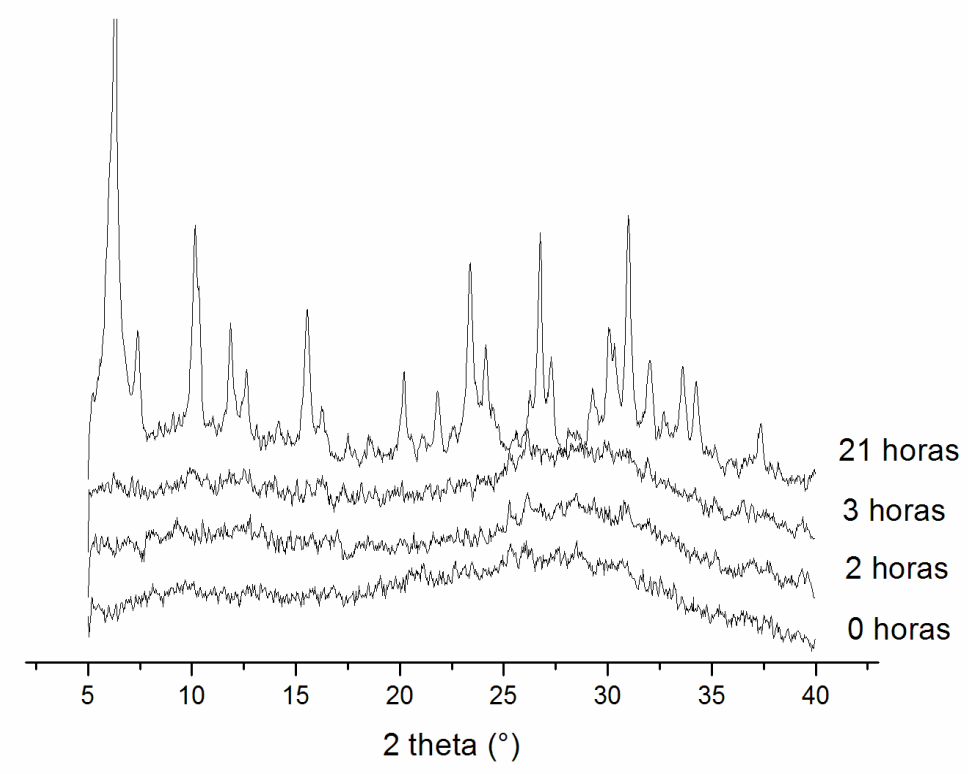

Figura 4.3. Difractogramas de rayos $X$ para los productos del ensayo 1272 a diferentes tiempos de reacción.

Síntesis y potenciales aplicaciones tecnológicas de materiales zeolíticos obtenidos a partir de catalizadores FCC agotados 104 
Capítulo IV - Influencia de la modificación de diferentes parámetros de síntesis sobre la evolución de la reacción de cristalización

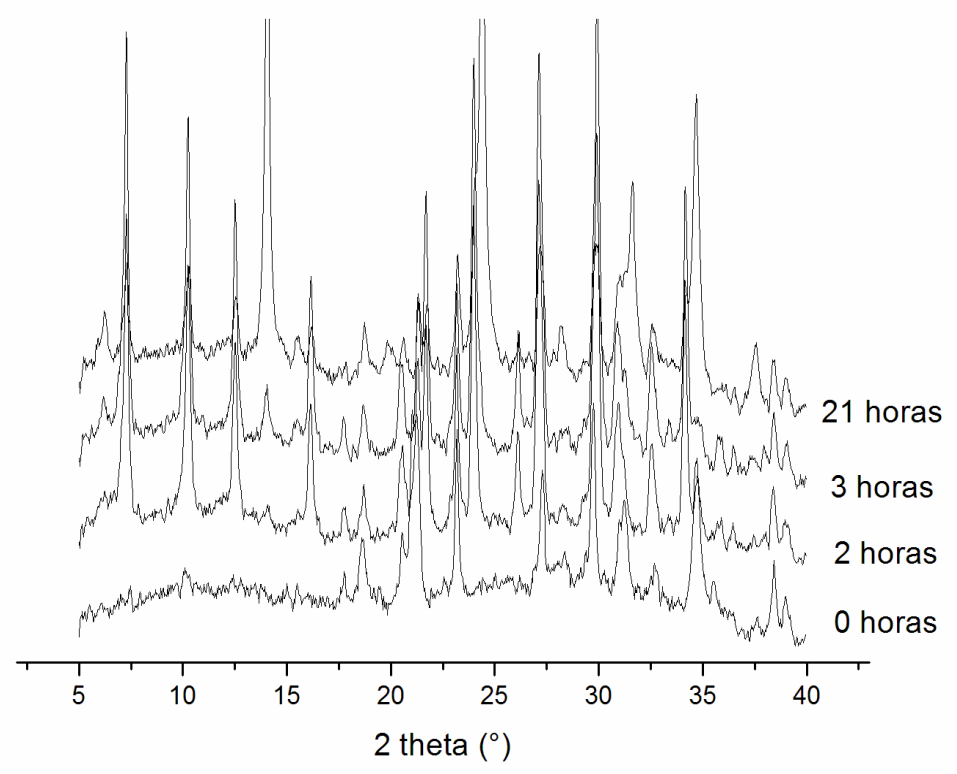

Figura 4.4. Difractogramas de rayos $X$ para los productos del ensayo 1273 a diferentes tiempos de reacción.

Síntesis y potenciales aplicaciones tecnológicas de materiales zeolíticos obtenidos a partir de catalizadores FCC agotados 105 
Capítulo IV - Influencia de la modificación de diferentes parámetros de síntesis sobre la evolución de la reacción de cristalización

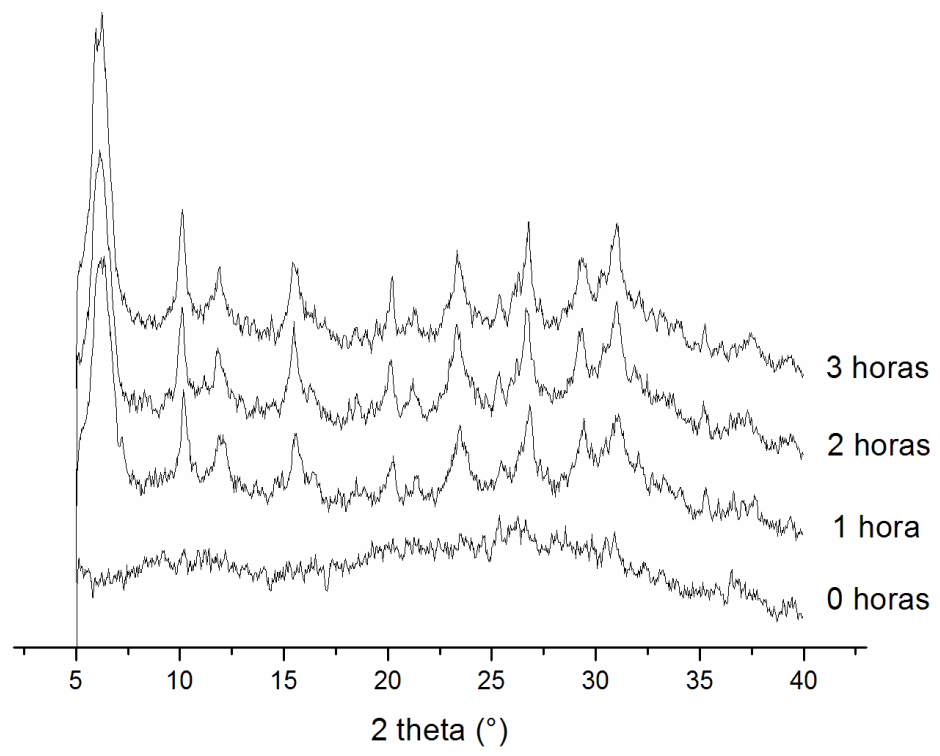

Figura 4.5. Difractogramas de rayos $X$ para los productos del ensayo 1279 a diferentes tiempos de reacción.

Síntesis y potenciales aplicaciones tecnológicas de materiales zeolíticos obtenidos a partir de catalizadores FCC agotados 106 
Capítulo IV - Influencia de la modificación de diferentes parámetros de síntesis sobre la evolución de la reacción de cristalización

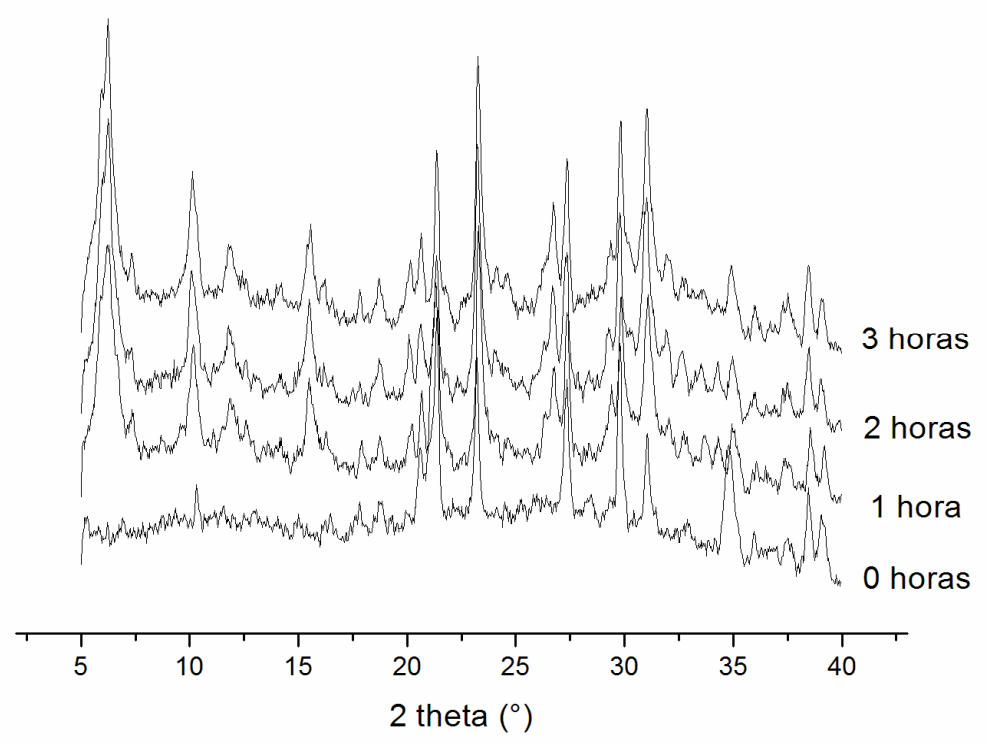

Figura 4.6. Difractogramas de rayos $X$ para los productos del ensayo 1280 a diferentes tiempos de reacción.

Síntesis y potenciales aplicaciones tecnológicas de materiales zeolíticos obtenidos a partir de catalizadores FCC agotados 107 
Capítulo IV - Influencia de la modificación de diferentes parámetros de síntesis sobre la evolución de la reacción de cristalización

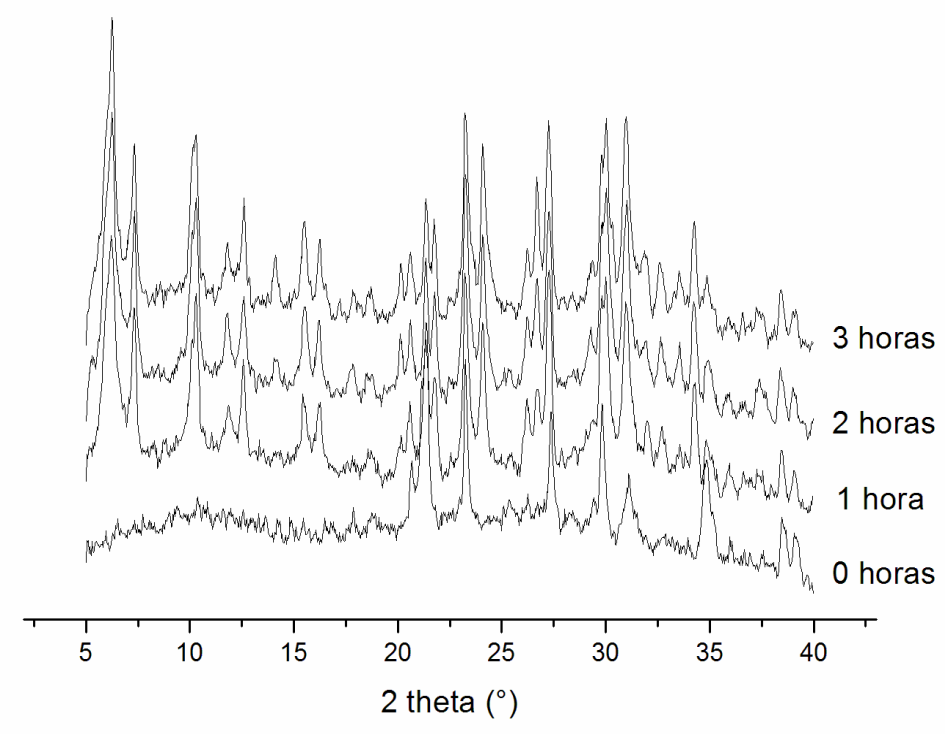

Figura 4.7. Difractogramas de rayos $X$ para los productos del ensayo 1281 a diferentes tiempos de reacción.

Síntesis y potenciales aplicaciones tecnológicas de materiales zeolíticos obtenidos a partir de catalizadores FCC agotados 108 
Capítulo IV - Influencia de la modificación de diferentes parámetros de síntesis sobre la evolución de la reacción de cristalización

Tabla 4.3. Composiciones iniciales, productos obtenidos y conversiones para los diferentes ensayos realizados.

\begin{tabular}{|c|c|c|c|c|}
\hline Ensayo & $\begin{array}{l}\mathrm{Na}_{2} \mathrm{CO}_{3} \\
(\% p / p)^{a}\end{array}$ & $\begin{array}{l}\mathrm{NaAlO}_{2} \\
(\% \mathrm{p} / \mathrm{p})^{\mathrm{b}}\end{array}$ & $\begin{array}{l}\text { Tipo de } \\
\text { zeolita }\end{array}$ & Conversión $^{c}$ \\
\hline 1272-0h & - & $2 \%$ & - & - \\
\hline 1272-2h & - & $2 \%$ & - & - \\
\hline 1272-3h & - & $2 \%$ & - & - \\
\hline 1272-21h & - & $2 \%$ & $X>A$ & 68 \\
\hline 1273-0h & $50 \%$ & $2 \%$ & - & - \\
\hline 1273-2h & $50 \%$ & $2 \%$ & $A+\operatorname{tr} X$ & 60 \\
\hline 1273-3h & $50 \%$ & $2 \%$ & $A+\operatorname{tr} X$ & 75 \\
\hline 1273-21h & $50 \%$ & $2 \%$ & $\operatorname{tr} \mathrm{A}+\mathrm{HS}$ & 90 \\
\hline 1279-0h & - & - & - & - \\
\hline 1279-1h & - & - & $X>A$ & 40 \\
\hline 1279-2h & - & - & $\mathrm{X}>\mathrm{A}$ & 50 \\
\hline 1279-3h & - & - & $X>A$ & 55 \\
\hline $1280-0 h$ & $25 \%$ & - & - & - \\
\hline $1280-1 \mathrm{~h}$ & $25 \%$ & - & $X>A$ & 40 \\
\hline $1280-2 \mathrm{~h}$ & $25 \%$ & - & $\mathrm{X}>\mathrm{A}$ & 66 \\
\hline 1280-3h & $25 \%$ & - & $X>A$ & 68 \\
\hline 1281-0h & $25 \%$ & $2 \%$ & - & - \\
\hline 1281-1h & $25 \%$ & $2 \%$ & $A \geq X$ & 60 \\
\hline 1281-2h & $25 \%$ & $2 \%$ & $A \geq X$ & 70 \\
\hline $1281-3 h$ & $25 \%$ & $2 \%$ & $A \geq X$ & 70 \\
\hline
\end{tabular}

${ }^{a}$ porcentaje en la mezcla sólida inicial a calcinar, ${ }^{b}$ porcentaje en la mezcla inicial de reacción, ${ }^{c}$ (fases zeolíticas/amorfo)\%.

Síntesis y potenciales aplicaciones tecnológicas de materiales zeolíticos obtenidos a partir de catalizadores FCC agotados 109 
Por otra parte, la mezcla de $\mathrm{A}+\mathrm{X}$ presentó una alta conversión utilizando un $25 \%$ en peso de $\mathrm{Na}_{2} \mathrm{CO}_{3}$ y agregando $\mathrm{NaAlO}_{2}$ (Fig. 4.7. y Tabla 4.3., muestra 1281-3h).

A partir del estudio de estas reacciones, se puede concluir que la muestra 1273-3h, es la que presentó mayor porcentaje de conversión en zeolita A, aproximadamente $75 \%$. Por lo tanto, la relación $50 \%$ de catalizador/ $\mathrm{Na}_{2} \mathrm{CO}_{3}$ para el pretratamiento y el agregado de un $2 \% \mathrm{p} / \mathrm{p}$ de $\mathrm{NaAlO}_{2}$ durante el proceso de síntesis son adecuados para la obtención de un producto rico en zeolita $\mathrm{NaA}$.

\subsubsection{Morfología y tamaño de los productos de síntesis}

La morfología y el tamaño de partícula de los productos de síntesis fueron estimados mediante microscopía de barrido electrónico. Se observó que el producto obtenido sin fusión alcalina conservó la morfología del catalizador de partida y además persistieron las zonas lisas sobre la superficie del catalizador, Fig. 4.8a.

Por el contrario, en el caso de los ensayos a los cuales se les aplicó pretratamiento, después de la reacción de síntesis se registró la conservación de la forma y el tamaño de las partículas pero se diferenció en su aspecto superficial. Se apreció el crecimiento de cristales zeolíticos uniformemente distribuidos sobre el área externa de la partícula, tal como puede observarse en la Figura 4.8b. El análisis correspondiente para el sólido obtenido en una de las pruebas (1273-3h) indicó que el producto está formado principalmente por cristales cúbicos de tamaño del orden de $1 \mu \mathrm{m}$ con alto porcentaje LTA (Fig. 4.8b.). 
Capítulo IV - Influencia de la modificación de diferentes parámetros de síntesis sobre la evolución de la reacción de cristalización

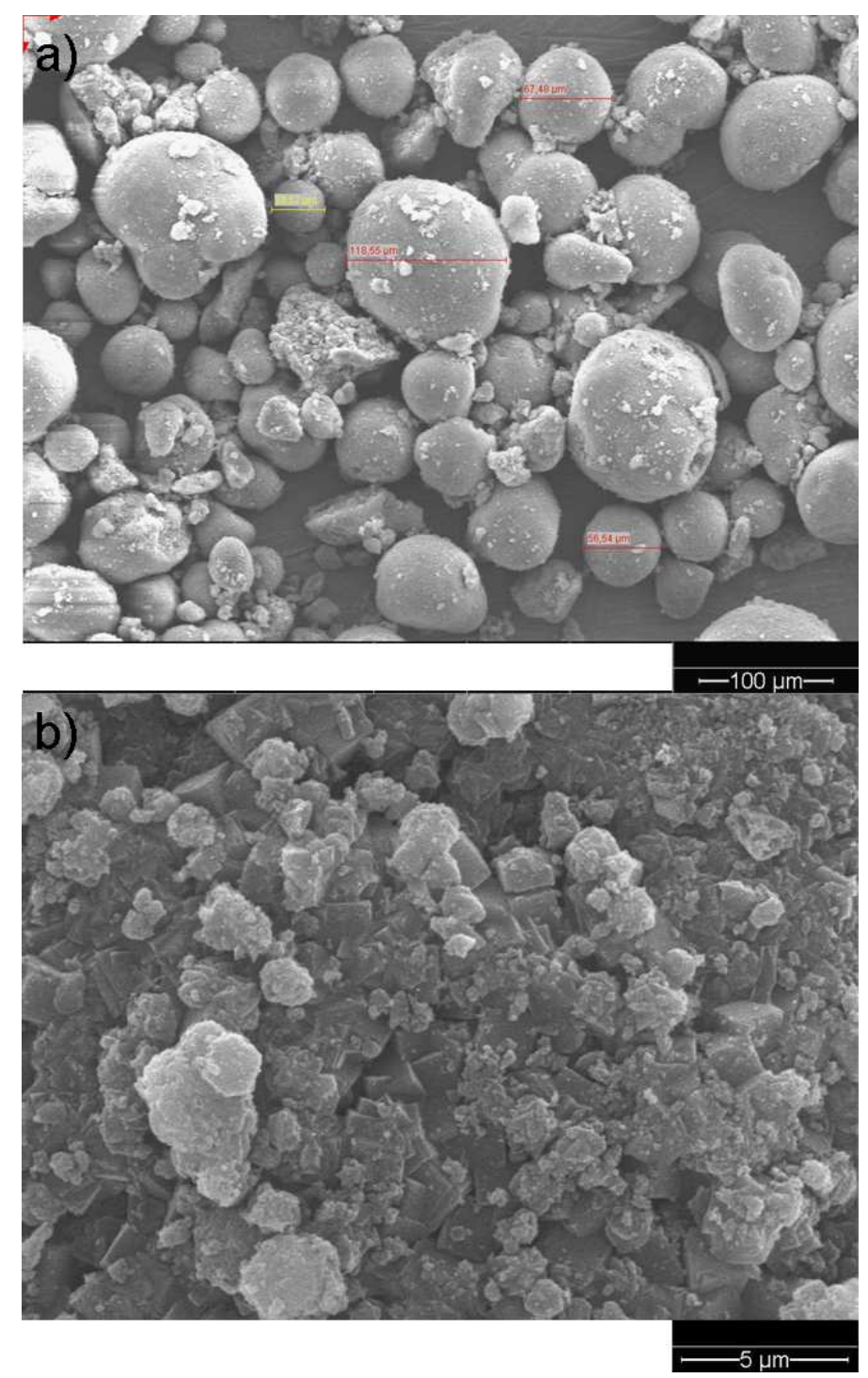

Figura 4.8. Micrografías SEM de los productos de síntesis. a) muestra 1271-21h, (sin pretratamiento) magnificación X200; b) muestra 1273-3h (con pretratamiento) magnificación X5000. 
Capítulo IV - Influencia de la modificación de diferentes parámetros de síntesis sobre la evolución de la reacción de cristalización

\subsubsection{Optimización de la reacción}

Posteriormente, con el fin de optimizar la reacción de síntesis y de emplear la menor cantidad de reactivos se llevó a cabo una serie de reacciones de manera de disminuir la cantidad de $\mathrm{NaOH}$ utilizado en el batch de reacción.

Para llevar a cabo este análisis, se tomó como referencia el ensayo 1273 debido a que presentó la mayor conversión en zeolita $\mathrm{NaA}$, cuantificada a través de los ensayos de XRD y comprobada su morfología a través de SEM. Para ello, se realizaron tres ensayos. En el primero de ellos se mantuvieron los parámetros en las mismas condiciones que en el ensayo 1273 , en este caso ensayo 4013 , el cual se tomó como referencia. Luego se redujo la cantidad de $\mathrm{NaOH}$ agregado. Los restantes reactivos se mantuvieron constantes. Las composiciones de las mezclas ensayadas se observan en la Tabla 4.4.

\subsubsection{Análisis de la conversión en zeolita tomando como variable la cantidad de hidróxido de sodio agregada a la mezcla inicial}

Las Figs. 4.9. a 4.11. muestran los difractogramas correspondientes a las muestras sólidas tomadas a diferentes tiempos de reacción ( $t=1 \mathrm{~h}, 2$ h y $3 \mathrm{~h}$ ) durante el transcurso de los experimentos de síntesis 4013, 4014 y 4015 . Los resultados de las conversiones para los diferentes ensayos realizados se detallan en la Tabla 4.5. Los porcentajes de conversión de las muestras se estimaron en base a la intensidad de los picos de difracción, de igual manera que en el punto 4.2.1.

Síntesis y potenciales aplicaciones tecnológicas de materiales zeolíticos obtenidos a partir de catalizadores FCC agotados 112 
Tabla 4.4. Composiciones iniciales de los ensayos realizados.

\begin{tabular}{|c|c|c|c|c|c|}
\hline Ensayo & $\begin{array}{c}\mathrm{NaOH} \\
(\mathbf{g})\end{array}$ & $\begin{array}{c}\mathrm{NaAlO}_{2} \\
(\mathbf{g})\end{array}$ & $\begin{array}{c}\mathrm{H}_{2} \mathrm{O} \\
(\mathbf{g})\end{array}$ & $\begin{array}{c}\text { Catalizador } \\
\text { calcinado con } \mathrm{Na}_{2} \mathrm{CO}_{3} \\
(\mathbf{g})\end{array}$ & $\begin{array}{c}\mathrm{H}_{2} \mathrm{O} / \mathrm{Na}_{2} \mathrm{O}^{\mathbf{a}} \\
(\% \mathrm{p} / \mathrm{p})\end{array}$ \\
\hline $\mathbf{4 0 1 3}$ & 35,6 & 3 & 219 & 24 & 27 \\
\hline $\mathbf{4 0 1 4}$ & 17,8 & 3 & 219 & 24 & 33 \\
\hline $\mathbf{4 0 1 5}$ & 8,9 & 3 & 219 & 24 & 45 \\
\hline
\end{tabular}

a porcentaje en la mezcla inicial de reacción. 
Capítulo IV - Influencia de la modificación de diferentes parámetros de síntesis sobre la evolución de la reacción de cristalización

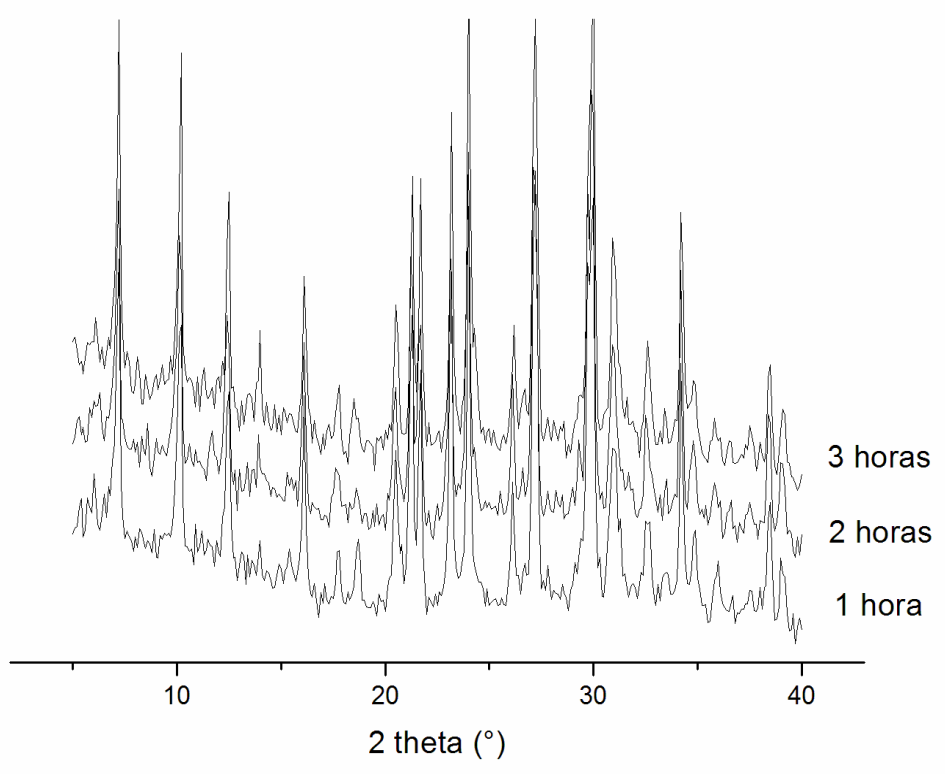

Figura 4.9. Difractogramas de rayos $X$ para los productos del ensayo 4013 a diferentes tiempos de reacción.

Síntesis y potenciales aplicaciones tecnológicas de materiales zeolíticos obtenidos a partir de catalizadores FCC agotados 114 
Capítulo IV - Influencia de la modificación de diferentes parámetros de síntesis sobre la evolución de la reacción de cristalización

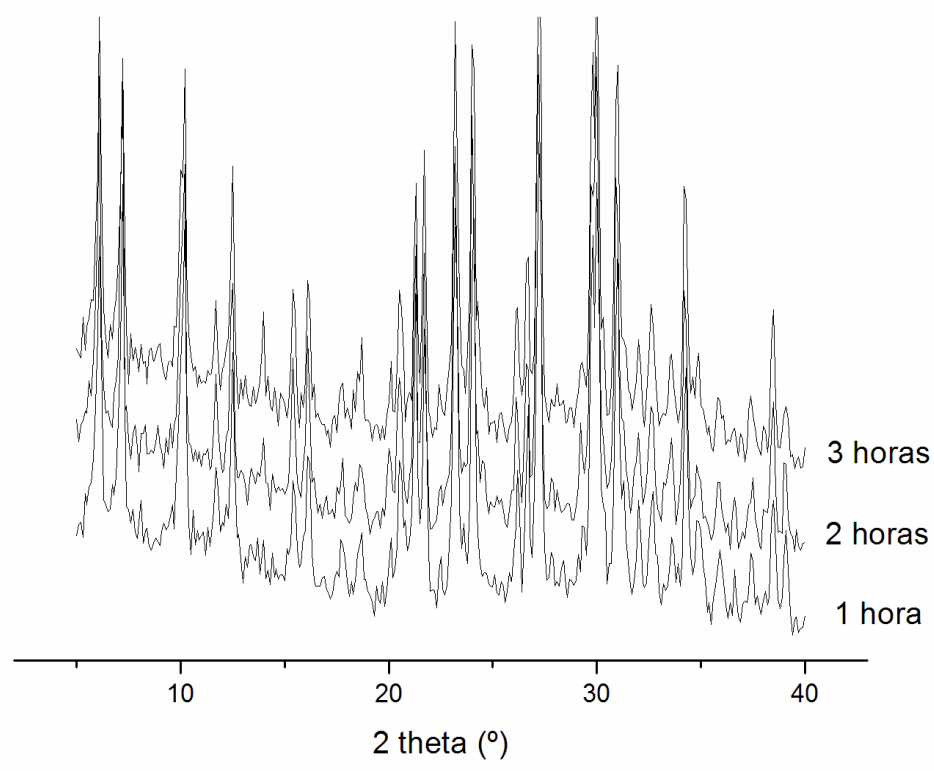

Figura 4.10. Difractogramas de rayos $X$ para los productos del ensayo 4014 a diferentes tiempos de reacción.

Síntesis y potenciales aplicaciones tecnológicas de materiales zeolíticos obtenidos a partir de catalizadores FCC agotados 115 
Capítulo IV - Influencia de la modificación de diferentes parámetros de síntesis sobre la evolución de la reacción de cristalización

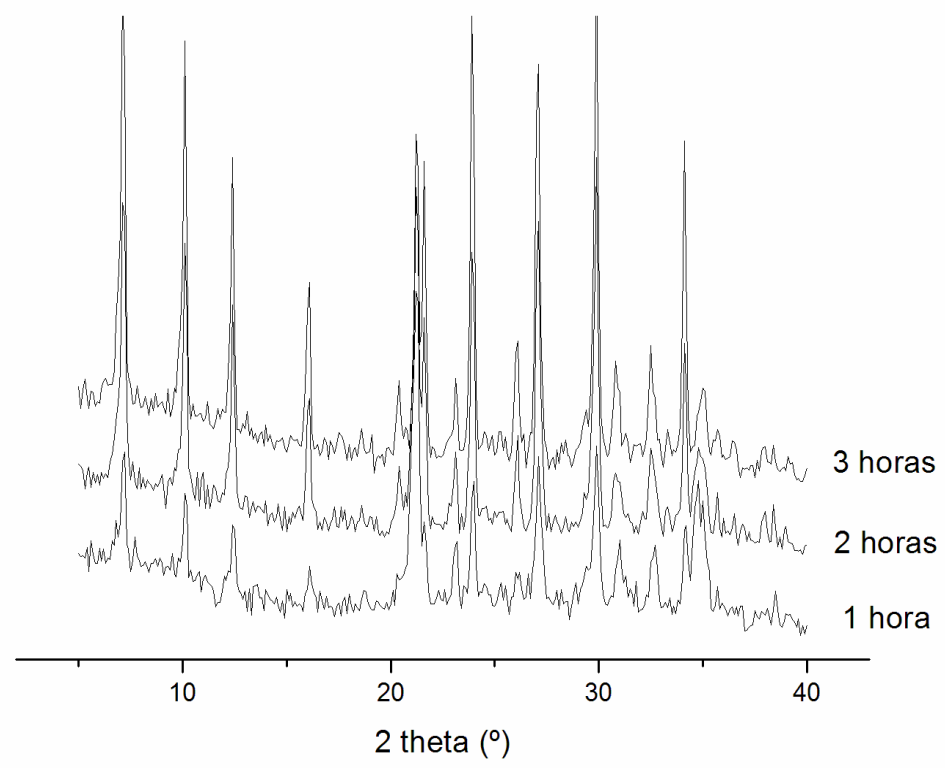

Figura 4.11. Difractogramas de rayos $X$ para los productos del ensayo $4015^{\mathrm{a}}$ diferentes tiempos de reacción.

Síntesis y potenciales aplicaciones tecnológicas de materiales zeolíticos obtenidos a partir de catalizadores FCC agotados 116 
Capítulo IV - Influencia de la modificación de diferentes parámetros de síntesis sobre la evolución de la reacción de cristalización

Tabla 4.5. Resultados de las conversiones para los diferentes ensayos realizados.

\begin{tabular}{|c|c|c|}
\hline Ensayo & $\begin{array}{c}\text { Tipo de } \\
\text { zeolita }\end{array}$ & Conversión $^{\text {a }}$ \\
\hline $\mathbf{4 0 1 3 - 1 h}$ & $\mathrm{A}$ & 50 \\
\hline $\mathbf{4 0 1 3 - 2 h}$ & $\mathrm{A}+\operatorname{tr} \mathrm{h}$ & 60 \\
\hline $\mathbf{4 0 1 3 - 3 h}$ & $\mathrm{A}+\operatorname{trX}$ & $75-80$ \\
\hline $\mathbf{4 0 1 4 - 1 h}$ & $\mathrm{A}>\mathrm{X}$ & 50 \\
\hline $\mathbf{4 0 1 4 - 2 h}$ & $\mathrm{A}+\mathrm{X}$ & 60 \\
\hline $\mathbf{4 0 1 4 - 3 h}$ & $\mathrm{X}>\mathrm{A}$ & $75-80$ \\
\hline $\mathbf{4 0 1 5 - 1 h}$ & $\mathrm{A}$ & 40 \\
\hline $\mathbf{4 0 1 5 - 2 h}$ & $\mathrm{A}$ & 60 \\
\hline $\mathbf{4 0 1 5 - 3 h}$ & $\mathrm{A}$ & $75-80$ \\
\hline
\end{tabular}

a(fases zeolíticas/amorfo)\%. 
Del análisis de los espectros de difracción para las distintas muestras a las que se le varió la cantidad de $\mathrm{NaOH}$ se pudo inferir que la conversión en zeolita A de las muestras 4013 y 4015 son similares, con valores cercanos a $75-80 \%$. El ensayo 4014 presentó una conversión en zeolita $A$ y $X$, siendo a las 3 horas la cantidad de zeolita $X$ superior en relación con la zeolita $A$. De estos resultados obtenidos, se concluye que resulta adecuado realizar los ensayos con la menor cantidad de $\mathrm{NaOH}$, es decir, reducir la cantidad de $\mathrm{NaOH}$ agregado en un $77 \%$.

\subsubsection{Análisis de la morfología y el tamaño del producto}

La morfología y el tamaño de partícula de los productos de reacción se observó por microscopía electrónica de barrido, macro (bajo aumento) y microscópicamente (alta ampliación), para confirmar que la morfología del catalizador de partida se mantuvo a medida que la zeolita NaA fue sintetizada.

Las micrografías SEM (Fig. 4.12.) del ensayo 4015 a las $3 \mathrm{~h}$, muestran que el producto obtenido mantiene la morfología del catalizador de partida, pues se observa que luego de la reacción todavía se tienen las partículas esféricas del orden de los 60-100 $\mu \mathrm{m}$ de diámetro (Fig.4.12.a.). Se evidencia en la Fig. 3.8b. que la superficie de las partículas de catalizador se encuentra recubierta por cristales zeolíticos. Podemos decir que la disminución del $\mathrm{NaOH}$ no produce alteración morfológica, además que se mantuvo la conversión en zeolita $A$, sin modificación en la formación de los cristales zeolíticos. 
Capítulo IV - Influencia de la modificación de diferentes parámetros de síntesis sobre la evolución de la reacción de cristalización

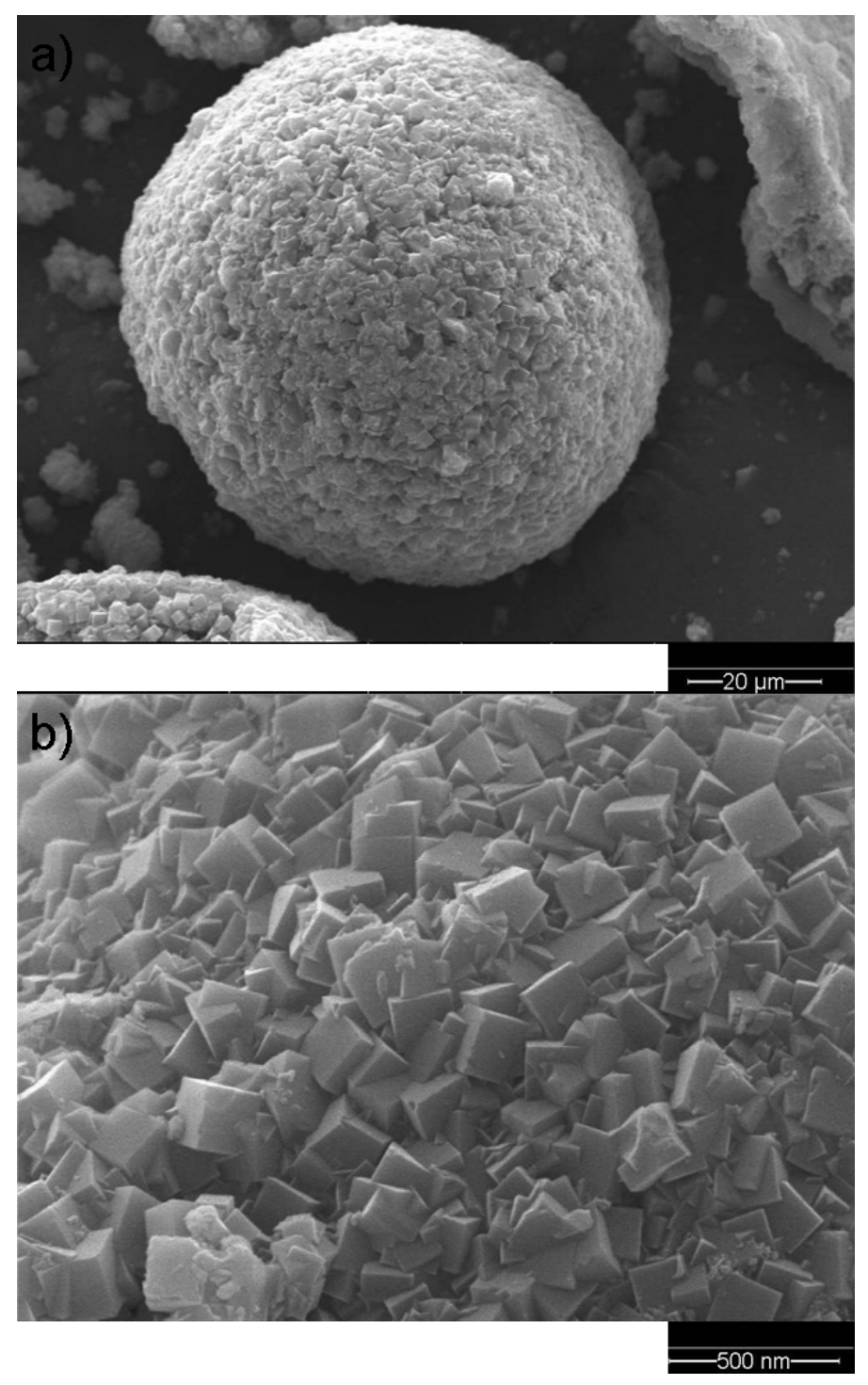

Figura 4.12. Micrografías SEM correspondientes al producto obtenido luego de la síntesis, muestra 4015 (3horas). a) esfera de catalizador, magnificación X1000, b) superficie de la esfera del catalizador, magnificación X5000.

Síntesis y potenciales aplicaciones tecnológicas de materiales zeolíticos obtenidos a partir de catalizadores FCC agotados 119 


\subsection{Análisis comparativo del producto obtenido y de la muestra patrón de zeolita NaA por FT-IR}

En la Fig. 4.13. se muestran los espectros de FT-IR de zeolita $\mathrm{NaA}$ obtenida a partir del catalizador FCC agotado (muestra 4015) y zeolita A pura patrón, en el rango de $4.000-400 \mathrm{~cm}^{-1}$. Los diagramas correspondientes a ambas muestras son coincidentes. Para las dos muestras, se encuentra un pico dominante en el rango 3.440 $3.450 \mathrm{~cm}^{-1}$. Esta señal se asocia con el estiramiento $\mathrm{H}-\mathrm{O}-\mathrm{H}$ del agua adsorbida. Además, el pico en $1.652 \mathrm{~cm}^{-1}$ podría ser también atribuido al enlace $\mathrm{H}-\mathrm{O}-\mathrm{H}$ correspondiente al agua adsorbida. Para este tipo de zeolita, se puede observar un pico importante en aproximadamente $998 \mathrm{~cm}^{-1}$, asociado al estiramiento asimétrico de Si-O-Al [2].

Las bandas de absorción entre 450 y $600 \mathrm{~cm}^{-1}$ representan la estructura característica de la zeolita $A$ (relacionada con los dobles anillos de cuatro miembros (D4R)). La banda de absorción en el rango de $553-557 \mathrm{~cm}^{-1}$ evidencia los dobles cuatro anillos, las bandas que aparecen en $463 \mathrm{~cm}^{-1}$ y $669 \mathrm{~cm}^{-1}$ corresponden al enlace Si-O-Al y a las vibraciones del estiramiento simétrico del Si-O-Al, respectivamente.

De acuerdo a estos resultados, la zeolita $\mathrm{NaA}$ obtenida a partir del catalizador es similar a la zeolita NaA pura, presentando los mismos enlaces.

\subsection{Estudio de la reacción a tiempos cortos de síntesis}

Dado que los resultados anteriores demostraron que a las $3 \mathrm{~h}$ de transcurrida la reacción de síntesis se obtiene un producto con un 75 $80 \%$ de zeolita A en su composición, se decidió repetir algunas 
Capítulo IV - Influencia de la modificación de diferentes parámetros de síntesis sobre la evolución de la reacción de cristalización

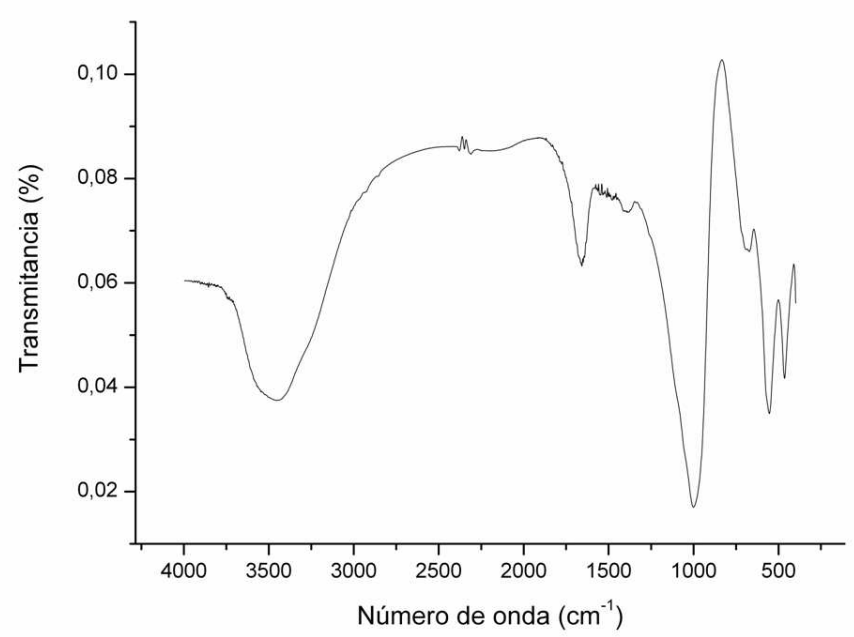

a)

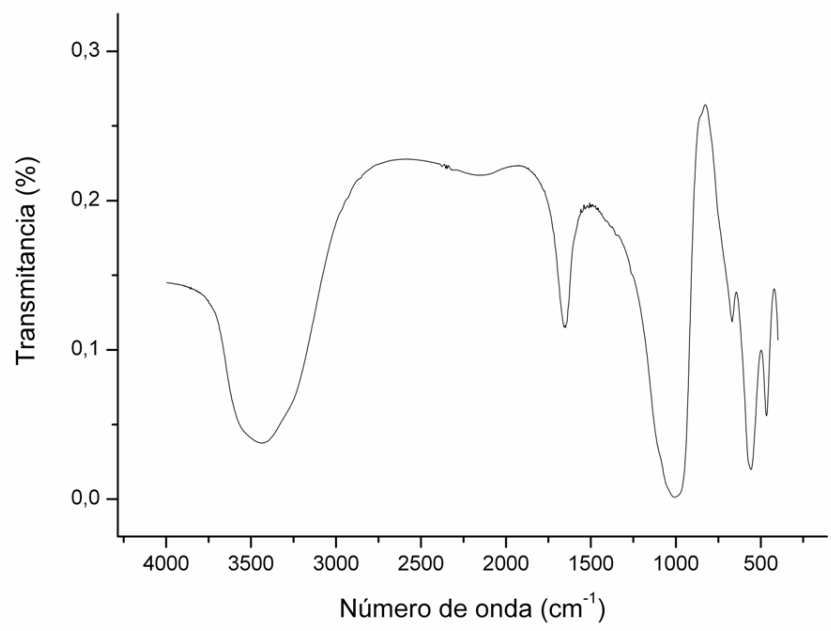

b)

Figura 4.13. Espectros de FT-IR de a) muestra 4015 y

b) zeolita NaA pura. 
experiencias de síntesis para tomar muestras a tiempo cortos con el fin de estudiar la evolución desde los primeros ordenamientos hasta llegar al producto final. Los ensayos se realizaron en las mismas condiciones que el ensayo 4015, registrándose la transformación en zeolita NaA por medio de diferentes técnicas de caracterización. El resumen de las muestras se detalla en la Tabla 4.6.

\subsubsection{Caracterización de las estructuras cristalinas}

Para determinar las diversas fases cristalinas obtenidas para los tiempos de síntesis indicados en la Tabla 4.6., se analizaron los difractoframas de las muestras 4090-1, 4090-3, 4090-4 y 4090-F (Fig. 4.14.)

El material de partida, es decir, la muestra 4090-1, fue la tomada del reactor en el tiempo cero. Esta muestra contiene $\mathrm{NaAlSiO}_{4}$, cristalizado mayormente como nefelina, además de una fracción amorfa enriquecida en silicio.

En las condiciones de ensayo de la muestra 4090-3, se observaron pequeños picos a $2 \theta=10,1^{\circ}$ y $12,4^{\circ}$ los cuales podrían atribuirse a la zeolita A, que resultó ser el componente principal de las muestras 4090-4 y 4090-F. La muestra 4090-4 presentó únicamente zeolita $A$ y una pequeña fracción de compuesto amorfo $(26 \%)$, similar a la observada en el material inicial $(27 \%)$.

La muestra 4090-F fue la que presentó la menor cantidad de sólido amorfo $(22 \%)$ y la que mostró la mayor cantidad de zeolita A; aun así, podría suponerse la presencia de pequeñas cantidades de hidroxisodalita, cuya fórmula es: $\mathrm{Na}_{6} \mathrm{Al}_{6} \mathrm{Si}_{6} \mathrm{O}_{24} \mathrm{Na}_{2}(\mathrm{OH})_{2}\left(\mathrm{H}_{2} \mathrm{O}_{2}\right)$, debido a la 
Capítulo IV - Influencia de la modificación de diferentes parámetros de síntesis sobre la evolución de la reacción de cristalización

Tabla 4.6. Clasificación de las muestras.

\begin{tabular}{|l|c|}
\hline Muestra & Tiempo de síntesis \\
\hline $\mathbf{4 0 9 0 - 0}$ & $\begin{array}{c}\text { Catalizador FCC } \\
\text { agotado }\end{array}$ \\
\hline $\mathbf{4 0 9 0 - 1}$ & 0 min \\
\hline $\mathbf{4 0 9 0 - 3}$ & 15 min \\
\hline $\mathbf{4 0 9 0 - 4}$ & 30 min \\
\hline $\mathbf{4 0 9 0 - 1 6}$ & $5 \mathrm{~h}$ \\
\hline $\mathbf{4 0 9 0 - F}$ & $6 \mathrm{~h}$ (Final) \\
\hline
\end{tabular}

Síntesis y potenciales aplicaciones tecnológicas de materiales zeolíticos obtenidos a partir de catalizadores FCC agotados 123 
Capítulo IV - Influencia de la modificación de diferentes parámetros de síntesis sobre la evolución de la reacción de cristalización

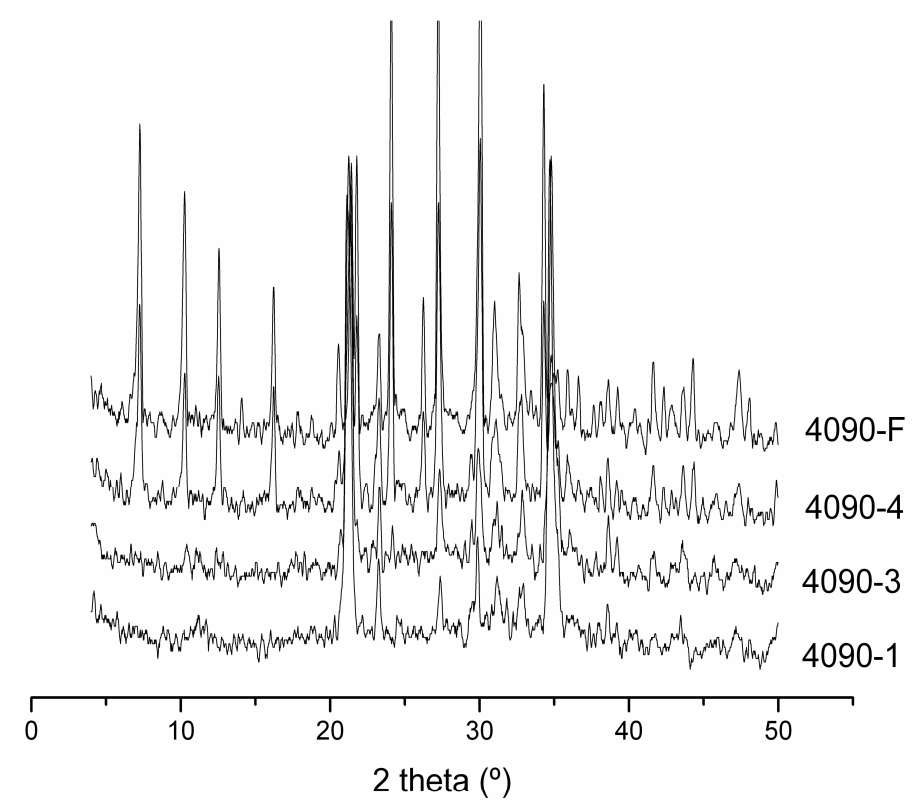

Figura 4.14. Difractogramas de rayos $X$ de las muestras 4090-1, 4090-3, 4090-4 y 4090-F.

Síntesis y potenciales aplicaciones tecnológicas de materiales zeolíticos obtenidos a partir de catalizadores FCC agotados 124 
presencia de picos de baja intensidad observados a $2 \theta=14^{\circ}$ y $35^{\circ}$, menos de un $4 \%$, aproximadamente.

En el espectro correspondiente a la Fig. 4.14. se puede observar que a medida que aumenta el tiempo de reacción se produce un incremento en las intensidades de los picos característicos de la zeolita tipo NaA. Paralelamente, con el incremento del tiempo se produjo una disminución en los picos que corresponden a la especie cristalina conocida como nefelina.

\subsubsection{Determinación de las estructuras presentes a través del estudio de las distancias interatómicas}

La función de distribución radial de las muestras 4090-1 y 4090-3, Fig. 4.15., presentan un primer pico en $r=1,6 \AA$ y un segundo pico en $r=$ $3,1 \AA$. El primer pico se puede atribuir a las distancias interatómicas ( $\mathrm{Si}$, Al) -O (en nuestras condiciones, las distancias $\mathrm{Si}-\mathrm{O}=1,6 \AA$ y $\mathrm{Al}-\mathrm{O}=1,75$ $\AA$ no pueden resolverse) y el segundo a las distancias ( $\mathrm{Si}, \mathrm{Al})$-( $\mathrm{Si}, \mathrm{Al}$ ) [35]. Este segundo pico presenta un hombro en $r=2,7 \AA$ que podría corresponder a la distancia O-O y/o Na-O. El pico en $r=4,05 \AA$ es debido a la distancia interatómica entre $(\mathrm{Si}, \mathrm{Al})$ y $\mathrm{O}$ como segundos vecinos. Al comparar las distribuciones radiales de las muestras 4090-3 y 4090-4, las diferencias son claras: uno contiene $\mathrm{NaAlSiO}_{4}$ como el componente principal y el otro está compuesto por zeolita $\mathrm{NaA}$.

El primer pico del diagrama correspondiente a la muestra 4090-4 se encuentra en $r=1,75 \AA$; el corrimiento de este pico hacia valores más altos se puede correlacionar con la presencia de aluminio en coordinación tetraédrica. El valor obtenido de acuerdo con el resultado teórico ya ha sido informado en la bibliografía [6, 7]. El siguiente pico se encuentra en $r$ $=3,5 \AA$ (4090-4) y, como en las otras muestras, corresponde a una 
distancia ( $\mathrm{Si}, \mathrm{Al})-(\mathrm{Si}, \mathrm{Al})$. El pico que aparece a $4,95 \AA$, probablemente representa la distancia ( $\mathrm{Si}, \mathrm{Al})-\mathrm{O}$ (segundos vecinos).

La función de distribución radial de la muestra 4090-F reproduce las características de la muestra 4090-4. Las funciones de distribución radial corresponden a toda la muestra; por lo tanto, incluye las distancias interatómicas de todos los compuestos presentes en cada material.

Teniendo en cuenta los primeros picos de la función de distribución radial: distancias ( $\mathrm{Si}, \mathrm{Al})-\mathrm{O}$ y ( $\mathrm{Al}, \mathrm{Si})-(\mathrm{Si}, \mathrm{Al})$, Tabla 4.7., se puede evaluar el ángulo entre los tetraedros ( $\mathrm{Si}, \mathrm{Al}$ ), como se muestra en la Fig. 4.16. Por simplicidad, en esta figura el átomo central del tetraedro está etiquetada como Si pero corresponde al Si o Al. Por supuesto que el enlace Al-Al es prohibido por la regla de Lowenstein [2].

En las muestras 4090-1 y 4090-3 el ángulo resulta ser 176 y en muestras 4090-4 y 4090-F es $180 \stackrel{\circ}{\circ}$. Por lo tanto, los tetraedros de oxígeno se reorganizaron hasta que se convierten en lineales, como se espera en una estructura cúbica (zeolita $\mathrm{NaA}$ ).

Se debe tener en cuenta que si el ángulo se calcula para la distancia $(\mathrm{Si}, \mathrm{Al})-(\mathrm{Si}, \mathrm{Al})=2,7 \AA$ (el hombro en la función de distribución

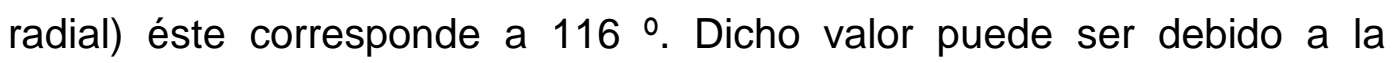
presencia de la red atómica del compuesto no cristalino observado en los difractoframas obtenidos.

Las distancias interatómicas obtenidas están en concordancia con los valores ya reportados para la nefelina [8]; los ángulos medidos entre los tetraedros en la zeolita $\mathrm{NaA}$, muestra 4090-F, sin embargo, difieren de los de Tait [9] (155,2-156,9 $\stackrel{\circ}{)}$. 
Capítulo IV - Influencia de la modificación de diferentes parámetros de síntesis sobre la evolución de la reacción de cristalización

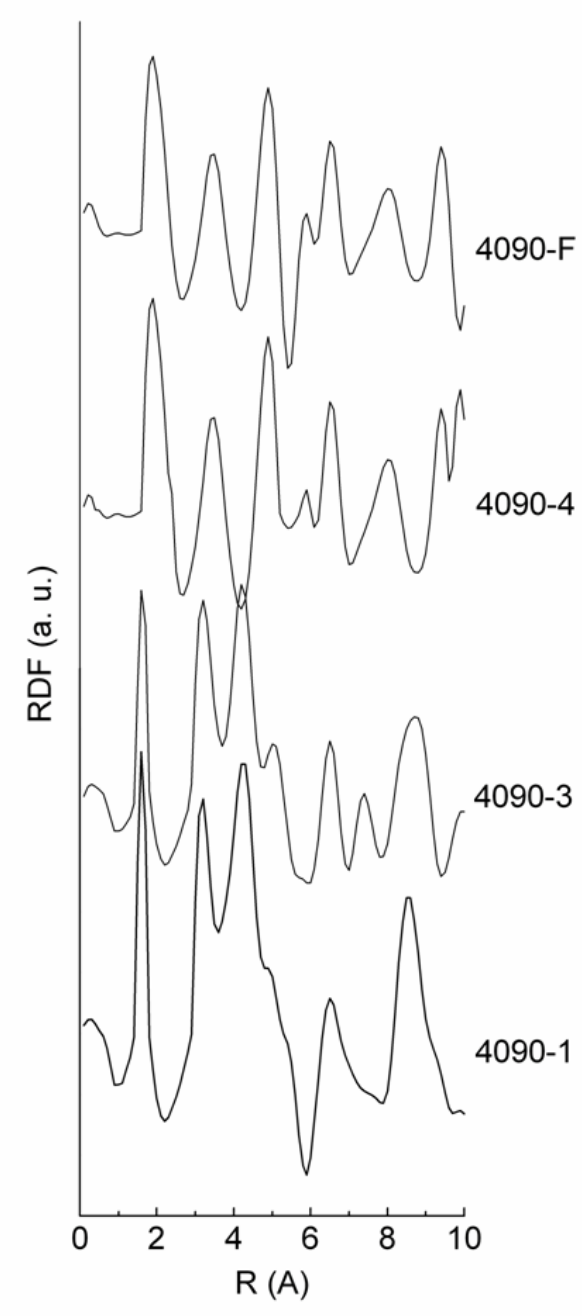

Figura 4.15. Funciones de distribución radial de muestras 4090-1, 4090-3, 4090-4 y 4090-F.

Síntesis y potenciales aplicaciones tecnológicas de materiales zeolíticos obtenidos a partir de catalizadores FCC agotados 127 
Tabla 4.7. Resultados de difracción de rayos $X$, correlación entre las distancias interatómicas y los compuestos identificados $(\mathrm{Nef}=$ nefelina $\mathrm{o}$

$$
\text { ZA = Zeolita A). }
$$

\begin{tabular}{|c|c|c|c|c|c|c|}
\hline \multirow[b]{2}{*}{ Muestra } & \multirow[b]{2}{*}{$\begin{array}{c}\text { Fases } \\
\text { presentes }\end{array}$} & \multicolumn{5}{|c|}{ Función de distribución radial } \\
\hline & & $\begin{array}{c}\text { Primer } \\
\text { pico } \\
(\mathrm{Si}, \mathrm{Al})- \\
0\end{array}$ & $\begin{array}{c}\text { Hombro } \\
\text { O-O o } \\
\text { (Si, Al)- } \\
\text { (Si,AL) }\end{array}$ & $\begin{array}{c}\text { Segund } \\
\text { o pico } \\
(\mathrm{Si}, \mathrm{Al})- \\
(\mathrm{Si}, \mathrm{Al})\end{array}$ & $\begin{array}{c}\text { Tercer } \\
\text { pico } \\
\text { (Si,Al)- } \\
0\end{array}$ & $\begin{array}{c}\text { Ángulo } \\
\text { (Si,Al)- } \\
\text { O- } \\
(\mathrm{Si}, \mathrm{Al})\end{array}$ \\
\hline $4090-1$ & Nef. & $1,6 \AA$ & $2,7 \AA$ & $3,1 \AA$ & $4,05 \AA$ & $176^{\circ}$ \\
\hline $4090-3$ & $\begin{array}{l}\text { Nef. } \\
+Z A^{*}\end{array}$ & $1,6 \AA$ & $2,7 \AA$ & $3,1 \AA$ & $4,05 \AA$ & $176^{\circ}$ \\
\hline $4090-4$ & $\mathrm{ZA}$ & $1,75 \AA$ & - & $3,5 \AA$ & $4,95 \AA$ & $180^{\circ}$ \\
\hline $4090-F$ & $\mathrm{ZA}$ & $1,75 \AA$ & - & $3,5 \AA$ & $4,95 \AA$ & $180^{\circ}$ \\
\hline
\end{tabular}

* pequeñas cantidades 
Capítulo IV - Influencia de la modificación de diferentes parámetros de síntesis sobre la evolución de la reacción de cristalización

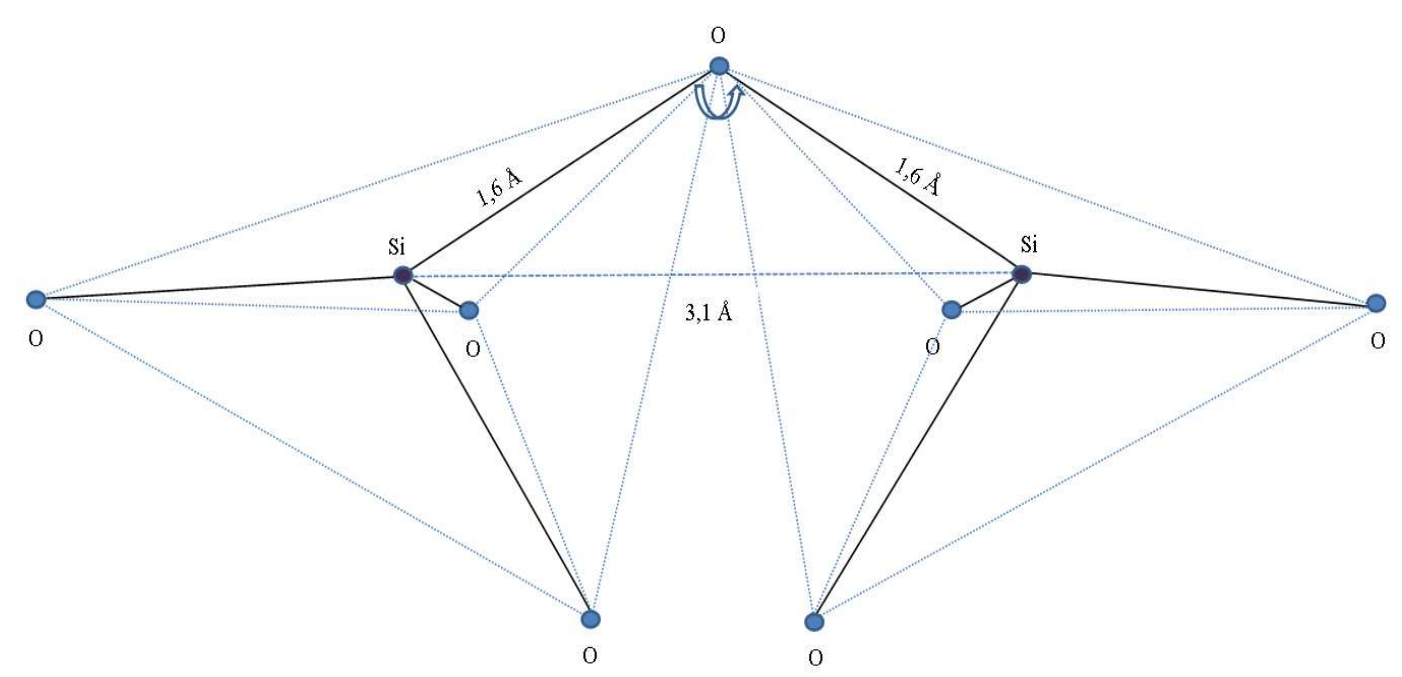

Figura 4.16. Ángulo entre tetraedros $(\mathrm{Si}, \mathrm{Al})-\mathrm{O}_{4}$ en muestras 4090-1 y 4090-3 cuya distancia ( $\mathrm{Si}, \mathrm{Al}$ ) - (Al, Si) es 3,1 $\mathrm{A}$.

Síntesis y potenciales aplicaciones tecnológicas de materiales zeolíticos obtenidos a partir de catalizadores FCC agotados 129 


\subsubsection{Determinación de las fases presentes a través del estudio de la coordinación atómica por Resonancia Magnética Nuclear}

El espectro ${ }^{29} \mathrm{Si}-\mathrm{MAS}$ de la muestra 4090-0 exhibió un pico amplio con dos máximos, el más intenso observado a -83 ppm, atribuido a la especie Si(4AI), y el máximo a -89 ppm, correspondiente a las especies $\mathrm{Si}$ (3Al) y Si (4Al) como se detalla en la Tabla 4.8. [10,11]. Cabe mencionar que la zeolita $A$ se caracteriza por un pico intenso a $-89 \mathrm{ppm}$. El máximo situado a -83 ppm disminuye con el tiempo de reacción hasta una intensidad relativa de $12 \%$ en la muestra $4090-\mathrm{F}$. Este pico de $\mathrm{Si}(4 \mathrm{Al})$ puede atribuirse a la zeolita $Y$ inicial, a la nefelina o a la zeolita NaA. En cambio, el pico a -89 ppm, correspondiente al $\mathrm{Si}(4 \mathrm{Al})$ asignado a la zeolita Y en la muestra 4090-0, de acuerdo a trabajos anteriores [12-15] , puede asociarse a la presencia de nefelina en muestra 4090-3 y a la zeolita A en muestras 4090-4 y 4090-F, ya que aumenta con el tiempo de síntesis. En las muestras 4090-1 y 4090-3 la gran amplitud de este pico revela una amplia gama de ambientes debido a las distorsiones de los ángulos de enlace de Si-O-Si (Al). En las muestras 4090-4 y 4090-F, el pico a -89 ppm asignado a la especie $\mathrm{Si}(4 \mathrm{Al})$ se intensificó y estrechó significativamente, reflejando el aumento del tamaño de los cristales de zeolita así como una mayor cristalinidad [13, 15-16]. El espectro de ${ }^{29} \mathrm{Si}-$ MAS de la muestra 4090-F se presenta en la Fig. 4.17.

Los espectros de ${ }^{27} \mathrm{Al}$-MAS complementan y corroboran los resultados de ${ }^{29} \mathrm{Si}-\mathrm{MAS}$. El espectro de ${ }^{27} \mathrm{Al}$ del catalizador FCC agotado, muestra 4090-0, mostró un máximo muy intenso a 59 ppm atribuido a una especie de aluminio de cuatro enlaces coordinados a átomos de silicio a través de puentes de oxígeno, $\mathrm{Al}(\mathrm{O}-\mathrm{Si})_{4}$, cuyo desplazamiento químico es característico del aluminio en zeolita $Y$ [16].

Síntesis y potenciales aplicaciones tecnológicas de materiales zeolíticos obtenidos a partir de catalizadores FCC agotados 130 
Capítulo IV - Influencia de la modificación de diferentes parámetros de síntesis sobre la evolución de la reacción de cristalización

Tabla 4.8. Picos característicos de NMR en ppm correspondientes a la nefelina $\left({ }^{*}\right)$, zeolita $\mathrm{A}\left(^{+}\right)$y zeolita $\mathrm{Y}\left({ }^{\circ}\right)$ para ${ }^{29} \mathrm{Si} \mathrm{y}{ }^{27} \mathrm{Al}$.

\begin{tabular}{|c|c|c|c|}
\hline Muestra & $\mathbf{S i ( 4 A l )}$ & $\mathbf{S i}(3 \mathrm{Al}) \mathbf{y ~ S i ( 4 A I )}$ & $\mathbf{A l ( 0 - S i ) _ { 4 }}$ \\
\hline $\mathbf{4 0 9 0 - 0}$ & $-88,9(60 \%)^{\circ}$ & $-83,9(100 \%)^{\circ}$ & $59^{\circ}$ \\
& & & \\
\hline $\mathbf{4 0 9 0 - 1}$ & $-88,9(80 \%)^{*}$ & $-82,5(100 \%)^{*}$ & $59^{*}$ \\
\hline $\mathbf{4 0 9 0 - 3}$ & $-89,3(100 \%)^{+}$ & $-83,2(50 \%)^{*},+$ & $59^{*}$ \\
\hline $\mathbf{4 0 9 0 - 4}$ & $-89,6(100 \%)^{+}$ & $-83,9(12 \%)^{*}{ }^{*}$ & $58^{+}$ \\
& & & \\
\hline $\mathbf{4 0 9 0 - F}$ & $-89,6(100 \%)^{+}$ & $-83,2(12 \%)^{+}$ & $58^{+}$ \\
& & & \\
\hline
\end{tabular}

Síntesis y potenciales aplicaciones tecnológicas de materiales zeolíticos obtenidos a partir de catalizadores FCC agotados 131 
Capítulo IV - Influencia de la modificación de diferentes parámetros de síntesis sobre la evolución de la reacción de cristalización

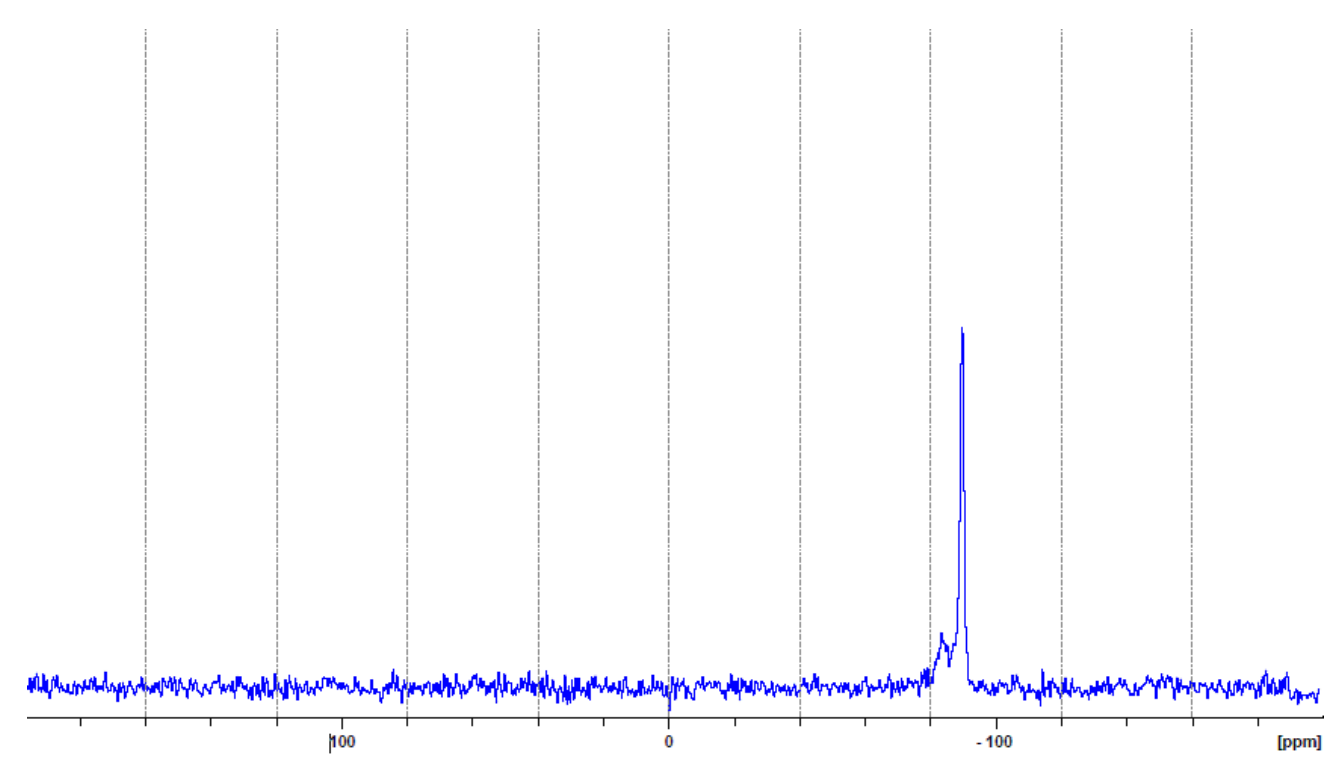

Figura 4.17. Espectro de RMN de ${ }^{29} \mathrm{Si}$ a $5000 \mathrm{~Hz}$, muestra 4090-F.

Síntesis y potenciales aplicaciones tecnológicas de materiales zeolíticos obtenidos a partir de catalizadores FCC agotados 132 
Para las muestras 4090-1 y 4090-3 este pico registrado a 59 ppm también se observó, y se asigna a la presencia de nefelina. En las muestras 4090-4 y 4090-F, el pico se desplazó a 58 ppm, siendo este valor de desplazamiento químico el correspondiente a la zeolita A [17]. El espectro ${ }^{27} \mathrm{Al}-\mathrm{MAS}$ de la muestra $4090-\mathrm{F}$ se presenta en la Fig. 4.18. Los resultados de NMR están en concordancia con los previamente presentados de difracción de rayos $X$, mostrando que la zeolita $\mathrm{NaA}$ aparece a medida que la nefelina desaparece con el tiempo de reacción.

\subsubsection{Determinación de la superficie específica}

La superficie específica de cada una de las muestras se determinó mediante adsorción de agua, Tabla 4.9. La superficie específica del catalizador agotado (4090-0) exhibió un valor de $156 \mathrm{~m}^{2} . \mathrm{g}^{-1}$. En la mencionada tabla, se incluye la muestra 4090-16, que corresponde a un tiempo de reacción de la $5 \mathrm{~h}$.

Al comienzo de la reacción, la superficie específica disminuyó de $202 \mathrm{~m}^{2} \cdot \mathrm{g}^{-1}$ (muestra 4090-1) a $134 \mathrm{~m}^{2} \cdot \mathrm{g}^{-1}$ (muestra 4090-4), aproximadamente un $35 \%$. Esta disminución inicial del área superficial con el tiempo de tratamiento muestra que, o bien la nefelina se descompone primero en un material de baja área superficial, y a continuación se origina la zeolita $\mathrm{NaA}$, o los poros de la zeolita $\mathrm{A}$ formada están ocluidos y no son accesibles al agua. Tales discontinuidades en las características de crecimiento de la zeolita han sido reportados previamente y se han atribuido a un modelo de "nucleación autocatalítica" de la cristalización de la zeolita, también apoyando la hipótesis acerca de la presencia de distribución no homogénea de los núcleos en fase gel [18].

Síntesis y potenciales aplicaciones tecnológicas de materiales zeolíticos obtenidos a partir de catalizadores FCC agotados 133 
Capítulo IV - Influencia de la modificación de diferentes parámetros de síntesis sobre la evolución de la reacción de cristalización

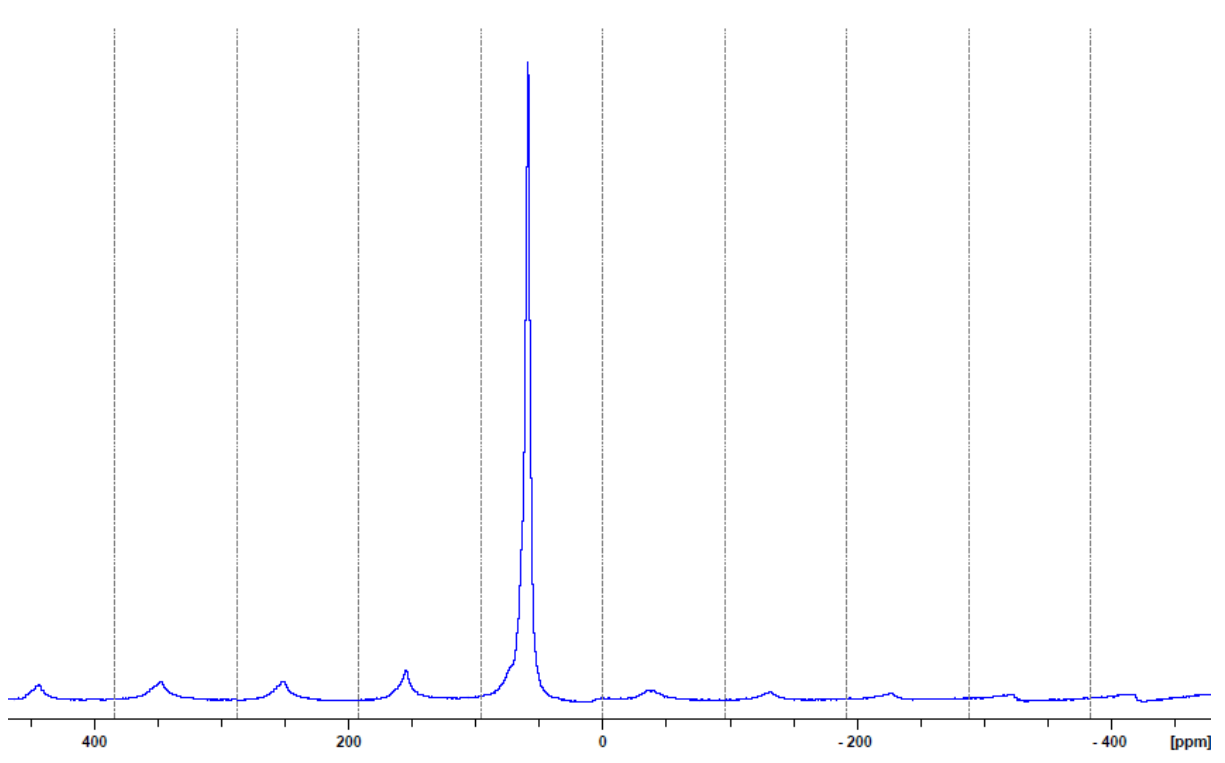

Figura 4.18. Espectro de RMN de ${ }^{27} \mathrm{Al}$ a $10000 \mathrm{~Hz}$, muestra $4090-\mathrm{F}$. 
La superficie específica aumenta regularmente con el tiempo de síntesis. Se incrementó hasta $314 \mathrm{~m}^{2} \cdot \mathrm{g}^{-1}$ (muestra 4090-16) y $681 \mathrm{~m}^{2} \cdot \mathrm{g}^{-1}$ (muestra 4090-F), como se detalla en la Tabla 4.6. Esta técnica marcha claramente los últimos pasos de la cristalización de la zeolita NaA. La nefelina, cuya área superficial es pequeña si se compara con la zeolita $\mathrm{NaA}$, va desapareciendo a medida que se genera la estructura zeolítica.

\subsubsection{Morfología y tamaño de los productos a cortos tiempos de síntesis}

En coherencia con el punto 4.2.3.2., las micrografías muestran claramente que los productos sintetizados bajo la síntesis hidrotérmica mantienen la morfología del catalizador a tiempos cortos de reacción e incluso después de un tiempo de reacción de $6 \mathrm{~h}$.

Luego de $24 \mathrm{~h}$ de reposo a temperatura ambiente, se observó para la muestra 4090-1 que la superficie de las partículas fueron cubiertas por cristales en forma de aguja que se identificaron como nefelina por los resultados de XRD, Fig. 4.19a.

Una magnificación mayor, Fig. 4.19b, permitió observar que los cristales de zeolita $\mathrm{NaA}$, comienzan a crecer en la superficie. A medida que la reacción avanza (muestras 4090-4 y 4090-F), Fig. 4.20., la superficie se cubre cada vez más por cristales de forma cúbica típica de la zeolita $\mathrm{NaA}$. El tamaño medio de los cristales de zeolita $\mathrm{A}$, en la muestra $4090-F$, es de $d=1,2 \mu \mathrm{m}$, la distribución de tamaño es bastante homogénea y no se observan partículas en forma de aguja. 
Capítulo IV - Influencia de la modificación de diferentes parámetros de síntesis sobre la evolución de la reacción de cristalización

Tabla 4.9. Superficie específica medida por adsorción de agua.

\begin{tabular}{|c|c|c|}
\hline Muestra & $\begin{array}{c}\text { Material / tiempo } \\
\text { de reacción }\end{array}$ & $\begin{array}{c}\text { Superficie } \\
\text { específica } \\
\left(m^{2} \cdot g^{-1}\right)\end{array}$ \\
\hline $4090-0$ & $\begin{array}{c}\text { Catalizador } \\
\text { agotado }\end{array}$ & 156 \\
\hline $4090-1$ & $\begin{array}{l}\text { Material inicial } \\
\qquad \operatorname{Tr}=0 \mathrm{~min}\end{array}$ & 202 \\
\hline $4090-3$ & $\mathrm{Tr}=15 \mathrm{~min}$ & -- \\
\hline $4090-4$ & $\mathrm{Tr}=30 \mathrm{~min}$ & 134 \\
\hline $4090-16$ & $\operatorname{Tr}=5 \mathrm{~h}$ & 314 \\
\hline 4090-F & Final & 681 \\
\hline
\end{tabular}

Síntesis y potenciales aplicaciones tecnológicas de materiales zeolíticos obtenidos a partir de catalizadores FCC agotados 136 
Capítulo IV - Influencia de la modificación de diferentes parámetros de síntesis sobre la evolución de la reacción de cristalización

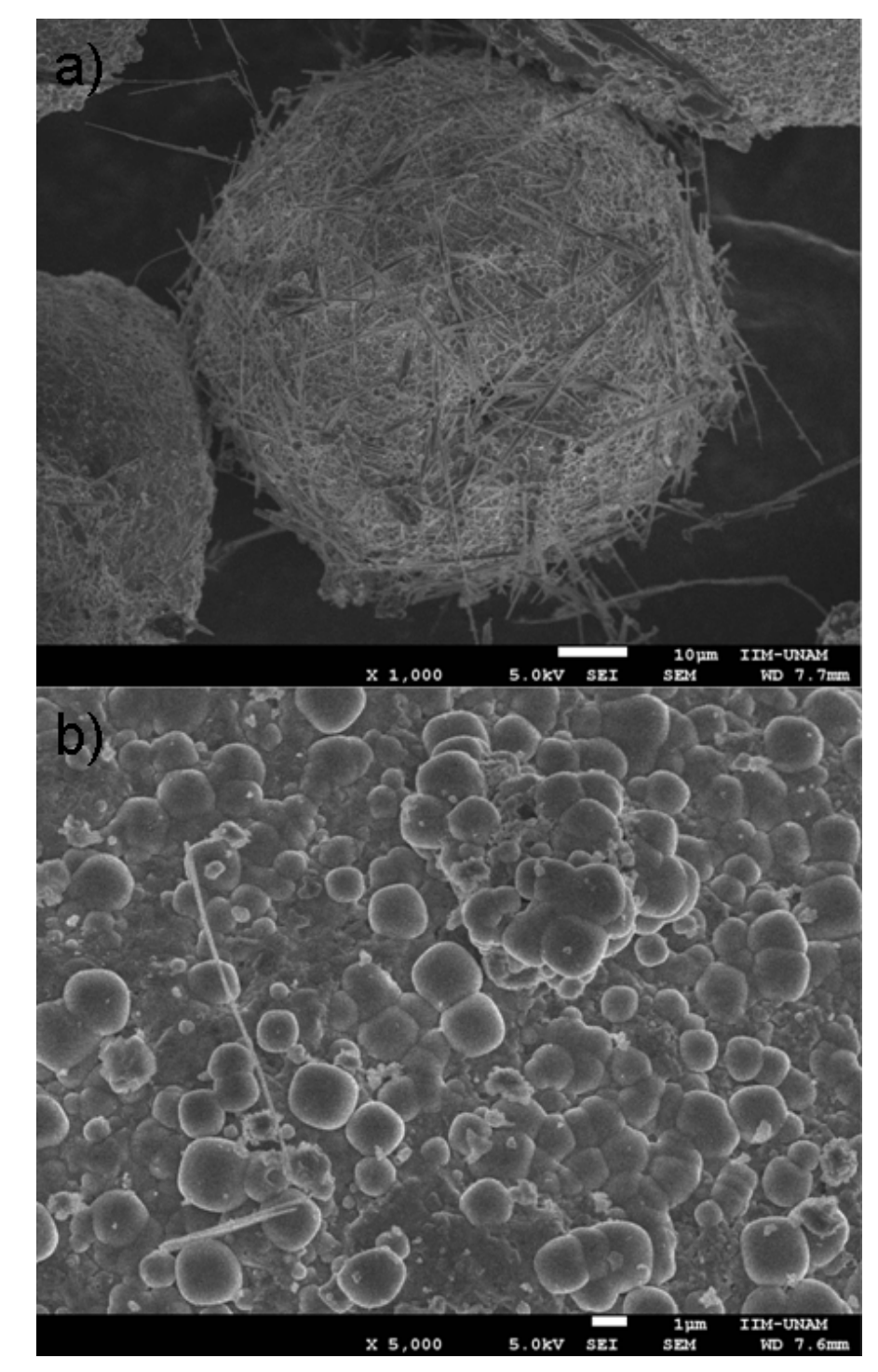

Figura 4.19. Micrografías de las muestras 4090-1. a) magnificación X1000 y b) magnificación X5000.

Síntesis y potenciales aplicaciones tecnológicas de materiales zeolíticos obtenidos a partir de catalizadores FCC agotados 137 
Capítulo IV - Influencia de la modificación de diferentes parámetros de síntesis sobre la evolución de la reacción de cristalización

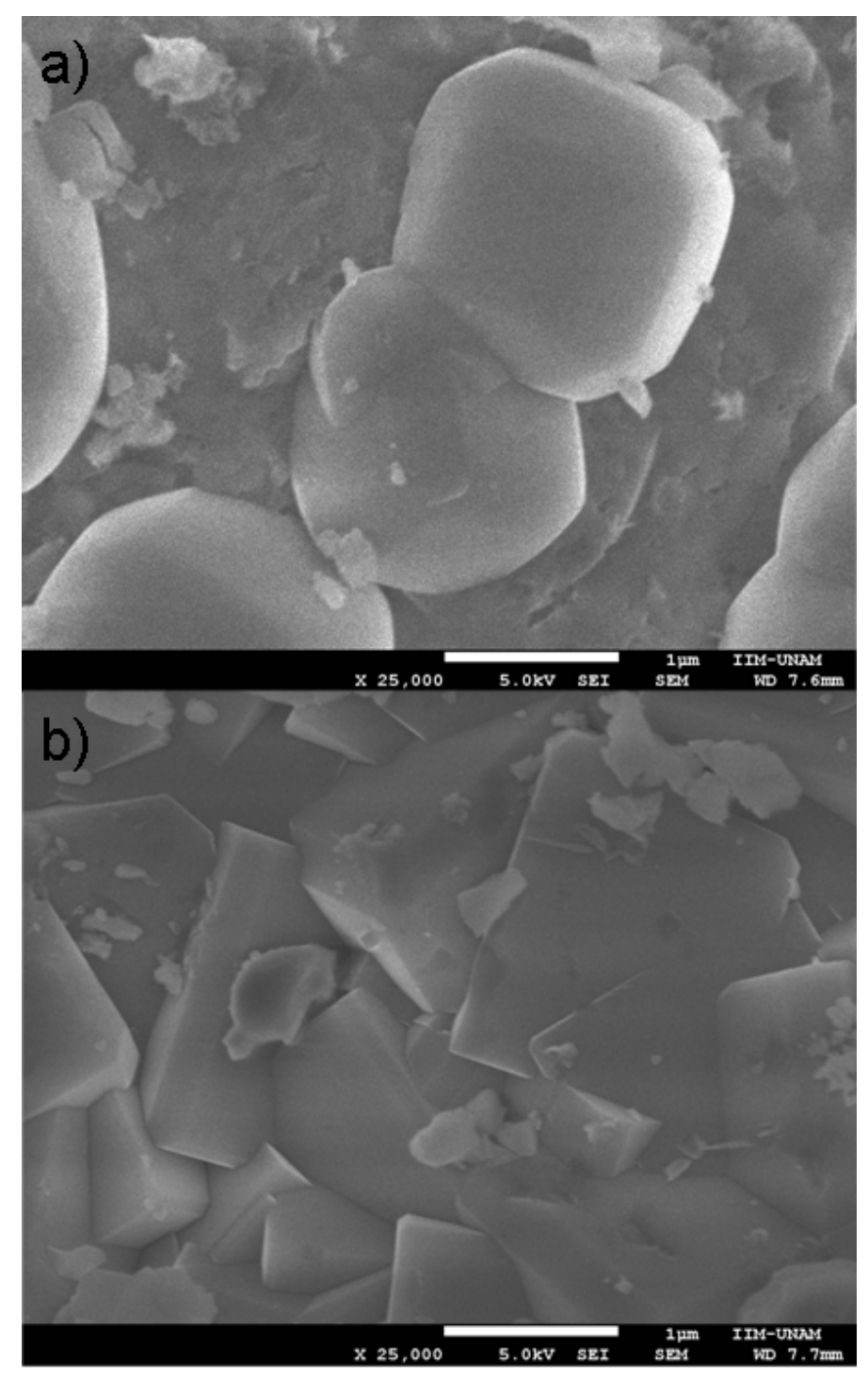

Figura 4.20. Comparación de las micrografías (magnificación X25000) de a) muestra 4090-4 y b) 4090-F.

Síntesis y potenciales aplicaciones tecnológicas de materiales zeolíticos obtenidos a partir de catalizadores FCC agotados 138 
Los cristales de zeolita $\mathrm{NaA}$ emergen desde la superficie, muestras 4090-4 y 4090-F, Fig. 4.20. En la muestra 4090-4 la zeolita NaA presenta dos tamaños de cristal, una más grande que es aproximadamente $d=1,0$ $\mu \mathrm{m}$, y una gran cantidad de pequeños cristales de aproximadamente 0,3 $\mu \mathrm{m}$.

Los resultados hasta aquí, pueden resumirse de la siguiente manera. Macroscópicamente, se observan las partículas de forma esférica completamente recubiertas por zeolita $\mathrm{NaA}$ formadas en un tiempo de reacción tan pequeño como 30 minutos (muestra 4090-4). En esta muestra los bordes de los cristales de zeolita $\mathrm{NaA}$ se encuentran suavizados. Como era de esperar, los cristales de zeolita crecen y llegan a ser cúbicos con bordes afilados a medida que aumenta el tiempo de reacción (muestra 4090-F).

Microscópicamente, la síntesis sigue dos pasos secuenciales. Primero se forma nefelina y a partir de ésta se genera la zeolita A. Además, una pequeña fracción de compuesto amorfo inicialmente presente en el catalizador no reacciona. En el primer paso del proceso global, es decir durante la calcinación del catalizador a $800^{\circ} \mathrm{C}$ en presencia de $\mathrm{Na}_{2} \mathrm{CO}_{3}$, se obtiene nefelina, como ya se ha reportado en otros trabajos previos $[19,20]$. Posteriormente, la transformación de nefelina en zeolita A implica la reordenación de la red hexagonal de nefelina como red cúbica de zeolita $A$. Ambas estructuras presentan una ventana de 8 anillos, siendo el tamaño de ésta de 3,7 x 4,8 $\AA$ en nefelina $y$ de $4,1 \times 4,1$ en la zeolita $A$ [21].

El inicio del proceso de nucleación de la zeolita A está dominado por especies de 4 anillos como lo demuestran los estudios teóricos [22]. Sin embargo, en nuestro caso, la nefelina sintetizada inicialmente ofrece otras unidades iniciales. En esta reacción, la geometría de las ventanas 
de 8 de anillos evoluciona con el tiempo colapsándose la estructura de la nefelina a medida que aparece la zeolita A. Esta transformación sólo puede deberse a las condiciones de síntesis que son una alta hidratación y un valor de $\mathrm{pH}$ muy alto. El colapso de red cristalina se describe comúnmente como una pérdida del orden de largo alcance, que se manifiesta, en funciones de distribución radial, como desaparición de los picos para altos valores de r. En la muestra 4090-1 no se observó esta característica. Por lo tanto, la conversión de nefelina a zeolita $\mathrm{NaA}$ se lleva a cabo por transformación topotáctica directa sólido-sólido. La nefelina deshidratada en presencia de altas cantidades de agua se transforma directamente a baja temperatura en zeolita $\mathrm{NaA}$.

Como ya se ha descrito en párrafos anteriores, la superficie especifica aumentó con el tiempo de reacción en correspondencia con la aparición de zeolita A, con excepción de la muestra 4090-4 cuya área superficial específica resultó aproximadamente $33 \%$ más baja que la del material de partida. Esta reducción podría explicarse en base al mecanismo de cristalización propuesto. Al producirse la transformación topotáctica de nefelina en zeolita, una fracción de la superficie total se torna inaccesible para la adsorción de agua, ya que tanto los cristales de zeolita A como la fase nefelina se cubren con una capa nanométrica de un compuesto amorfo no observable por microscopía electrónica de barrido, registrándose así una disminución del área adsorbente. 
Capítulo IV - Influencia de la modificación de diferentes parámetros de síntesis sobre la evolución de la reacción de cristalización

\subsection{Referencias}

[1] Basaldella. E.I., Torres Sanchez, R.M., Conconi, M.S. (2009) Appl. Clay Sci. 42, 611.

[2] Breck. D.W. (1974) Zeolite Molecular Sieves. Wiley, New York.

[3] Klug H.P., Alexander L.E. (1954) X-Ray Diffraction Procedures, Wiley, New York, U.S.A.

[4] Gutiérrez, G. (2002) Revista Mexicana de Física 3, 60.

[5] Song, M.K, Chon, H. (1993) Bull. Korean Chem. Soc. 14, 255.

[6] Leonard, A.J., Ratnasamy P., Declerck D., Fripiat J.J. (1971) Discuss. Faraday Soc. 52, 98.

[7] Aguilar-Pliego, J., Bosch, P., Zicovich-Wilson, C., Herrera-Pérez, G., Lara, V.H. (2012) Open Catalysis Journal, 5, 50.

[8] Dimitrijevic, R., Dondur, V., Vulic, P., Markovic, S., Macura, S. (2004) J. Phys. Chem. Solids 65, 1623.

[9] Tait K.T., Sokolova E., Hawthorne F.C., Khomyakov A.P. (2003) Can. Mineral. 41, 61.

[10] Engelhardt G., Fahlke B., Mägi M., Lippmaa E. (1983) Zeolites, 3, 292.

[11] Stöker M. (1996) Stud. Surf. Sci. Catal., 102, 141.

[12] Basaldella, E.I., Paladino, J.C., Solari, M., Valle, G.M. (2006) Appl. Catal., B 66, 186.

[13] Shi, J., Anderson M.W. (1996) Chem. Mater. 8, 369.

[14] Radulovic, A., Dondur, V., Vulic, P., Miladinovic, Z., Ciric-Marjanovic, G., Dimitrijevic, R. (2013) J. Phys. Chem. Solids 74, 1212.

[15] Tabernero, V., Camejo, C., Terreros, P., Alba, M.D., Cuenca, T. (2010) Materials 3, 1015.

[16] Engelhardt, G., Michel, D., (1987) John Wiley \& Sons, Norwich, U.K.

[17] Freude, D., Fröhlich, T., Pfeifer, H., Scheler, G. (1983). Zeolites 3, 171. 
Capítulo IV - Influencia de la modificación de diferentes parámetros de síntesis sobre la evolución de la reacción de cristalización

[18] Miladinovic, Z., Zakrzewska, J., Kovacevic, B., Bacic, G. (2007) Mater. Chem. 104, 384.

[19] Ohgushi, T., Ishimaru, K. (2001). J. Am. Ceram. Soc. 84, 321.

[20] Dondur, V., Vulic, P., Markovic, S., Macura, S. (2004) J. Phys. Chem. Solids 65, 1623.

[21] Baerlocher, Ch., McCusker, L.B., Olson D.H. (2007) Atlas of zeolite framework types, 6th revised edition. IZA-SC Publications, Elsevier, Amsterdam, Holland.

[22] Yang, C.S., Mora-Fonz, J.M., Catlow, C.R.A. (2013). Phys. Chem. C117, 24796. 


\section{CAPÍTULO $v$}

\section{PROCESOS DE INTERCAMBIO CATIÓNICO. ESTUDIO DE LA CINÉTICA DE SORCIÓN DE Cr(III)}




\section{PROCESOS DE INTERCAMBIO CATIÓNICO. ESTUDIO DE LA CINÉTICA DE SORCIÓN DE CR(III)}

En este capítulo se analizan y discuten los resultados obtenidos en las reacciones de intercambio catiónico realizadas. También se evalúa la incidencia de la incorporación de $\mathrm{Cr}$ (III) en el material sintetizado mediante las técnicas de XRD, SEM, FT-IR y PZC. Adicionalmente, se estudia el comportamiento cinético de la retención de $\mathrm{Cr}$ (III) en los materiales sintetizados, comparando el comportamiento de estos nuevos sólidos con el de una zeolita NaA pura.

\subsection{Intercambio catiónico con $\mathrm{Cr}(\mathrm{III})$}

\subsubsection{Determinación de la capacidad de intercambio del catalizador zeolitizado}

Los ensayos realizados en sistemas tipo batch (discontinuo) fueron diseñados para poder estudiar la cinética del proceso de retención de $\mathrm{Cr}$ (III) y evaluar la capacidad de intercambio catiónico del producto zeolítico obtenido a partir del catalizador FCC agotado. Se emplearon como variables el tiempo de sorción y la temperatura del proceso.

Como ya se ha mencionado, los intercambios catiónicos se realizaron con soluciones cuyas concentraciones de $\operatorname{Cr}$ (III) fueron $\sim 42$ mg. $\mathrm{L}^{-1}$ y $\sim 135 \mathrm{mg} \cdot \mathrm{L}^{-1}$. Los ensayos consistieron en adicionar a $1 \mathrm{~L}$ de solución 1 ó $3 \mathrm{~g}$ de material zeolítico obtenido. Para la realización de estos experimentos se sintetizó previamente una muestra usando la composición inicial de la mezcla utilizada para obtener la muestra 4015, dado que ésta fue la que presentó mayor conversión en zeolita $\mathrm{NaA}$. A esta muestra zeolítica obtenida se la denominó 4090. La concentración de 
$\mathrm{Cr}$ (III) en la solución se determinó por AA. También se realizaron ensayos de referencia con una zeolita $A$ pura sintetizada en nuestro laboratorio. Ambos ensayos, según se explicó en 3.3., fueron realizados a dos temperaturas diferentes, tomando muestras de la mezcla a diferentes tiempos de reacción.

Las Tabla 5.1. y 5.2. muestran la evolución de la concentración de Cr(III) empleando la muestra 4090; en las Tabla 5.3. y 5.4. se detallan los resultados del intercambio catiónico empleando la zeolita $\mathrm{NaA}$ de referencia.

Para el caso de las experiencias realizadas a $25^{\circ} \mathrm{C}$, utilizando la

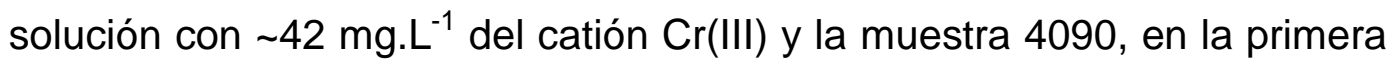
y segunda columna de la Tabla 5.1. se detalla la evolución de la concentración del catión en la fase liquida para los experimentos realizados con $1 \mathrm{~g} \mathrm{y} 3 \mathrm{~g}$ de sólido respectivamente (ensayos 5000 y 5001). En las columnas tercera y cuarta se detallan las concentraciones para $1 \mathrm{~g}$ y $3 \mathrm{~g}$ a $50 \stackrel{\circ}{ } \mathrm{C}$ (ensayos 5003 y 5004 ). Trabajando a temperatura constante de $25 \stackrel{\circ}{\circ}$, se observa que la sorción de $\mathrm{Cr}$ (III) se produce en forma más rápida y efectiva al aumentar la cantidad de zeolita. Al emplear $3 \mathrm{~g}$ se observa que a los 20 min el $\mathrm{Cr}$ (III) desaparece de la solución, ya no se detecta por medidas de espectroscopía de absorción atómica. Cuando se duplica la temperatura, se observa un incremento de la velocidad del proceso de intercambio, llegando a captar casi la totalidad del $\mathrm{Cr}$ (III) en la solución tanto cuando se usa $1 \mathrm{~g}$ ó $3 \mathrm{~g}$ (ensayo 5003 y 5004). Por otra parte, al emplear la zeolita $\mathrm{NaA}$ pura se observan resultados similares, y si se comparan los datos de la Tabla 5.3. de las columnas correspondientes a distintas temperaturas para tiempos semejantes, se detecta un leve incremento en los valores de retención. Comparando los resultados de las Tablas 5.1. y 5.2. con los de las Tablas 5.3. y 5.4., se observan las mismas tendencias, y valores mayores de retención para 
$\mathrm{NaA}$, datos esperados debido a la mayor pureza de este material, ya que la muestra 4090 contiene un $75 \%$ de zeolita.

Para el caso de las muestras que están en contacto con 135 mg. $\mathrm{L}^{-1}$, se observa que a $25 \stackrel{\circ}{\circ} \mathrm{C}$ la zeolita $\mathrm{NaA}$ presenta una mayor captación de $\mathrm{Cr}$ (III) con respecto a la muestra 4090. Al aumentar la temperatura, la sorción de $\mathrm{Cr}$ (III) para la muestra 4090 aumenta considerablemente llegando a intercambiar casi la totalidad del $\mathrm{Cr}$ (III) en la solución.

En todos los casos la concentración a los 150 min es similar a la concentración detectada a las $24 \mathrm{~h}$, por lo tanto podemos considerar que a los 150 min se ha llegado al equilibrio.

Se puede concluir de estas experiencias que la retención de cromo es tan efectiva como la que se presenta en una zeolita pura, por lo cual el material zeolitizado que se ensayó presenta alta eficiencia y puede ser usado para este tipo de proceso.

\subsection{Influencia de la sorción de $\mathrm{Cr}$ (III) sobre las propiedades del catalizador zeolitizado}

Los estudios se basaron en evaluar si la incorporación de $\mathrm{Cr}$ (III) en el material sintetizado a partir del catalizador, produce cambios en las propiedades del producto original. Para ello, se evaluó el catalizador zeolitizado antes y después del intercambio con $\mathrm{Cr}$ (III) a través de las técnicas de XRD, SEM, FT-IR y PZC. 
Tabla 5.1. Valores de la concentración de $\operatorname{Cr}(\mathrm{III})\left(\mathrm{mg} \cdot \mathrm{L}^{-1}\right)$ en la fase líquida de intercambio usando $1 \mathrm{~g}$ ó $3 \mathrm{~g}$ de la muestra 4090 a $\mathrm{T}=25 \stackrel{\circ}{ } \mathrm{C}$ y $\mathrm{T}=50 \stackrel{\circ}{\circ} \mathrm{C}$ para una concentración inicial de $\sim 42 \mathrm{mg} . \mathrm{L}^{-1}$.

\begin{tabular}{|c|c|c|c|c|}
\hline Ensayo $\mathrm{N}^{\circ}$ & 5000 & 5001 & 5003 & 5004 \\
\hline $\begin{array}{l}\text { Tiempo } \\
\text { (min) } \downarrow\end{array}$ & $\begin{array}{c}\mathrm{Cr}(\mathrm{III}) \\
\left(\mathrm{mg} \cdot \mathrm{L}^{-1}\right) \\
\left(\text { a } 25^{\circ} \mathrm{C}\right)\end{array}$ & $\begin{array}{c}\mathrm{Cr}(\mathrm{III}) \\
\left(\mathrm{mg} \cdot \mathrm{L}^{-1}\right) \\
\left(\text { a } 25^{\circ} \mathrm{C}\right)\end{array}$ & $\begin{array}{c}\mathrm{Cr}(\mathrm{III}) \\
\left(\mathrm{mg}^{-\mathrm{L}^{-1}}\right) \\
\left(\mathrm{a} 50^{\circ} \mathrm{C}\right)\end{array}$ & $\begin{array}{c}\mathrm{Cr}(\mathrm{III}) \\
\left(\mathrm{mg}^{-\mathrm{L}^{-1}}\right) \\
\left(\mathrm{a} 50^{\circ} \mathrm{O}\right)\end{array}$ \\
\hline 0 & 43,9 & 43,5 & 42 & 37 \\
\hline 1 & 38,9 & 15,2 & 31 & 13,6 \\
\hline 5 & 36,5 & 10,9 & 26 & 4,8 \\
\hline 20 & 30,4 & 0,22 & 18 & 1,5 \\
\hline 60 & 27,2 & 0,1 & 4,81 & 1,5 \\
\hline 120 & 21 & 0,07 & 0,15 & 0,22 \\
\hline 150 & 18 & 0,04 & 0,03 & 0,15 \\
\hline 24 horas & 15 & 0,04 & 0,06 & 0,14 \\
\hline
\end{tabular}


Capítulo V-Procesos de intercambio catiónico. Estudio de la cinética de sorción de $\mathrm{Cr}$ (III)

Tabla 5.2. Valores de la concentración de $\operatorname{Cr}(\mathrm{III})\left(\mathrm{mg} \cdot \mathrm{L}^{-1}\right)$ en la fase líquida de intercambio usando $3 \mathrm{~g}$ de la muestra 4090 a $\mathrm{T}=25^{\circ} \mathrm{O}$ y $\mathrm{T}=$ $50 \stackrel{\circ}{\circ}$ para una concentración inicial de $\sim 135 \mathrm{~g} \cdot \mathrm{mL}^{-1}$.

\begin{tabular}{|c|c|c|}
\hline Ensayo $\mathbf{N}^{\circ}$ & 5002 & 5005 \\
\hline $\begin{array}{l}\text { Tiempo } \\
\text { (min) } \downarrow\end{array}$ & $\begin{array}{c}\mathrm{Cr}(\mathrm{III}) \\
\left(\mathrm{mg} \cdot \mathrm{L}^{-1}\right) \\
\left(\text { a } 25{ }^{\circ} \mathrm{C}\right)\end{array}$ & $\begin{array}{c}\mathrm{Cr}(\mathrm{III}) \\
\left(\mathrm{mg}^{-\mathrm{L}^{-1}}\right) \\
\left(\mathrm{a} 50^{\circ} \mathrm{o}\right)\end{array}$ \\
\hline 0 & 115 & 138 \\
\hline 1 & 102 & 128 \\
\hline 5 & 101 & 108 \\
\hline 20 & 90 & 87 \\
\hline 60 & 83 & 16 \\
\hline 120 & 80 & 11 \\
\hline 150 & 72 & 6,6 \\
\hline 24 horas & 68 & 4,5 \\
\hline
\end{tabular}

Síntesis y potenciales aplicaciones tecnológicas de materiales zeolíticos obtenidos a partir de catalizadores FCC agotados 148 
Capítulo V-Procesos de intercambio catiónico. Estudio de la cinética de sorción de $\mathrm{Cr}$ (III)

Tabla 5.3. Valores de la concentración de $\operatorname{Cr}(\mathrm{III})\left(\mathrm{mg} \cdot \mathrm{L}^{-1}\right)$ en la fase líquida de intercambio usando $1 \mathrm{~g}$ ó $3 \mathrm{~g}$ de la zeolita $\mathrm{NaA}$ a $\mathrm{T}=25 \stackrel{\circ}{\circ} \mathrm{C}$ y $\mathrm{T}=50 \stackrel{\circ}{\mathrm{C}}$ para una concentración inicial de $\sim 42 \mathrm{mg} \cdot \mathrm{L}^{-1}$.

\begin{tabular}{|c|c|c|c|c|}
\hline Ensayo $\mathrm{N}^{\circ}$ & 5006 & 5007 & 5009 & 5010 \\
\hline $\begin{array}{c}\text { Tiempo } \\
\text { (min) } \downarrow\end{array}$ & $\begin{array}{c}\mathrm{Cr}(\mathrm{III}) \\
\left(\mathrm{mg} \cdot \mathrm{L}^{-1}\right) \\
\left(\mathrm{a} 25^{\circ} \mathrm{C}\right)\end{array}$ & $\begin{array}{c}\mathrm{Cr}(\mathrm{III}) \\
\left(\mathrm{mg} \cdot \mathrm{L}^{-1}\right) \\
\left(\mathrm{a} 25{ }^{\circ} \mathrm{C}\right)\end{array}$ & $\begin{array}{c}\mathrm{Cr}(\mathrm{III}) \\
\left(\mathrm{mg} \cdot \mathrm{L}^{-1}\right) \\
\left(\mathrm{a} 50^{\circ} \mathrm{C}\right)\end{array}$ & $\begin{array}{c}\mathrm{Cr}(\mathrm{III}) \\
\left(\mathrm{mg} \cdot \mathrm{L}^{-1}\right) \\
\left(\mathrm{a} 50^{\circ} \mathrm{O}\right)\end{array}$ \\
\hline 0 & 41 & 38,83 & 36 & 39,8 \\
\hline 1 & 26,3 & 1,98 & 17,99 & 6,2 \\
\hline 5 & 19,3 & 0,57 & 6,96 & 2,4 \\
\hline 20 & 15,3 & 0,13 & 0,52 & 0 \\
\hline 60 & 10,3 & 0 & 0,38 & 0 \\
\hline 120 & 7,6 & 0 & 0,19 & 0 \\
\hline 150 & 7,8 & 0 & 0,13 & 0 \\
\hline 24 horas & 7,7 & 0 & 0,14 & 0 \\
\hline
\end{tabular}

Síntesis y potenciales aplicaciones tecnológicas de materiales zeolíticos obtenidos a partir de catalizadores FCC agotados 149 
Tabla 5.4. Valores de la concentración de $\mathrm{Cr}(\mathrm{III})\left(\mathrm{mg} \cdot \mathrm{L}^{-1}\right)$ en la fase líquida de intercambio usando $3 \mathrm{~g}$ de la zeolita $\mathrm{NaA}$ a $\mathrm{T}=25 \stackrel{\circ}{\circ} \mathrm{C}$ y $\mathrm{T}=50 \stackrel{\circ}{\mathrm{C}}$ para una concentración inicial de $\sim 135 \mathrm{mg} \cdot \mathrm{L}^{-1}$.

\begin{tabular}{|c|c|c|}
\hline Ensayo $\mathbf{N}^{\circ}$ & 5008 & 5011 \\
\hline $\begin{array}{l}\text { Tiempo } \\
\text { (min) } \downarrow\end{array}$ & $\begin{array}{c}\mathrm{Cr}(\mathrm{III}) \\
\left(\mathrm{mg}^{-\mathrm{L}^{-1}}\right) \\
\left(\text { a } 25^{\circ} \mathrm{o} \text { ) }\right.\end{array}$ & $\begin{array}{c}\mathrm{Cr}(\mathrm{III}) \\
\left(\mathrm{mg}^{-\mathrm{L}^{-1}}\right) \\
\left(\mathrm{a} 50^{\circ} \mathrm{o}\right)\end{array}$ \\
\hline 0 & 134 & 133 \\
\hline 1 & 50,7 & 72 \\
\hline 5 & 32 & 31,6 \\
\hline 20 & 13,7 & 18 \\
\hline 60 & 2,8 & 2,02 \\
\hline 120 & 2,6 & 1,88 \\
\hline 150 & 2,78 & 1,44 \\
\hline 24 horas & 2,7 & 1,04 \\
\hline
\end{tabular}


Para la realización de estos estudios se seleccionó el material que incorporó la mayor cantidad de $\mathrm{Cr}$ (III), es decir, la muestra intercambiada con 135 mg. $\mathrm{L}^{-1}$ obtenida en el ensayo 5005, denominada Cr-4090-135, y se comparó con la muestra 4090 que es la de partida antes de los intercambios.

\subsubsection{Análisis por XRD de la influencia de la reacción de intercambio sobre la estructura cristalina}

Los estudios se basaron en evaluar a través de XRD si la incorporación de $\mathrm{Cr}$ (III) en el material sintetizado a partir del catalizador, produce cambios en la intensidad de los picos de difracción o alteraciones del parámetro de red original.

Se observó que para la muestra sin intercambiar 4090 y para la intercambiada, Cr-4090-135 se mantienen los picos característicos correspondientes a una zeolita $\mathrm{NaA}$. Comparando estos difractogramas obtenidos, se apreció que tampoco existen diferencias en las posiciones de los picos característicos asociados a la presencia de estructuras zeolíticas, lo cual indica que los parámetros de red se han conservado. También se observa que la intensidad disminuyó apreciablemente en la muestra con cromo, lo cual sería un indicador de un efectivo remplazo del sodio por el cromo en posiciones de compensación de cargas. En la Fig. 5.1. se muestran los espectros de XRD de ambos productos. 
Capítulo V-Procesos de intercambio catiónico. Estudio de la cinética de sorción de $\mathrm{Cr}$ (III)

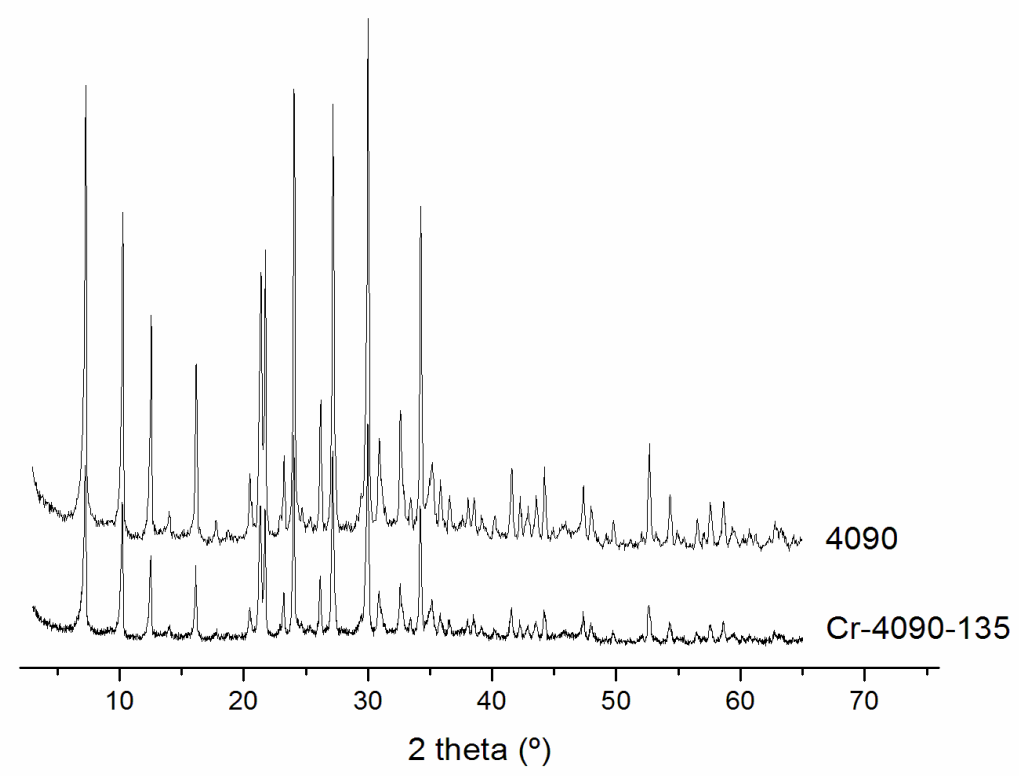

Figura 5.1. Difractogramas de rayos $X$ de los muestras 4090 y Cr4090-135.

Síntesis y potenciales aplicaciones tecnológicas de materiales zeolíticos obtenidos a partir de catalizadores FCC agotados 152 


\subsubsection{Análisis por EDX de la distribución del $\mathrm{Cr}$ (III) en el sólido obtenido. Características morfológicas del producto}

Los resultados de EDX de los análisis de la superficie trasversal de la pastilla obtenida como se detalla en 3.4.2. se muestran en la Fig. 5.2. Los porcentajes de átomos de cromo fueron significativamente más altos en la superficie exterior, en donde los cristales de zeolita estarían situados (valores de alrededor de $3 \%$ ), en comparación con los valores determinados en el interior de las microesferas $(0.1 \%)$. Puede observarse en la micrografía la zona de mayor intensidad de color situada en los contornos de las microesferas, indicativa de mayores valores de concentración del catión. Entonces, se podría decir que los cationes cromo reemplazan los cationes de sodio más accesibles situados en las áreas más expuestas de las microesferas y desempeñan el papel de contrarrestar la carga negativa del entramado de la zeolita. Probablemente exista también una cantidad de cromo adsorbido sobre la superficie externa bajo la forma de óxido o hidróxido.

\subsubsection{Estudios por FT-IR de las muestras intercambiadas con $\mathrm{Cr}$ (III)}

La Fig. 5.3. muestra los espectros FT-IR del material zeolítico obtenido antes y después de estar en contacto con la solución de concentración inicial de $\sim 135 \mathrm{mg}^{-\mathrm{L}^{-1}} \mathrm{de} \mathrm{Cr}$ (III). Se observaron bandas de absorción que representan la estructura secundaria de la zeolita (D4R) entre 450 y $600 \mathrm{~cm}^{-1}$, bandas por lo tanto relacionadas con el orden estructural. Las intensidades de estas bandas disminuyeron notablemente después del contacto con la solución de $\operatorname{Cr}($ III) y se observó una nueva banda entre $800-900 \mathrm{~cm}^{-1}$, que puede ser atribuida a una leve degradación de la estructura de la zeolita, fenómeno ya observado en experiencias similares realizadas usando zeolita $\mathrm{Na}-\mathrm{A}$ pura [1]. 
Capítulo V-Procesos de intercambio catiónico. Estudio de la cinética de sorción de $\mathrm{Cr}$ (III)

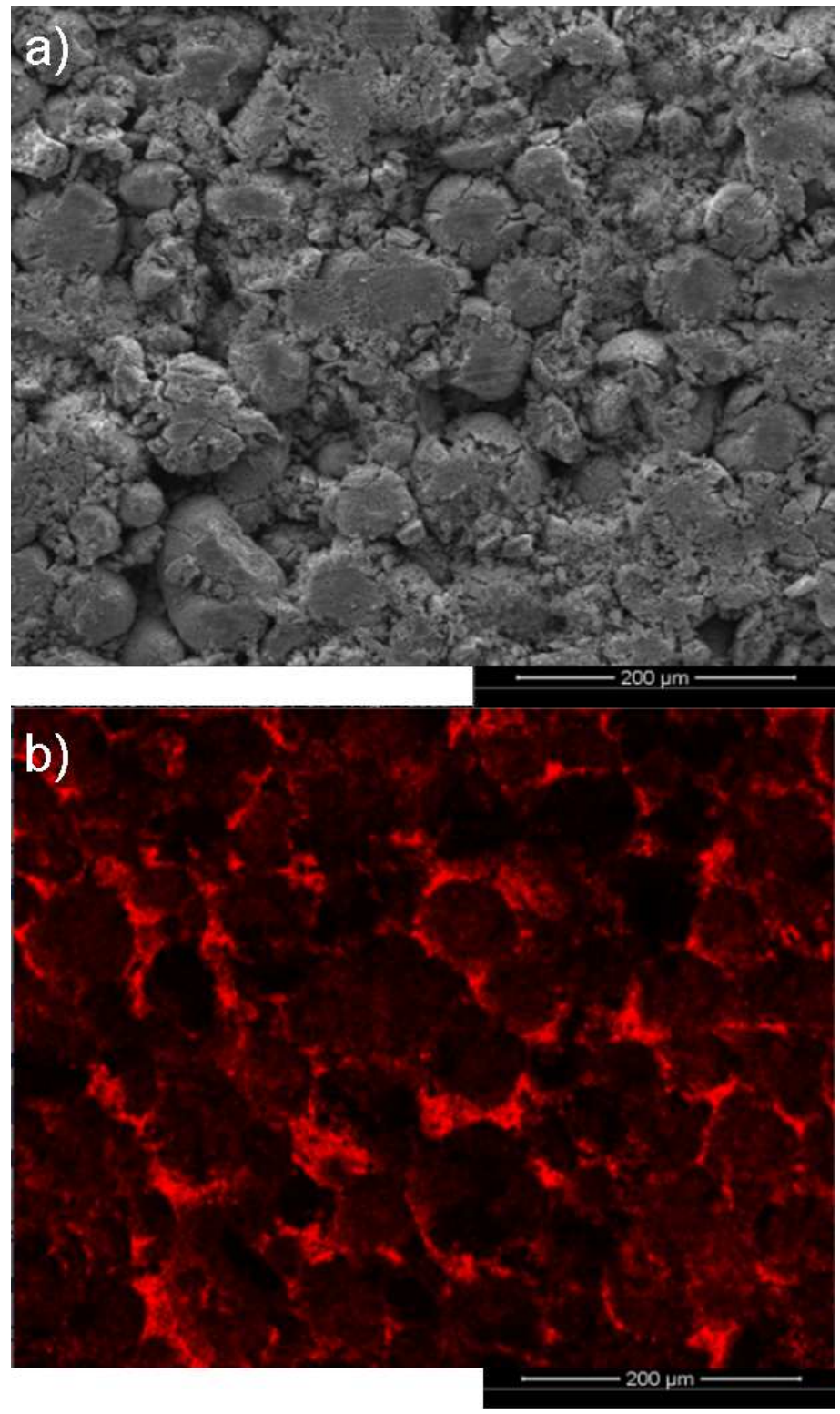

Figura 5.2. Análisis de una pastilla del producto Cr-4090-135. a) micrografía SEM que muestra un área plana seleccionada expuesta por pulido. b) mapeo de Cr por EDX correspondiente a la micrografía observada en a). Aumento X500. 


\subsubsection{Mecanismo de sorción del $\mathrm{Cr}$ (III). Determinación del punto de cero carga.}

Se determinaron los valores de potencial zeta del material antes del intercambio (4090) y los correspondientes a las muestras obtenidas luego del intercambio con soluciones de $\sim 42 \mathrm{mg} \cdot \mathrm{L}^{-1}$ de cromo (Cr-4090-42) y $\sim 135 \mathrm{mg}^{-L^{-1}}$ de cromo (Cr-4090-135).

En la Fig. 5.4. se graficaron los datos obtenidos de los valores de potencial zeta medidos en función del $\mathrm{pH}$. Se observa que tanto la muestra 4090, como las muestras Cr-4090-42 y Cr-4090-35 presentan PZC similares, ubicándose éstos alrededor de 5,4.

La diferencia entre los valores medidos del punto de cero carga para el material obtenido a partir del catalizador FCC agotado (PZC a pH $=5,2$, Fig. 3.15.) y el correspondiente la zeolita pura ( $\mathrm{Na}-\mathrm{A}, \mathrm{PZC}$ a pH $=$ 8,1) [2] puede estar relacionada con la diferente composición en minerales que presentan ambas muestras. Es conocido que se miden valores de punto de cero carga diferentes en muestras de suelo con diferente contenido mineral [3] o en mezclas de $\mathrm{SiO}_{2}$ y $\mathrm{Al}_{2} \mathrm{O}_{3}$ [4], teniendo en cuenta que la anatasa, mullita, Na-nefelina e hidroxisodalita tienen PZC de 5,9, 7,3, 4,0 y 11,0 respectivamente [5-7, 2].

Se sabe también que en soluciones ácidas, el $\mathrm{Cr}$ (III) se hidroliza a especies tales como $\mathrm{Cr}(\mathrm{OH})^{2+}, \mathrm{Cr}(\mathrm{OH})_{2}, \mathrm{Cr}_{2}(\mathrm{OH})_{4}, \mathrm{Cr}_{6}(\mathrm{OH})_{12}, \mathrm{y} \mathrm{Cr}_{6}(\mathrm{OH})_{15}$ [8], por lo que adicionalmente puede ocurrir adsorción superficial de $\mathrm{Cr}$ (III) o de sus especies hidratadas, fenómeno que desplazaría el PZC hacia valores de pH más altos que los óxidos de $\mathrm{Cr}$ (III) hidratados, alrededor de $\mathrm{pH} 8,45$ [9]. 


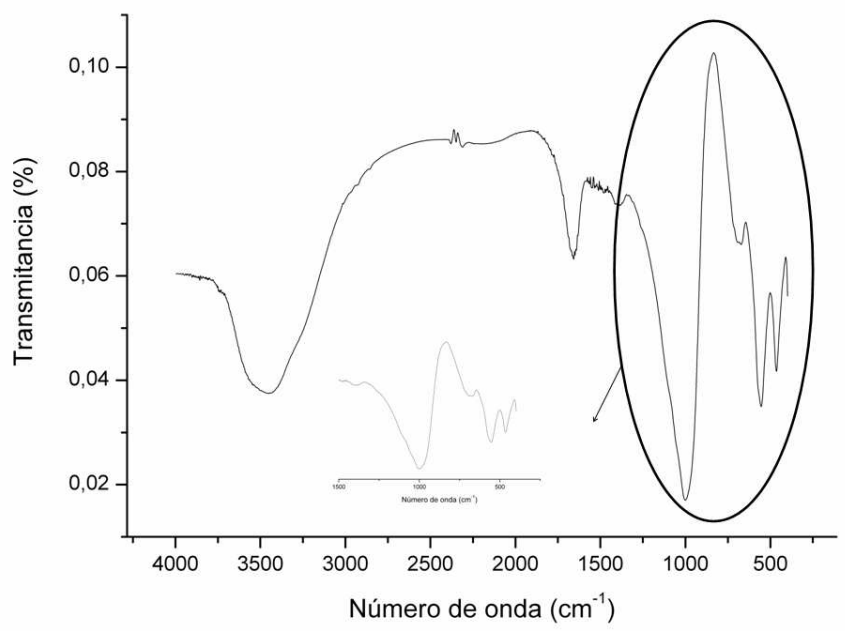

a)

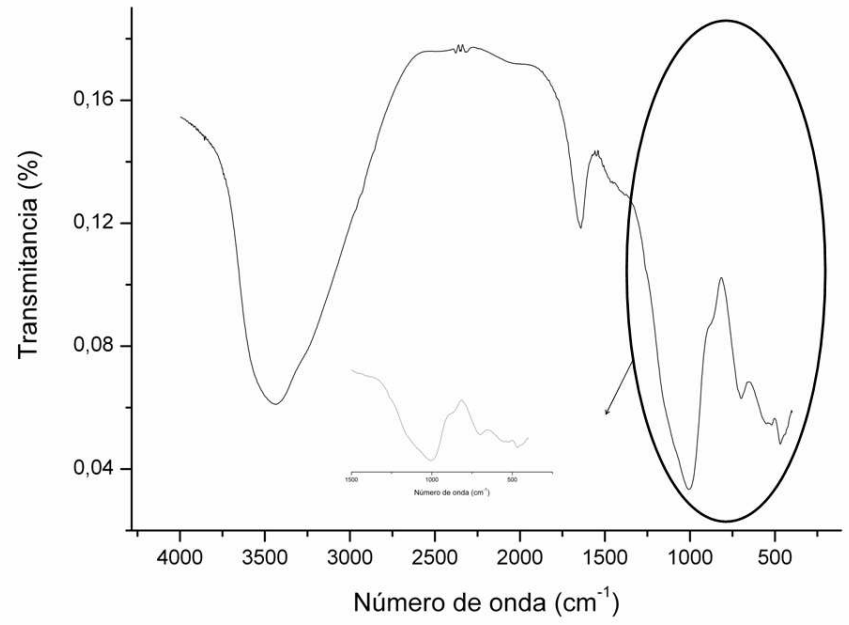

b)

Figure 5.3. Espectro FTIR del material zeolítico antes y luego del contacto con una solución de $\sim 135 \mathrm{mg}^{-\mathrm{L}^{-1}}$ de $\mathrm{Cr}(\mathrm{III})$. 
Capítulo V-Procesos de intercambio catiónico. Estudio de la cinética de sorción de $\mathrm{Cr}$ (III)

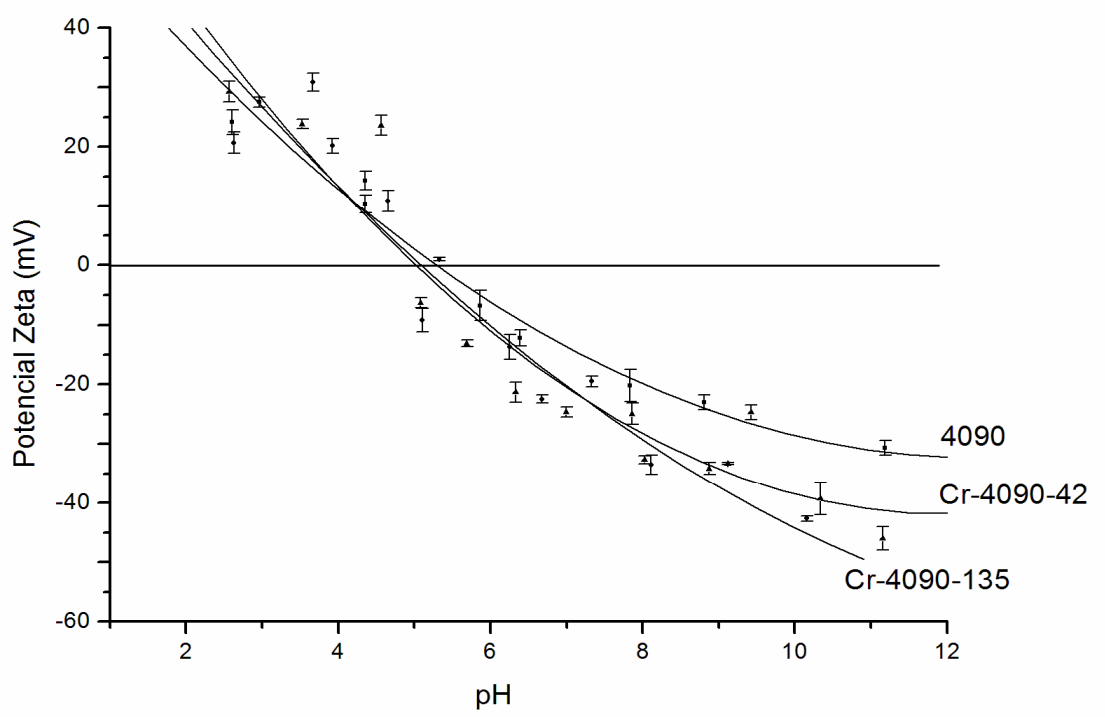

Figura 5.4. Curvas de Potencial zeta en función del pH de las muestras 4090, Cr-4090-42 y Cr-4090-135.

Síntesis y potenciales aplicaciones tecnológicas de materiales zeolíticos obtenidos a partir de catalizadores FCC agotados 157 
La diferencia de PZC encontrado entre la muestra 4090 y las muestras que contienen $\mathrm{Cr}$, muestras $\mathrm{Cr}-4090-42$ y Cr-4090-135, de 0,2 (0,5 unidad de $\mathrm{pH})$ correspondió a la mitad de una desviación estándar [6].

La ausencia de un cambio de carga neta observada en el intervalo de $\mathrm{pH} 2$ - 7 para superficies de zeolita con y sin $\mathrm{Cr}$ (III) adsorbido podría indicar que el catión $\mathrm{Cr}$ (III) esta predominantemente presente en los sitios de intercambio de la zeolita como ocurrió con la adsorción de $\operatorname{Cr}(I I I)$ en bentonita [10] ó $\mathrm{Pb}$ (II) sobre zeolitas [11].

Como resumen de este capítulo, podemos decir que por el análisis de los difractogramas obtenidos antes y luego del intercambio catiónico, se determina que los parámetros de red se han conservado. También se aprecia que la intensidad disminuye significativamente en la muestra con cromo, lo cual sería un indicador de un efectivo reemplazo del sodio por este catión, situándose en posiciones de compensación. En concordancia con los resultados del mapeo EDX de cromo, los porcentajes de átomos de cromo son mayores en la superficie exterior de las microesferas, en donde los cristales de zeolita están mayoritariamente situados, en comparación con los valores medidos en el interior de las microesferas. Este análisis de los resultados es corroborado por las determinaciones de punto de cero carga, las cuales muestran una conservación de la carga neta observada en la superficie de la zeolita luego del intercambio, lo que indica que el catión $\mathrm{Cr}(\mathrm{III})$ está predominantemente ocupando sitios de intercambio en la estructura zeolítica. 
Capítulo V-Procesos de intercambio catiónico. Estudio de la cinética de sorción de Cr(III)

\subsection{Resultados de estudios cinéticos.}

La cinética de sorción de $\mathrm{Cr}$ (III) sobre los materiales sintetizados y sobre las zeolitas de referencia se analizaron utilizando modelos cinéticos de primero y segundo orden, de acuerdo a lo descripto en [12].

Los modelos empleados y el desarrollo de las ecuaciones se encuentran descriptos en el capítulo 2.3.

En las Figs. 5.5. y 5.6. se grafica $\log \left(q_{e}-q_{t}\right)$ en función del tiempo para la muestra 4090 y para la zeolita NaA. Del mismo modo, en las Figs. 5.7. y 5.8. se grafica $t / q_{t}$ para las mismas muestras.

En las Tablas 5.5. y 5.6. se detallan las constantes cinéticas experimentales comparadas con las obtenidas aproximando con los modelos cinéticos de primer orden y segundo orden. 
Capítulo V-Procesos de intercambio catiónico. Estudio de la cinética de sorción de $\mathrm{Cr}$ (III)

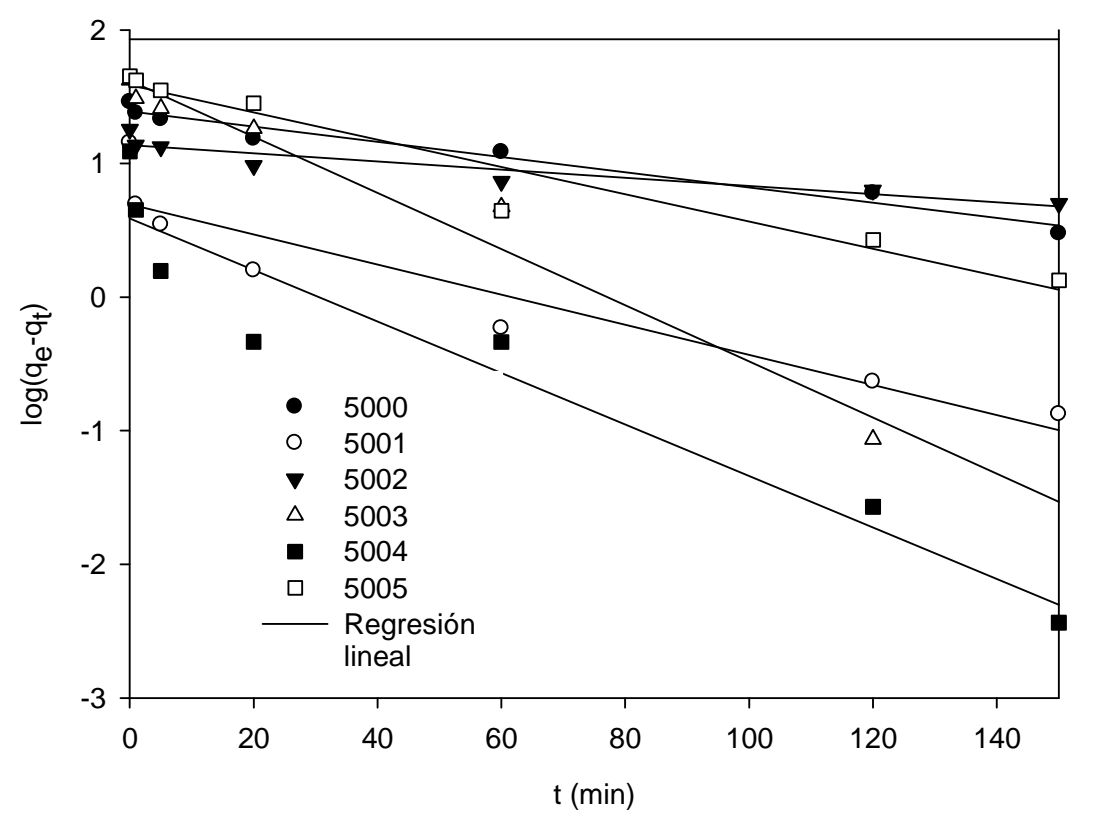

Figura 5.5. Gráfica de Lagergren para la sorción de cromo de la muestra 4090.

Síntesis y potenciales aplicaciones tecnológicas de materiales zeolíticos obtenidos a partir de catalizadores FCC agotados 160 
Capítulo V-Procesos de intercambio catiónico. Estudio de la cinética de sorción de $\mathrm{Cr}$ (III)

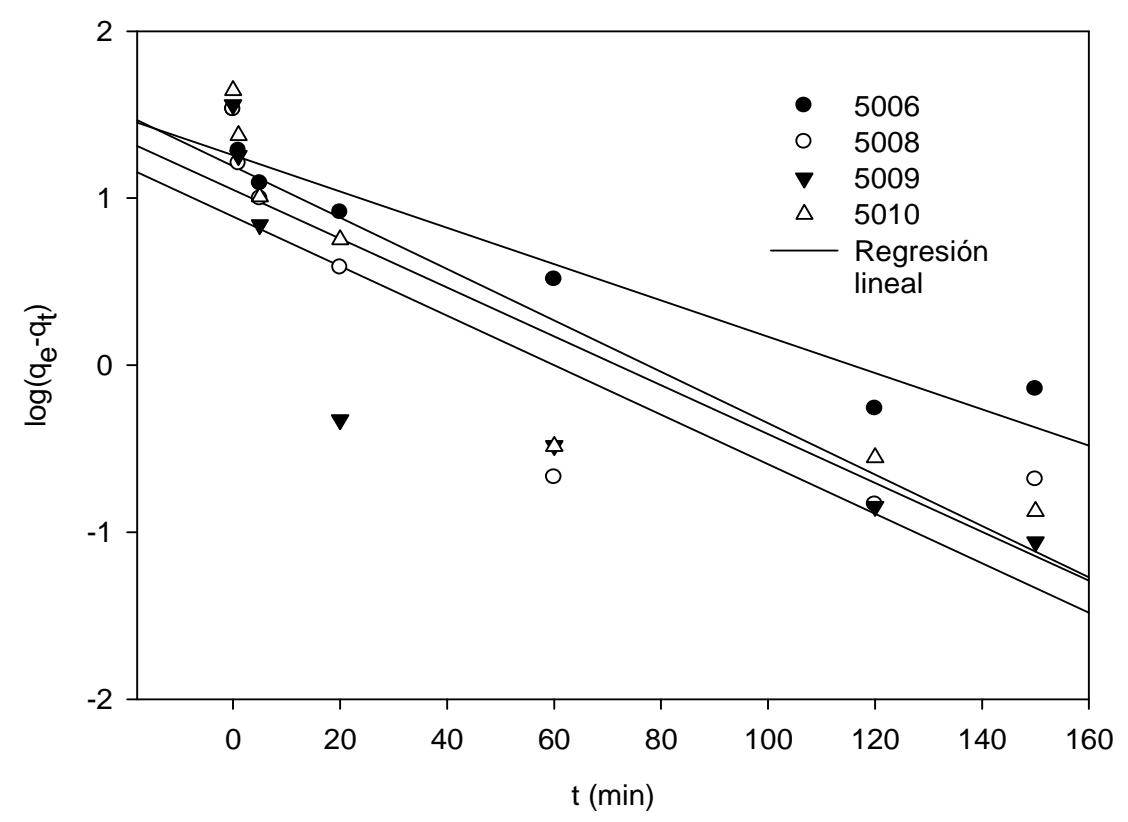

Figura 5.6. Gráfica de Lagergren para la sorción de cromo de la zeolita NaA. 
Capítulo V-Procesos de intercambio catiónico. Estudio de la cinética de sorción de $\mathrm{Cr}$ (III)

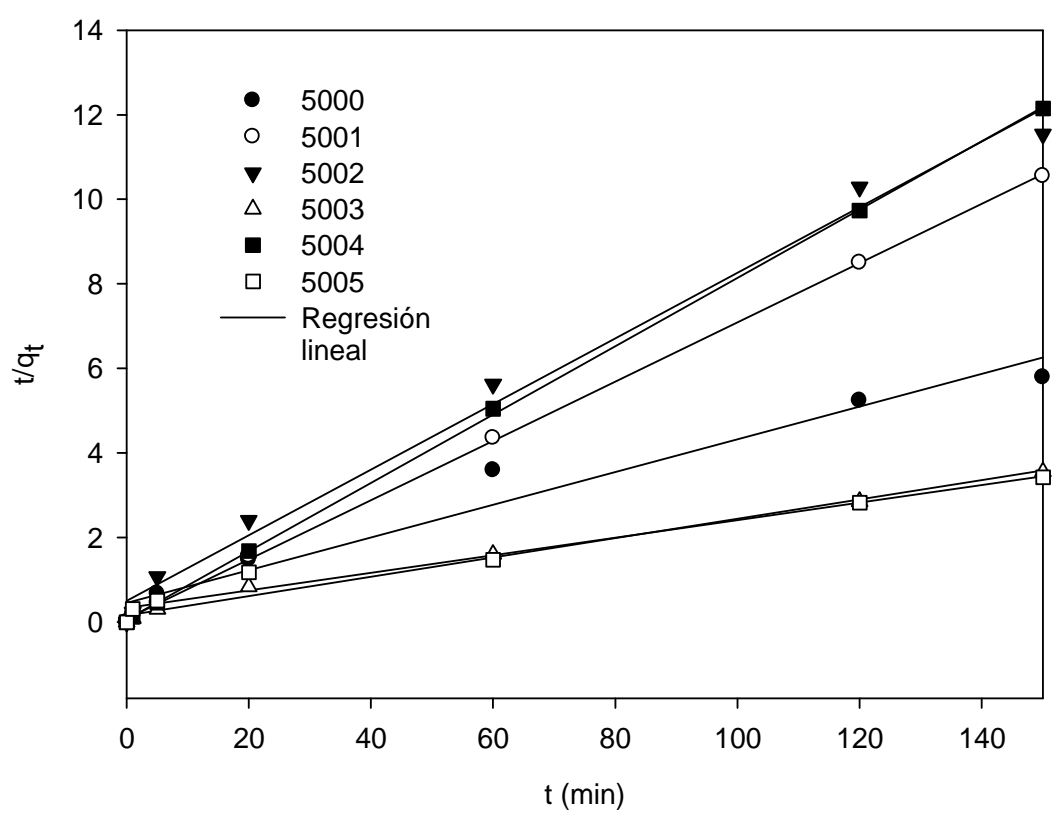

Figura 5.7. Cinética de Pseudo segundo orden para la sorción de cromo sobre la muestra 4090 .

Síntesis y potenciales aplicaciones tecnológicas de materiales zeolíticos obtenidos a partir de catalizadores FCC agotados 162 
Capítulo V-Procesos de intercambio catiónico. Estudio de la cinética de sorción de $\mathrm{Cr}$ (III)

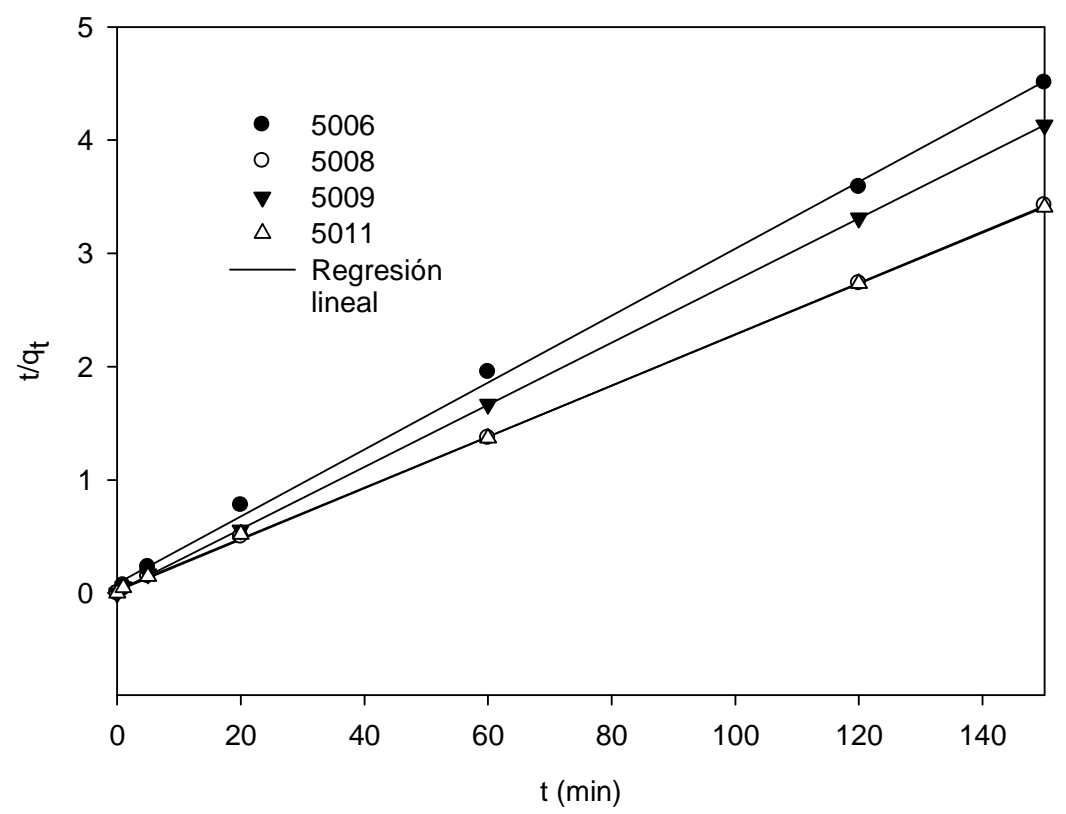

Figura 5.8. Cinética de Pseudo segundo orden para la sorción de cromo sobre la zelota $\mathrm{NaA}$.

Síntesis y potenciales aplicaciones tecnológicas de materiales zeolíticos obtenidos a partir de catalizadores FCC agotados 163 
Tabla 5.5. Constantes cinéticas experimentales comparadas con las obtenidas aproximando con modelos cinéticos de primer orden.

\begin{tabular}{|c|c|c|c|c|}
\hline & \multicolumn{2}{|c|}{$\begin{array}{c}\text { Pseudo Primer } \\
\text { Orden }\end{array}$} & \multirow[b]{2}{*}{$\begin{array}{c}k_{1 \text { ads }} \times 10^{2} \\
\left(\min ^{-1}\right)\end{array}$} & \multirow[b]{2}{*}{$\mathbf{R}^{2}$} \\
\hline & $\begin{array}{c}q_{e}(\text { cal }) \\
\left(m g \cdot g^{-1}\right)\end{array}$ & $\begin{array}{l}q_{e}(\exp ) \\
\left(m g \cdot g^{-1}\right)\end{array}$ & & \\
\hline 5000 & 24,50 & 28,9 & 0,0131 & 0,96 \\
\hline 5001 & 4,88 & 14,35 & 0,0267 & 0,88 \\
\hline 5002 & 13,69 & 18 & 0,0071 & 0,87 \\
\hline 5003 & 41,77 & 42,11 & 0,0063 & 0,97 \\
\hline 5004 & 3,88 & 12,35 & 0,0444 & 0,92 \\
\hline 5005 & 38,58 & 45,12 & 0,0234 & 0,94 \\
\hline 5006 & 18,05 & 34 & 0,0250 & 0,92 \\
\hline 5008 & 11,18 & 44 & 0,0336 & 0,80 \\
\hline 5009 & 7,72 & 36,37 & 0,0340 & 0,74 \\
\hline 5011 & 15,56 & 44,16 & 0,0354 & 0,85 \\
\hline
\end{tabular}


Tabla 5.6. Constantes cinéticas experimentales comparadas con las obtenidas aproximando con modelo cinético de segundo orden.

\begin{tabular}{|c|c|c|c|c|c|}
\hline & $\begin{array}{c}\text { Pseudo Segundo } \\
\text { Orden }\end{array}$ & \multicolumn{2}{l}{} \\
\hline & $\begin{array}{c}\mathbf{q}_{\mathrm{e}}(\mathbf{c a l}) \\
\left(\mathbf{m g}^{-1} \mathbf{~}^{-1}\right)\end{array}$ & $\begin{array}{c}\mathbf{q}_{\mathrm{e}}(\mathbf{e x p}) \\
\left(\mathbf{m g} \cdot \mathbf{g}^{-1}\right)\end{array}$ & $\begin{array}{c}\boldsymbol{k}_{\mathbf{2 d s}} \\
\left(\mathbf{m i n}^{-1}\right)\end{array}$ & $\mathbf{R}^{2}$ & $\begin{array}{c}\boldsymbol{h}\left(\mathbf{m g ~ g}^{-1}\right. \\
\left.\mathbf{m i n}^{-1}\right)\end{array}$ \\
\hline $\mathbf{5 0 0 0}$ & 26 & 28,9 & 0,0032 & 0,96 & 2,17 \\
\hline $\mathbf{5 0 0 1}$ & 14,5 & 14,3 & 0,0674 & 0,99 & 14,28 \\
\hline $\mathbf{5 0 0 2}$ & 12,9 & 18 & 0,0120 & 0,99 & 2 \\
\hline $\mathbf{5 0 0 3}$ & 43,2 & 42,1 & 0,0033 & 0,98 & 6,4 \\
\hline $\mathbf{5 0 0 4}$ & 12,4 & 12,3 & 0,1049 & 0,99 & 16,07 \\
\hline $\mathbf{5 0 0 5}$ & 48,3 & 45,1 & 0,0012 & 0,96 & 3 \\
\hline $\mathbf{5 0 0 6}$ & 33,7 & 34 & 0,0103 & 0,99 & 11,7 \\
\hline $\mathbf{5 0 0 8}$ & 44,2 & 44 & 0,0255 & 0,99 & 49,5 \\
\hline $\mathbf{5 0 0 9}$ & 36 & 36,4 & 0,0439 & 1 & 58 \\
\hline $\mathbf{5 0 1 1}$ & 44,4 & 44,2 & 0,0172 & 0,99 & 34,1 \\
\hline
\end{tabular}


Capítulo V-Procesos de intercambio catiónico. Estudio de la cinética de sorción de $\operatorname{Cr}($ III)

Tabla 5.7. Coeficientes de difusión calculados de las experiencias con muestra 4090 a diferentes temperaturas y concentraciones.

\begin{tabular}{|c|c|c|c|}
\hline \multicolumn{4}{|c|}{ Coeficiente de difusión (D) $\left.\mathbf{( m}^{2} \cdot \mathbf{s}^{-1}\right)$} \\
\hline $\begin{array}{c}\text { Temperatura } \\
\text { (ㅇ) })\end{array}$ & $\begin{array}{c}\mathbf{1} \mathbf{~ g} ; ~ \mathbf{4 2} \\
\mathbf{m g} \cdot \mathbf{L}^{-1}\end{array}$ & $\begin{array}{c}\mathbf{3} \mathbf{~} ; \sim \mathbf{4 2} \\
\mathbf{m g} \cdot \mathbf{L}^{-1}\end{array}$ & $\begin{array}{c}\mathbf{3} \mathbf{~ g} ; \sim \mathbf{1 3 5} \\
\mathbf{m g} \cdot \mathbf{L}^{-1}\end{array}$ \\
\hline $\mathbf{2 5}$ & $1,32 \times 10^{-15}$ & $2,62 \times 10^{-15}$ & $7,09 \times 10^{-16}$ \\
\hline $\mathbf{5 0}$ & $4,9 \times 10^{-15}$ & $4,49 \times 10^{-15}$ & $2,38 \times 10^{-15}$ \\
\hline
\end{tabular}


Como puede verse, los coeficientes de correlación $R^{2}$ son 0,96-0,99 para el modelo de pseudosegundo orden y de 0,80-0,97 para el pseudoprimer orden, indicando un mejor ajuste con el modelo de segundo orden. Este mejor ajuste con el modelo cinético de segundo orden puede verse también con los valores de $q_{e}$ que se aproximan más a los valores generados a partir del modelo de segundo orden.

Resultados indican velocidades de adsorción inicial (h) y constantes de velocidad que aumentan con la temperatura, los que podrían ratificar un modelo de sorción de segundo orden predominante [13].

Por otra parte, es conocido que las etapas controlantes del proceso de intercambio pueden deberse a fenómenos difusionales en una película difusional, difusión intraparticular o a la propia reacción de intercambio. Como la reacción de intercambio se lleva a cabo bajo agitación, se puede concluir que en este caso podría existir alguno de los otros dos tipos de control.

En este caso, se calcularon a través de un modelo basado en la ley de Fick [14] los coeficientes de difusión para dos temperaturas y dos concentraciones de la solución de intercambio para evaluar si podría existir control por difusión intraparticular.

Los coeficientes de difusión calculados de esta forma se muestran en la Tabla 5.7.

Se observa que los valores de $\mathrm{D}$ se incrementan con el aumento de la temperatura y disminuyen con el aumento de la concentración de iones $\mathrm{Cr}(\mathrm{III})$. Esta tendencia podría estar indicando un proceso de intercambio controlado por difusión intraparticular. 


\subsection{Referencias}

[1] Basaldella E.I., Vázquez P.G., Lucolano F., Caputo D. (2007) J. of Colloid and Interf. Sci. 313, 574.

[2] Torres Sánchez R.M., Basaldella E.I., Tara J.C. (2001) Mater. Letters $50,138$.

[3] Taubaso C., Dos Santos Afonso, M., Torres Sánchez, R.M. (2004) Geoderma 121, 123.

[4] Torres Sánchez R.M. (1997) Colloids Surf. A 127, 135.

[5] Liu X., Chen G., Su C.H. (2001) J. of Colloid and Interf. Sci. 363, 84.

[6] M. Kosmulski, M. (2009) Surface charging and PZC in: A. Hubberd (Ed.). Surfactant Sci Series, 145, CRC Press, Boca Raton USA.

[7] Kosmulski M. (2002) Adv. Colloid Interf. Sci. 99, 255.

[8] Rollinson, C.L. (1956) Chemistry of the Coordination Compounds In: J.

C. Bailar. Jr., Busch D.H. (Eds.), Reinhold, NY, Chapter 13.

[9] Magaz, G.E., Rodenas L.G., Morando P.J., Blesa M.A. (1998) Croat. Chem. Acta 71, 917.

[10] Chakir A., Bessiere, J., Kacemia, K.E., Marouf, B. (2002) J. Hazard. Mater. 95, 29.

[11] Lamdaour, M.A. (2001) University thesis, Mohamed V University, Science Faculty, Rabat.

[12] Ruthven D.M. (1984) Principles of Adsorption and Adsorption Process, John Wiley. New York.

[13] Biskup B. Subotic B. (2004) Sep. Purif. Technol. 37, 17.

[14] Niboua D., Mekatela H., Amokranea S., Barkatb M., Trari M. (2010) J. Hazard. Mater.173, 637. 


\section{CAPÍTULO VI}

\section{INMOVILIZACIÓN EN MORTEROS}

Síntesis y potenciales aplicaciones tecnológicas de materiales zeolíticos obtenidos a partir de catalizadores FCC agotados 169 


\section{INMOVILIZACIÓN EN MORTEROS}

En este capítulo se evalúa la influencia de la incorporación del catalizador zeolitizado sobre las propiedades mecánicas de matrices cementíceas. Para ello, se presentan diversas formulaciones de morteros con diferentes concentraciones en peso de catalizador zeolitizado a las cuales se les cuantifica su resistencia a la flexión, compresión y contracción por secado. Asimismo, se evalúa su potencialidad como material puzolánico.

Finalmente, se presentan los ensayos de lixiviación que comprueban que la encapsulación del $\mathrm{Cr}$ (III) en los morteros diseñados es un método válido y ambientalmente sustentable.

\subsection{Estudio preliminares de la influencia del agregado zeolítico sobre las propiedades mecánicas de los morteros cementíceos y ensayos de lixiviación.}

En primer lugar se obtuvo una serie de morteros conteniendo porcentajes de zeolita de 10\%, 20\% y 30\%. El material zeolítico utilizado fue la muestra obtenida a partir del catalizador FCC agotado intercambiada con una solución de $\sim 135 \mathrm{mg} . \mathrm{L}^{-1}$ de $\mathrm{Cr}$ (III) (muestra $\mathrm{Cr}$ 4090-135). Para la elaboración de los morteros, el material zeolítico fue agregado como reemplazo de la misma cantidad en peso de cemento. Esta serie de probetas fue diseñada con el fin de determinar los valores máximos de reemplazo que podrían llegar a manejarse para poder conservar propiedades mecánicas aceptables para posteriormente evaluar la potencial lixiviación del $\mathrm{Cr}$ (III) y las propiedades puzolánicas del agregado. 
Todos los ensayos se realizaron por triplicado y se tomó como referencia una muestra patrón $(P)$ de formulación de cemento convencional. Se trabajó de acuerdo a la norma IRAM 1622, tal como se detalla en el apartado 3.6.1.

\subsubsection{Evaluación de las propiedades mecánicas}

Los morteros elaborados en esta etapa conteniendo un reemplazo de cemento por una cantidad de producto zeolitizado en niveles del $10 \%$, $20 \%$ y $30 \%$ se denominaron como muestras ZC10, ZC20 y ZC30 respectivamente. Luego de la conformación de la probeta y respectivo curado realizados como se describió en 3.6.1., se sometieron a ensayos de flexión, compresión y lixiviación de $\mathrm{Cr}(\mathrm{III})$.

\subsubsection{Resistencia a la flexión y a la compresión}

Los resultados de resistencia a la flexión y a la compresión a los 28 días de curado de las probetas fueron obtenidos empleando un equipo Amsler, tipo 1033 según norma IRAM 1622. En la Tabla 6.1 se detallan los valores obtenidos para cada ensayo.

Síntesis y potenciales aplicaciones tecnológicas de materiales zeolíticos obtenidos a partir de catalizadores FCC agotados 171 
Tabla 6.1. Resistencia a la flexión y compresión de los morteros a los 28 días de curado.

\begin{tabular}{|c|c|c|}
\hline Morteros & $\begin{array}{c}\text { Resistencia a la } \\
\text { Flexión } \\
\text { (MPa) }\end{array}$ & $\begin{array}{c}\text { Resistencia a la } \\
\text { Compresión } \\
\text { (MPa) }\end{array}$ \\
\hline $\mathbf{P}$ & 6,8 & 33,7 \\
\hline ZC10 & 5,7 & 23,4 \\
\hline ZC20 & 4,3 & 14,4 \\
\hline ZC30 & 3,5 & 11,1 \\
\hline
\end{tabular}


Se observó que todas las muestras redujeron los valores de sus propiedades mecánicas con respecto a los valores presentados por la muestra patrón. Además, el valor de resistencia a la flexión de la muestra $\mathrm{ZC} 10$ se redujo un $16 \%$ con respecto al mortero patrón $(\mathrm{P})$. Por otra parte, para los morteros ZC20 y ZC30 se apreció una considerable disminución en los valores de flexión, es decir, disminuyeron su resistencia en un $25 \%$ y $48 \%$ con respecto al mortero patrón, respectivamente.

Con respecto a los valores de resistencia a la compresión, se observa un comportamiento similar, ya que los valores de resistencia también disminuyen a medida que aumenta el porcentaje añadido de zeolita, siendo la mayor reducción del $67 \%$ para el mortero ZC30 en referencia con el mortero patrón.

Este efecto en las propiedades mecánicas indica que los valores de reemplazo utilizados en esta serie producen una disminución muy acentuada de las propiedades mecánicas. Al reducirse la cantidad de cemento presente, paralelamente se reduce la posibilidad de formación de la fase H-S-C, constituida por silicato de calcio hidratado, cuya presencia está directamente relacionada con la resistencia mecánica del mortero.

\subsubsection{Pruebas de lixiviación}

En la Tabla 6.2. se muestran los resultados de los ensayos de lixiviación. El análisis se realizó utilizando muestras tomadas de los morteros endurecidos ZC10, ZC20 y ZC30 previamente utilizados en las pruebas de resistencia mecánica. 
Tabla 6.2. Resultados de las pruebas de lixiviación (tiempo de lixiviación = $18 \mathrm{~h})$.

\begin{tabular}{|c|c|}
\hline Morteros & $\begin{array}{r}\text { Concentración de } \mathbf{C r}(\mathrm{III}) \\
\text { en el lixiviado } \\
\left(\mathrm{mg} \cdot \mathrm{L}^{-1}\right)\end{array}$ \\
\hline ZC10 & 0,058 \\
\hline ZC20 & 0,074 \\
\hline ZC30 & 0,120 \\
\hline
\end{tabular}


Se observó que a medida que se incrementó el porcentaje de reemplazo por zeolita, la concentración de cromo en la fase de lixiviación aumentó. Cabe destacar que los valores obtenidos se encuentran por debajo de los límites permitidos ( $2 \mathrm{mg}^{\mathrm{L} \mathrm{L}^{-1}}$ ) establecidos por la Resolución 336/2003 de la Autoridad del Agua de Buenos Aires, Argentina.

\subsection{Reducción del agregado zeolítico}

Posteriormente, tomando en consideración los resultados obtenidos, se diseñó una segunda serie de morteros, en las cuales se redujo la proporción de reemplazo de cemento por Cr-4090-135. Para estos ensayos la proporción de reemplazo fue $5 \%$ y $10 \%$, estudiándose sobre estas nuevas muestras las propiedades mecánicas y adicionalmente la contracción por secado.

Para fines comparativos tanto de la resistencia mecánica como de la actividad puzolánica, se elaboraron series de morteros donde el cemento se reemplazó por otros materiales. Se reemplazaron diferentes porcentajes de cemento utilizando una zeolita $\mathrm{NaA}$ pura con cromo incorporado y también se usó para el reemplazo un material de grano muy fino conocido como microsílice, que es una adición mineral de reconocida actividad puzolánica.

Inicialmente, se usaron las mezclas preparadas o morteros frescos para determinar los valores correspondientes de asentamiento y cantidad de aire. Con cada mezcla se elaboraron dos tipos de morteros que difieren en sus dimensiones, tal como se describe en 3.6.1. Una vez elaborados los morteros, se utilizaron los de menor longitud para realizar las evaluaciones de las propiedades mecánicas y posteriormente los ensayos de lixiviación de cromo, con el objetivo de verificar si se produce 
una inmovilización efectiva del ion metálico. Los morteros de mayor longitud se usaron para los ensayos de contracción por secado.

\subsubsection{Propiedades de los morteros frescos}

La Tabla 6.3. muestra el efecto de la incorporación de las diferentes adiciones minerales en el ensayo de asentamiento y por su parte, el contenido de aire se estimó a partir de las mediciones de la unidad de peso.

Los morteros con $5 \%$ de zeolita (Z5, ZC5) o microsílice (S5) de reemplazo, mostraron valores de asentamiento similares a los del mortero de referencia. Se observó una disminución de la trabajabilidad cuando se utilizó un $10 \%$ de sustitución de adiciones; la alta área superficial de estas adiciones minerales aumentó la demanda de agua para el mantenimiento de la trabajabilidad. Se pudo notar una reducción más pequeña en la muestra ZC10 comparada con los otros casos (Z10, S10). Esta diferencia en los valores de trabajabilidad podría estar asociada con el tamaño de partícula, ya que se conoce que las microesferas del catalizador Cr-4090135 son las partículas más grandes. En las medidas de contenido de aire, los valores medidos mostraron una pequeña disminución para los morteros que incorporaron las dosis más altas de adiciones minerales, coincidente con la disminución en la fluidez de los morteros. 
Tabla 6.3. Propiedades de los morteros frescos.

\begin{tabular}{|c|c|c|}
\hline Morteros & $\begin{array}{c}\text { Asentamiento } \\
(\mathbf{m m})\end{array}$ & $\begin{array}{c}\text { Contenido de aire } \\
\text { (\%) }\end{array}$ \\
\hline $\mathbf{P}$ & 30 & 6,0 \\
\hline $\mathbf{Z 5}$ & 35 & 5,0 \\
\hline $\mathbf{Z 1 0}$ & 5 & 7,5 \\
\hline $\mathbf{Z C 5}$ & 35 & 7,0 \\
\hline ZC10 & 25 & 5,5 \\
\hline S5 & 25 & 5,5 \\
\hline S10 & 5 & 4,5 \\
\hline
\end{tabular}




\subsubsection{Resistencia a la flexión y a la compresión}

Los resultados de resistencia a la flexión y a la compresión para los tiempos de 28 y 90 días se muestran en la Tabla 6.4.

Se observó que los morteros Z5 y ZC5 alcanzaron casi el mismo nivel de resistencia a la flexión comparados con el mortero de referencia (P) a la edad de 90 días. En el caso de la resistencia a la compresión, los resultados muestran que la evolución de los valores de resistencia entre 28 y 90 días fue mayor en morteros que incorporan Cr-4090-135 comparados con el mortero de referencia $(P)$, lo que indicó que hay algún tipo de acción puzolánica de estas adiciones. Aunque esta evolución no se observó en los ensayos de resistencia a la flexión, hay que señalar que, como es bien conocido, esta última aumenta más rápido que la resistencia a la compresión. 
Tabla 6.4. Propiedades mecánicas.

\begin{tabular}{|c|c|c|c|c|}
\hline \multirow{2}{*}{ Morteros } & \multicolumn{2}{|c|}{$\begin{array}{c}\text { Resistencia a la } \\
\text { Flexión } \\
\text { (MPa) }\end{array}$} & \multicolumn{2}{c|}{$\begin{array}{c}\text { Resistencia a la } \\
\text { Compresión } \\
\text { (MPa) }\end{array}$} \\
\cline { 2 - 5 } & $\mathbf{2 8 \text { días }}$ & $\mathbf{9 0}$ días & 28 días & 90 días \\
\hline P & 6,7 & 6,8 & 33,1 & 35,2 \\
\hline Z5 & 6,4 & 6,4 & 24,9 & 32,6 \\
\hline Z10 & 5,9 & 6,0 & 24,6 & 28,5 \\
\hline ZC5 & 6,8 & 6,8 & 31,2 & 35,8 \\
\hline ZC10 & 5,5 & 6,6 & 26,2 & 32,7 \\
\hline S5 & 7,2 & 7,0 & 39,4 & 41,7 \\
\hline S10 & 7,5 & 7,9 & 45,6 & 51,5 \\
\hline
\end{tabular}


La Fig. 6.1. muestra los resultados de resistencia a la flexión y de compresión representados como valores relativos del mortero de referencia.

Cuando se utilizó un 5\% ó 10\% de reemplazo, ya sea de Cr-4090135 como de $\mathrm{NaA}$, o sea cuando se usaron materiales zeolíticos, la ganancia de resistencia entre 28 y 90 días fue más alta que la mostrada por el mortero de referencia, aunque finalmente las muestras zeolíticas registraron valores de resistencia a los esfuerzos menores que los correspondientes al patrón P. A los 90 días, Z5 y Z10 lograron una resistencia a la compresión de $93 \%$ y $81 \%$ con respecto al mortero de referencia.

Aunque el mecanismo de acción puzolánica de zeolitas aún no es claramente conocido, se puede suponer que el consumo de sílice de la zeolita mediante la reacción de hidróxido de calcio disuelto podría conducir a la formación de fases de tipo H-C-S. Sin embargo, los datos experimentales reportados en trabajos anteriores [1, 3], indicaron que se obtuvo una menor formación de la fase $\mathrm{H}-\mathrm{S}-\mathrm{C}$ cuando el cemento fue reemplazado por materiales zeolíticos. 


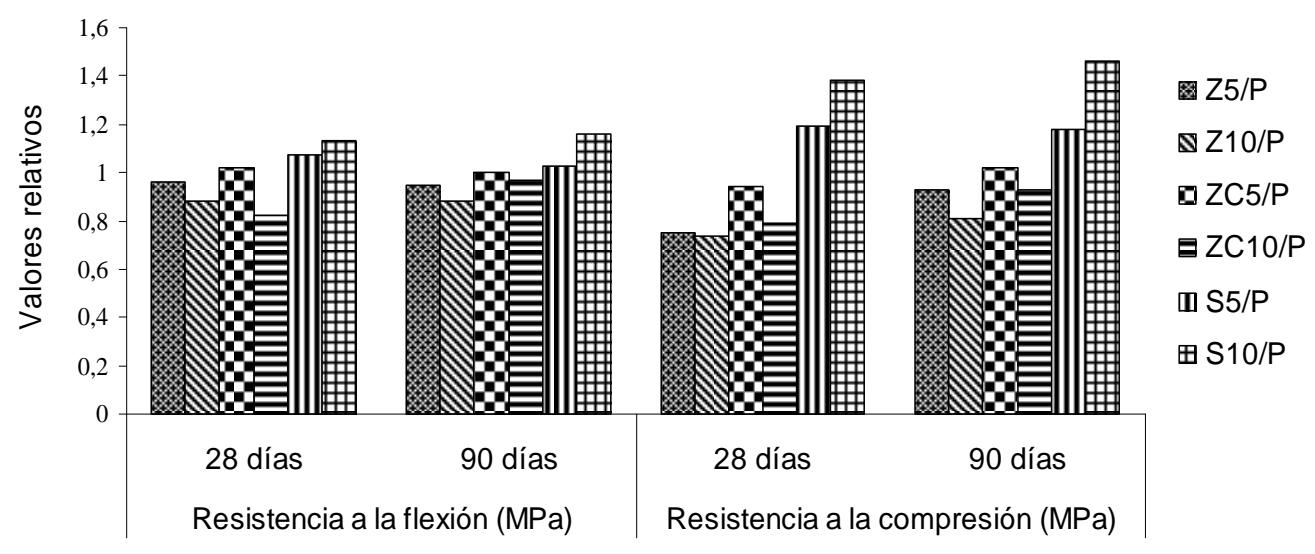

Figura 6.1. Resultados de resistencia a la flexión y de compresión representados como valores relativos del mortero de referencia. 
Los resultados también demostraron que la actividad puzolánica es significativamente menor para los materiales zeolíticos en comparación con la microsílice, una adición mineral de alta calidad. De hecho, la adición SF aumenta la resistencia a la compresión en el orden de $20 \%$ y $40 \%$ en las edades de 28 y 90 días, respectivamente.

\subsubsection{Contracción por secado}

La Fig. 6.2. muestra la evolución de la contracción por secado para las muestras bajo estudio.

El mortero de referencia mostró un valor de contracción por secado de 0,09\% después de 6 meses, y valores similares fueron medidos en los morteros que incorporan SF o Cr-4090-135. En el caso de los morteros que incorporan zeolita A pura intercambiada (Z5 y Z10) se observó un aumento en la contracción, que es más significativo a medida que aumenta el contenido de zeolita.

Se observó que la zeolita A pura juega un papel importante en las propiedades de contracción de los morteros cuando su porcentaje es superior a $5 \%$. La tendencia observada se puede atribuir a las características texturales de los materiales zeolíticos utilizados, que tienen un pequeño tamaño de partícula, altos valores de superficie específica, gran porosidad y alta capacidad de adsorción de agua. En el caso de sustitución basada en la zeolita obtenida a partir del catalizador FCC agotado, la menor influencia registrada podría atribuirse a su mayor tamaño de partícula y a su menor contenido de zeolita, lo que ocasionaría una limitación en el movimiento de masa de agua [4].

Síntesis y potenciales aplicaciones tecnológicas de materiales zeolíticos obtenidos a partir de catalizadores FCC agotados 182 


\subsubsection{Pruebas de lixiviación}

La Tabla 6.5. muestra los resultados de los ensayos de lixiviación. El análisis se realizó utilizando muestras tomadas de los morteros Z5, Z10, ZC5 y ZC10 previamente utilizados en las pruebas de resistencia mecánica.

Se observó un ligero incremento en la concentración de cromo en la fase de lixiviación con el aumento del contenido de zeolita, pero su valor fue siempre inferior a los límites permitidos $\left(2 \mathrm{mg}^{-1} \mathrm{~L}^{-1}\right)$ establecidos por la Resolución 336/2003 de la Autoridad del Agua de Buenos Aires, Argentina. Vale la pena señalar que la concentración de cromo también se determinó en las aguas de curado final. Estas mediciones indicaron que no se produce lixiviación de $\mathrm{Cr}$ (III) durante el proceso de curado. 


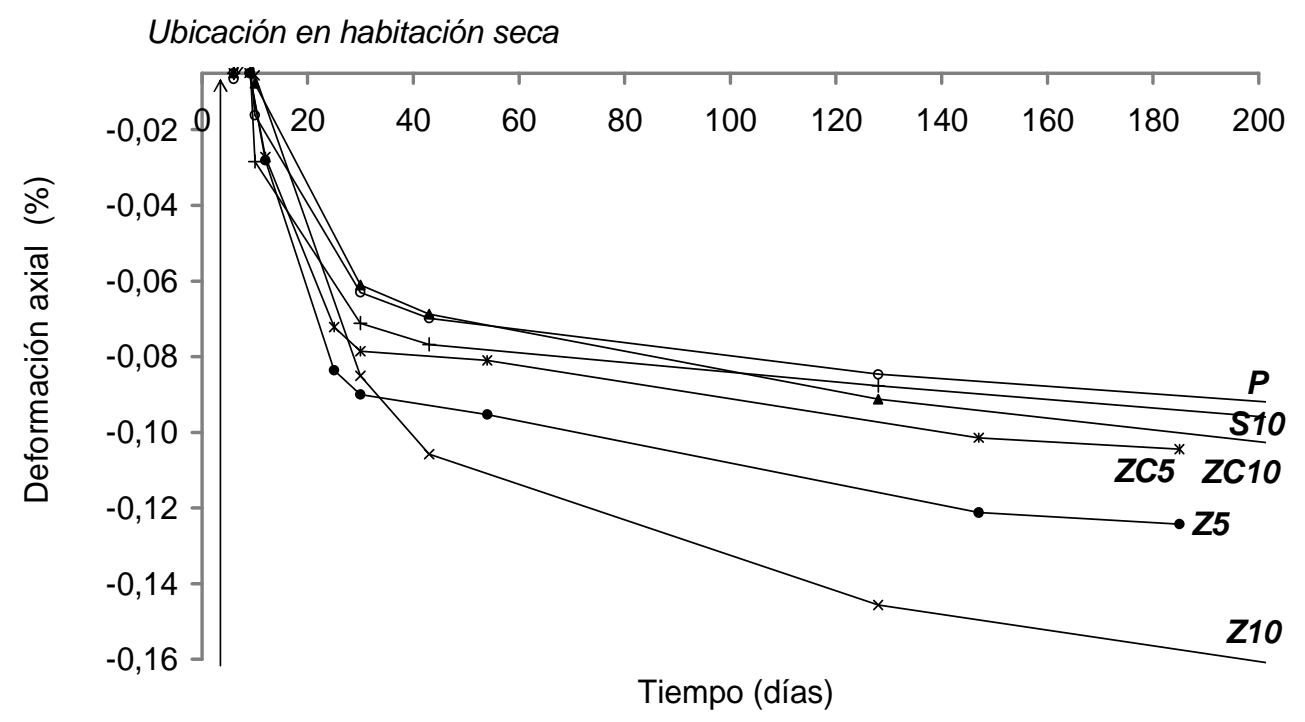

Figura 6.2. Resultados de las pruebas de contracción por secado. 
Tabla 6.5. Resultados de las pruebas de lixiviación (tiempo de lixiviación = $18 \mathrm{~h})$.

\begin{tabular}{|c|c|}
\hline Morteros & $\begin{array}{r}\text { Concentración de } \\
\mathbf{C r}(\mathrm{III}) \\
\left(\mathbf{m g} \cdot \mathrm{L}^{-1}\right)\end{array}$ \\
\hline ZC5 & 0,054 \\
\hline ZC10 & 0,062 \\
\hline Z5 & 0,053 \\
\hline Z10 & 0,065 \\
\hline
\end{tabular}




\subsection{Referencias}

[1].Caputo D., Gennaro B., Pansini M., Colella C. (1999) Stud. Surf. Sci. Catal. 125, 723.

[2].Perraki T., Kakali G.,Kontoleon F. (2003) Micropor. Mesopor. Mater. 61, 205.

[3].Zhang, W., Zakaria, M., Hama, Y. (2013) Constr. Build. Mater. 49, 500. 


\section{CAPÍTULO VII}

\section{CONCLUSIONES}

Síntesis y potenciales aplicaciones tecnológicas de materiales zeolíticos obtenidos a partir de catalizadores FCC agotados 187 


\section{CONCLUSIONES}

Es posible la transformación de catalizadores FCC agotados en productos zeolíticos de interés tecnológico.

La implementación de una etapa de pretratamiento consistente en producir un incremento significativo de la reactividad de la materia prima por fusión alcalina empleando $\mathrm{Na}_{2} \mathrm{CO}_{3}$ resultó en un gran aumento de la conversión en zeolita. Con esta metodología innovadora se lograron valores de cristalinidad zeolítica tan altos como $75 \%$

Adicionalmente, la fusión con $\mathrm{Na}_{2} \mathrm{CO}_{3}$ permitió acortar en forma marcada los tiempos de reacción, ya que se obtuvieron productos ricos en zeolitas a tiempos cortos de síntesis, comparables a los usados en las síntesis tradicionales de zeolita NaA.

Las diferentes caracterizaciones de los productos sólidos obtenidos a lo largo del proceso de cristalización mostraron modificaciones progresivas de la estructura dirigidas a la ordenación de la red cristalina.

Se comprobó que el material zeolitizado obtenido a partir del catalizador FCC agotado puede ser utilizado para la eliminación de cationes $\mathrm{Cr}$ (III) presentes en fase acuosa, siendo este proceso de gran utilidad para la eliminación de metales pesados contaminantes.

Los materiales zeolíticos sintetizados presentaron una cinética similar a la encontrada para una zeolita $\mathrm{NaA}$. El análisis de los datos cinéticos indicó con buena aproximación que en las condiciones experimentales utilizadas la reacción de intercambio catiónico se produce a través de un mecanismo de pseudo segundo orden.

Síntesis y potenciales aplicaciones tecnológicas de materiales zeolíticos obtenidos a partir de catalizadores FCC agotados 188 
La fase sólida altamente contaminada con el catión pesado, obtenida después del intercambio iónico, puede incluirse minoritariamente en las formulaciones de cemento sin alterar las propiedades del mismo, efectuando una inmovilización eficiente de metales pesados. 
TRABAJOS DESARROLLADOS PRODUCTO DE LA TESIS REALIZADA

\section{TRABAJOS EN PUBLICACIONES PERIÓDICAS CON REFERATO}

\section{a) Directamente relacionados con el tema de tesis}

1- Título: Trivalent chromium ion removal from aqueous solutions using low-cost zeolitic materials obtained from exhausted FCC catalysts

Autores: M.R. Gonzalez, A.M. Pereyra, E I. Basaldella

Revista: Adsorption Science and Technology

Editorial: Multi-Science Publishing Co. Ltd.

ISSN: 0263-6174

29 (7) 629-636, 2011

2- Título: Chromium removal by zeolite-rich materials obtained from an exhausted FCC catalyst: Influence of chromium incorporation on the sorbent structure

Autores: M.R. Gonzalez, A.M. Pereyra, R.M. Torres Sanchez, E.I. Basaldella

Revista: Journal of Colloid and Interface Science

Editorial: Elsevier

ISSN: 0021-9797

$40821-24,2013$

3- Título: Removal and cementitious immobilization of heavy metals: chromium capture by zeolite-hybridized materials obtained from spent fluid cracking catalysts

Autores: M.R. Gonzalez, A.M. Pereyra, R. Zerbino, E.I. Basaldella

Revista: Journal of Cleaner Production

Editorial: Elsevier

Síntesis y potenciales aplicaciones tecnológicas de materiales zeolíticos obtenidos a partir de catalizadores FCC agotados 191 
ISSN: 0959-6526

91 187-190, 2015

4- Título: Structural and morphological evolution of spent FCC catalyst pellets towards $\mathrm{NaA}$ zeolite

Autores: M. R. Gonzalez, A. M. Pereyra, P. Bosch, G. Fetter, V.H. Lara, E. I. Basaldella

A enviar

b) Otras publicaciones relacionadas

1- Título: "A-type zeolite containing $\mathrm{Ag}^{+} / \mathrm{Zn}^{2+}$ as inorganic antifungal for waterborne coating formulations"

Autores: A.M. Pereyra, M.R. Gonzalez, V.G. Rosato, E.I. Basaldella.

Revista: Progress in Organic Coatings

Editorial: Elsevier.

ISSN: $0300-9440$

77, 213-218, 2014

2-Título: Separation of $\mathrm{CO}_{2}$ from $\mathrm{CH}_{4}$ and $\mathrm{CO}_{2}$ capture in the presence of water vapour in NOTT-400

Autores: M.R. Gonzalez, J.H. González-Estefan, H.A. Lara- García, P. Sánchez-Camacho, E.I. Basaldella, H. Pfeiffer, I.A. Ibarra

Revista: New Journal of Chemistry

Editorial: Royal Society of Chemistry

ISSN: $1144-0546$

39 2400-2403, 2015

3-Título: Enhancement of biocorrosion resistance of epoxy coating by addition of $\mathrm{Ag} / \mathrm{Zn}$ exchanged $\mathrm{A}$ zeolite

Autores: A.M. Pereyra, M.R. Gonzalez, T.A. Rodrigues, M.T. Soares 
Luterbach, E.I. Basaldella

Revista: Surface and Coatings Technology

Editorial: Elsevier

ISSN: $0257-8972$

$270284-289,2015$

4-Título: Removal of $\mathrm{CO}_{2}$ from $\mathrm{CH}_{4}$ and $\mathrm{CO}_{2}$ capture in the presence of $\mathrm{H}_{2} \mathrm{O}$ vapour in NOTT-401

Autores: H. A. Lara- García, M. R. Gonzalez, J. H. González-Estefan, P. Sánchez-Camacho, E. J. Lima I. A. Ibarra,

Revista: Inorganic Chemistry Frontiers

Editorial: Royal Society of Chemistry

ISSN: 2052-1553

Enviado

TRABAJOS COMPLETOS PUBLICADOS EN ACTAS DE CONGRESOS

a) Directamente relacionados con el tema de tesis

1-"XVI Congreso Argentino de Catálisis"

Título: "Materiales zeolíticos para purificación de aguas obtenidos a partir de catalizadores de cracking agotados"

Autores: M.R. Gonzalez, N. Firpo, E.I. Basaldella

Tipo de presentación: póster

Lugar: Ciudad Autónoma de Buenos Aires, Argentina

Fecha: 03 al 07 de agosto de 2009

Editorial: Consejo Nacional Investigaciones Científicas Técnicas

ISBN: 978-950-692-090-6

2-"10th Congress of Italian Zeolite Association Advances in Zeolite Science and Technology"

Síntesis y potenciales aplicaciones tecnológicas de materiales zeolíticos obtenidos a partir de catalizadores FCC agotados 193 
Título: "Trivalent chromium removal from wastewater using low cost zeolitized mixtures derived from exhausted FCC catalysts"

Autores: M.R. Gonzalez, A.M. Pereyra, E I. Basaldella

Tipo de presentación: póster

Lugar: Nápoles, Italia

Fecha: 14 al 17 de septiembre de 2011

Editorial: De Frede Editore

ISBN: 978-88-89976-33-3

3-"XVII Congreso Argentino de Catálisis y VI Congreso de Catálisis del Mercosur"

Título: "Retención de $\mathrm{Cr}^{+3}$ en productos zeolíticos obtenidos a partir de catalizadores de FCC: Estudios Cinéticos"

Autores: M.R. Gonzalez, A.M. Pereyra, R M. Torres Sánchez, E.I. Basaldella

Tipo de presentación: póster

Lugar: Salta, Argentina

Fecha: 17 al 20 de octubre de 2011

Editorial: Universidad Nacional de Salta

ISBN: 978-987-633-075-6

4-"Congreso Internacional de Ciencia y Tecnología Ambiental y I

Congreso Nacional de la Sociedad Argentina de Ciencia y Tecnología Ambiental"

Título: "Inmovilización de cationes $\mathrm{Cr}$ (III) retenidos en estructuras zeolíticas estabilizadas en matrices cementiceas"

Autores: M.R. Gonzalez, R.M. Torres Sánchez, A.M. Pereyra, E.I. Basaldella

Tipo de presentación: oral

Lugar: Mar del Plata, Argentina

Fecha: 28 de mayo al 01 de junio de 2012 
Editorial: Asociación Argentina para el Progreso de las Ciencias ISBN: 978-987-28123-2-4

5-"XI Jornadas Argentinas de Tratamiento de Minerales"

Título: " Retención e inmovilización de cromo en materiales zeolíticos"

Autores: M.R. Gonzalez, A.M. Pereyra, E.I. Basaldella

Tipo de presentación: oral

Lugar: Neuquén, Argentina

Fecha: 8 al 10 de octubre de 2012

Editorial: Universidad Nacional del Comahue

ISBN: 978-987-604-311-3

6-"XII Jornadas Argentinas de Tratamiento de Minerales"

Título: " Retención de cromo en materiales zeolíticos obtenidos a partir de catalizadores FCC agotados"

Autores: M.R. Gonzalez, A.M. Pereyra, E.I. Basaldella

Tipo de presentación: oral

Lugar: San Luis, Argentina

Fecha: 15 al 17 de octubre de 2014

Editorial: Universidad Nacional de San Luis

ISBN: 978-987-1819-19-5

\section{COMUNICACIONES O TRABAJOS CORTOS PRESENTADOS EN CONGRESOS, ENCUENTROS, JORNADAS, SIMPOSIOS}

\section{a) Directamente relacionados con el tema de tesis}

1-"Fronteras en Fisicoquímica. Un enfoque interdisciplinario" (Instituto de Investigaciones Fisicoquímicas Teóricas y Aplicadas, INIFTA)

Título: "Retención de cromo utilizando productos zeolíticos obtenidos a partir de una reconversión de catalizadores FCC" 
Autores: M.R. Gonzalez

Tipo de presentación: póster

Lugar: La Plata, Prov. de Buenos Aires, Argentina

Fecha: 24 al 28 de noviembre de 2008

Editorial: Universidad Nacional de La Plata - INIFTA

ISBN: 978-950-34-0512-3

2-"16th International Zeolite Conference joint with the 7th International Mesostructured Materials Symposium"

Título: "Chromium retention by zeolite-rich materials obtained from exhausted cracking catalysts"

Autores: E.I. Basaldella, M.R. Gonzalez, J. C. Tara

Tipo de presentación: póster

Lugar: Sorrento, Italia

Fecha: 04 al 09 de julio de 2010

3-"Il Jornadas Patagónicas de Biología I Jornadas Patagónicas de Ciencias Ambientales IV Jornadas Estudiantiles de Ciencias Biológicas" Título: "Reconversión de catalizadores de FCC en productos de interés industrial"

Autores: M.R. Gonzalez, N. Arrieta, A.M. Pereyra, E.I. Basaldella Tipo de presentación: póster

Lugar: Trelew, Argentina

Fecha: 20 al 24 de septiembre de 2011

ISSN: $1850-4639$

4-"Il Workshop de Transferencia de Tecnología en al área de Materiales" Título: " Eliminación de $\mathrm{Cr}^{+3}$ de soluciones acuosas usando intercambiadores catiónicos obtenidos por zeolitización de catalizadores de cracking agotados"

Autores: M.R. Gonzalez, A.M. Pereyra, E.I. Basaldella 
Tipo de presentación: póster

Lugar: Mar del Plata, Argentina

Fecha: 28 al 30 de noviembre de 2011

5-"XXIII Congreso Iberoamericano de Catálisis"

Título: "Estudio de la cinética de intercambio de $\mathrm{Cr}$ (III) en materiales zeolíticos obtenidos a partir de catalizadores FCC agotados"

Autores: M.R. Gonzalez, A.M. Pereyra, E.I. Basaldella

Tipo de presentación: póster

Lugar: Santa Fe, Argentina

Fecha: 02 al 07 de septiembre de 2012

Editorial: Universidad Nacional del Litoral

ISBN: 978-987-657-806-6

6-"XXIX Congreso Argentino de Química"

Título: "Síntesis y caracterización de materiales zeolíticos obtenidos a partir de catalizadores FCC agotados"

Autores: M.R. Gonzalez, A.M. Pereyra, E.I. Basaldella

Tipo de presentación: póster

Lugar: Mar del Plata, Argentina

Fecha: 3 al 5 de octubre de 2012

ISSN: $1852-1207$

7-"17th International Zeolite Conference"

Título: "Removal of $\mathrm{Cr}$ (III) from aqueous solution by zeolites sintetized from exhausted FCC catalysts. Kinetics studies and effect of $\mathrm{Cr}$ (III) exchange on the zeolitic structure"

Autores: M.R. Gonzalez, A.M. Pereyra, E.I. Basaldella

Tipo de presentación: póster

Lugar: Moscú, Rusia

Fecha: 07 al 12 de julio de 2013

Síntesis y potenciales aplicaciones tecnológicas de materiales zeolíticos obtenidos a partir de catalizadores FCC agotados 197 
ISBN: 978-5-903391-97-4

8-"3Reunión Materiales Tecnológicos en Argentina"

Título: "Inmovilización en morteros de material zeolítico utilizado en purificación de aguas contaminadas con $\mathrm{Cr}$ (III)"

Autores: M.R. Gonzalez, A.M. Pereyra, E.I. Basaldella

Tipo de presentación: póster

Lugar: La Plata, Argentina

Fecha: 13 al 15 de mayo de 2014

\section{b) Otras publicaciones relacionadas}

1-"2ํㅗำosio sobre Adsorción, Adsorbentes y sus Aplicaciones"

Título: " Retención de iones metálicos $\mathrm{Ni}$ (II) y Cd (II) por sólidos porosos obtenidos a partir de residuos industriales"

Autores: M.R. Gonzalez, P. Rodríguez-Estupiñán, L. Giraldo, A M.

Pereyra, J.C. Moreno-Piraján, E.I. Basaldella

Tipo de presentación: póster

Lugar: San Luis, Argentina

Fecha: 20 al 22 de febrero de 2013

2-"17th International Zeolite Conference"

Título: "LTA containing biocidal cations as additive for waterborne coating formulations"

Autores: A.M. Pereyra, M.R. Gonzalez, V.G. Rosato, E.I. Basaldella

Tipo de presentación: póster

Lugar: Moscú, Rusia

Fecha: 07 al 12 de julio de 2013

ISBN: 978-5-903391-97-4 
3- "3ํ Reunión Materiales Tecnológicos en Argentina"

Título: "Estructuras LTA bifuncionalizadas para la prevención de la corrosión microbiológica"

Autores: A.M. Pereyra, G.E. Machado, M.R. Gonzalez, T. Abrantes Rodrigues, M.T. Soares Lutterbach, E.I. Basaldella

Tipo de presentación: Póster

Lugar: La Plata, Argentina

Fecha: 13 al 15 de mayo de 2014

4- "3ํ Reunión Materiales Tecnológicos en Argentina"

Título: "Estudio comparativo de la adsorción del catión $Z n+2$ sobre zeolita NaA y residuo de catalizador zeolitizado"

Autores: M.R. Gonzalez, A.M. Pereyra, E.I. Basaldella

Tipo de presentación: Póster

Lugar: La Plata, Argentina

Fecha: 13 al 15 de mayo de 2014 